\title{
Evaluation of Gas Disengaging Equipment Supporting a Crystalline Silicotitanate Ion-Exchange Column System
}

\section{April 2001}

Barry B. Spencer

Kimberly K. Anderson

Hal L. Jennings

Timothy E. Kent

Paul A. Taylor

Mark W. Geeting 


\section{DOCUMENT AVAILABILITY}

Reports produced after January 1, 1996, are generally available free via the U.S. Department of Energy (DOE) Information Bridge:

Web site:http://www.osti.gov/bridge

Reports produced before January 1, 1996, may be purchased by members of the public from the following source:

National Technical Information Service

5285 Port Royal Road

Springfield, VA 22161

Telephone: 703-605-6000 (1-800-553-6847)

TDD: 703-487-4639

Fax: 703-605-6900

E-mail:info@ntis.fedworld.gov

Web site: http://www.ntis.gov/support/ordernowabout.htm

Reports are available to DOE employees, DOE contractors, Energy Technology Data Exchange (ETDE) representatives, and International Nuclear Information System (INIS) representatives from the following source:

Office of Sc ientific and Technical Information

P.O. Box 62

Oak Ridge, TN 37831

Telephone: 865-576-8401

Fax: 865-576-5728

E-mail:reports@adonis.osti.gov

Web site: http://www.osti.gov/contact.html

This report was prepared as an account of work sponsored by an agency of the United States Government. Neither the United States government nor any agency thereof, nor any of their employees, makes any warranty, express or implied, or assumes any legal liability or responsibility for the accuracy, completeness, or usefulness of any information, apparatus, product, or process disclosed, or represents that its use would not infringe privately owned rights. Reference herein to any specific commercial product, process, or service by trade name, trademark, manufacturer, or otherwise, does not necessarily constitute or imply its endorsement, recommendation, or favoring by the United States Government or any agency thereof. The views and opinions of authors expressed herein do not necessarily state or reflect those of the United States Government or any agency thereof. 
ORNL/TM-2001/46

Chemical Technology Division

\title{
EVALUATION OF GAS DISENGAGING EQUIPMENT SUPPORTING A CRYSTALLINE SILICOTITANATE ION-EXCHANGE COLUMN SYSTEM
}

\author{
Barry B. Spencer* \\ Kimberly K. Anderson \\ Hal L. Jennings \\ Timothy E. Kent \\ Paul A. Taylor \\ Mark W. Geeting
}

*Robotics and Process Systems Division, ORNL

${ }^{\dagger}$ Westinghouse Savannah River Company

Date Published: April 2001

Prepared by

OAK RIDGE NATIONAL LABORATORY

Oak Ridge, Tennessee 37831-6285

managed by

UT-BATTELLE, LLC

for the

U.S. DEPARTMENT OF ENERGY

under contract DE-AC05-00OR22725 


\section{CONTENTS}

\section{Page}

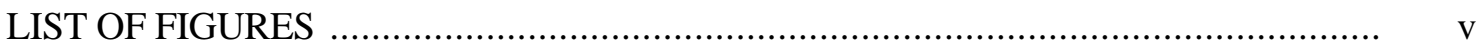

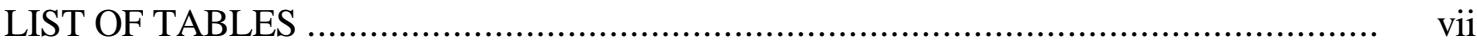

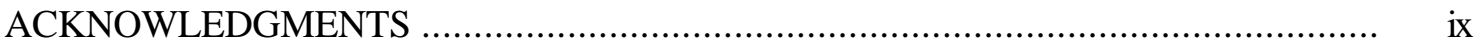

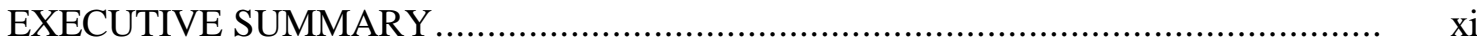

1. BACKGROUND AND INTRODUCTION........................................................ 1

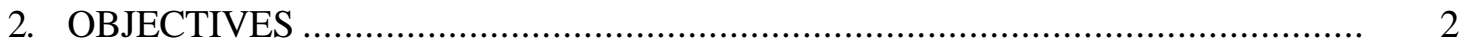

3. EXPERIMENTAL APPARATUS AND REAGENTS …................................... 3

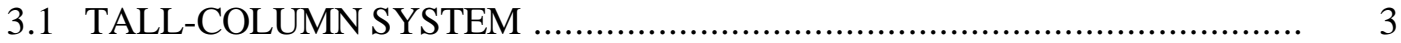

3.1.1 Columns and Ancillary Devices ...................................................... 4

3.1.2 Gas Disengaging Equipment ........................................................... 11

3.1.3 Control and Data Acquisition System ............................................ 13

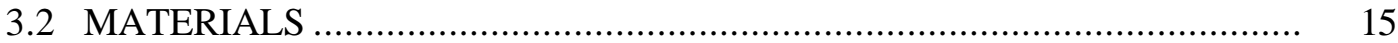

3.2.1 Supernatant Simulant ........................................................... 15

3.2.2 Granulated CST ........................................................................ 15

4. PERFORMANCE OF GAS DISENGAGING EQUIPMENT …........................ 17

4.1 ENTRAINED-GAS MEASUREMENTS .......................................... 18

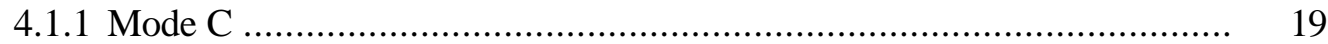

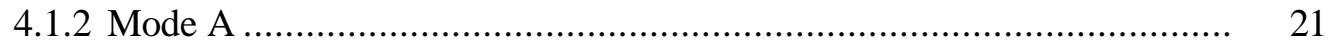

4.1.3 Mode B ................................................................................ 27

4.1.4 Summary ...................................................................................... 28

4.2 ACCUMULATION OF GAS IN COLUMN HEADSPACE …...................... 29

4.3 ACCUMULATION OF GAS IN THE CST BEDS …............................ 33

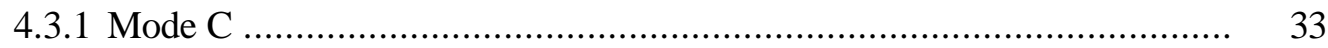

4.3.2 Mode A ….......................................................................... 35

4.3.3 Mode B ...................................................................................... 37

4.4 DISCUSSION OF GAS-MEASUREMENT DATA ................................ 39

4.5 EFFECT OF ULTRASONIC WAVE-ENHANCED COALESCENCE ............ 40

5. PERFORMANCE OF CONTROL SYSTEM …............................................ 41

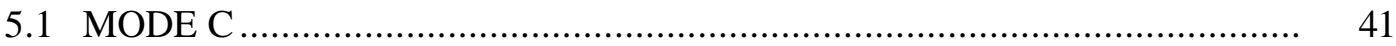

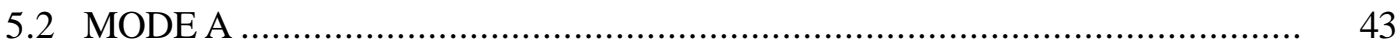

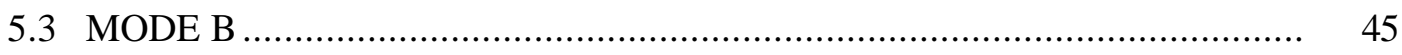

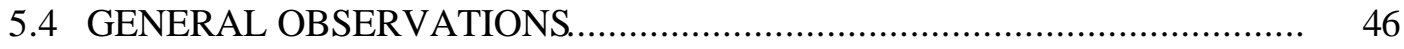

6. EFFECT OF OPERATIONS ON THE CST …............................................... 47

6.1 LEACHING OF COMPONENTS FROM THE CST .............................. 47

6.2 MICROSCOPIC ANALYSIS OF CST …......................................... $\quad 50$

6.3 COLUMN UNLOADING............................................................ 55 
7. CONCLUSIONS AND RECOMMENDATIONS …....................................... 57

7.1 CONCLUSIONS ..................................................................... 57

7.2 RECOMMENDATIONS ............................................................... 59

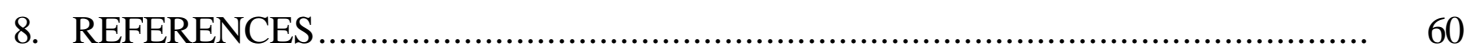

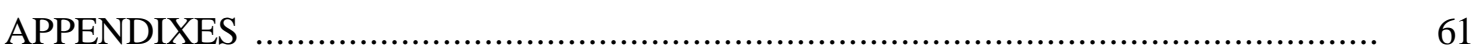

A. SIZING OF EXPERIMENTAL-SCALE JOHNSON SCREEN .......................... 63

B. SAMPLING AND SLUICING OF CST FROM THE TALL COLUMN .................. 65

C. SLUICING CST FROM THE SHORT COLUMN ..................................... 67 


\section{LIST OF FIGURES}

Figure $\quad$ Page

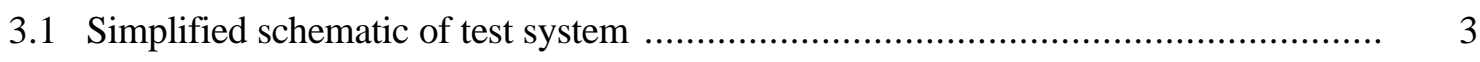

3.2 Lower section of tall column following modifications ................................... 5

3.3 Standard Johnson screen shown alongside custom 5-slot and 2-slot units .................. 6

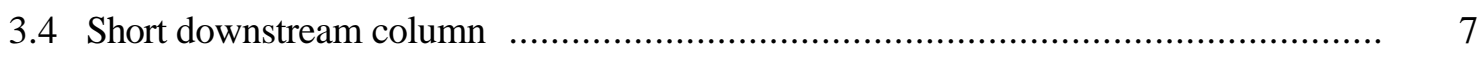

3.5 Gas separation and measurement chamber shown plumbed to tall-column effluent riser pipe (with tall column to the left) .............................................. 9

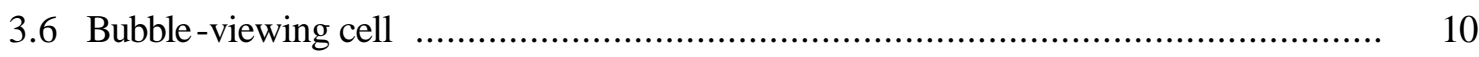

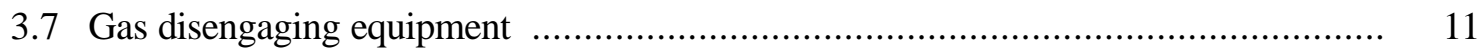

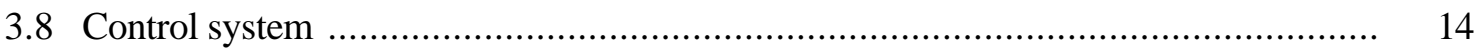

3.9 Particle size distribution of CST, lot 99909881006, used to charge the tall column $\ldots \quad 16$

4.1 Entrained-gas flow rates measured during experiments conducted using Mode C ...... 20

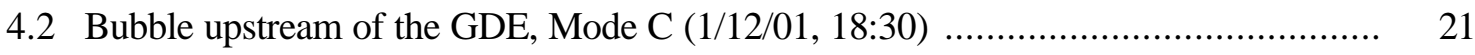

4.3 Entrained-gas flow rates measured during Mode A ..................................... 23

4.4 Entrained-gas flow rates measured during steady-state methods of Mode A............. 23

4.5 Bubbles upstream of the GDE, Mode A, passive settling method (1/14/01, 23:00) ... $\quad 25$

4.6 Bubbles downstream of the GDE, Mode A, sparging method $(1 / 18 / 01,08: 30) \quad \ldots \ldots \ldots . \quad 26$

4.7 Bubbles upstream of the GDE, Mode A, reduced-pressure method (1/19/01, 01:40) 26

4.8 Entrained-gas flow rates measured during specific methods of Mode B ................. 27

4.9 Bubbles upstream of the GDE, Mode B, passive settling method (1/21/01, 08:30) ... 28

4.10 Gas accumulation in the headspace of columns during Mode $\mathrm{C}$............................ 30

4.11 Gas accumulation in the headspace of columns during Mode A .......................... 31

4.12 Gas accumulation in the headspace of columns during Mode B .......................... 32

4.13 Pressure drop across the downstream column during startup of Mode C ................. 34

4.14 CST bed of downstream column during Mode $\mathrm{C}$ at 09:25, 1/13/01 ..................... 34 
4.15 Pressure drop across the downstream column during the first portion of Mode A ......

4.16 CST bed of downstream column during Mode A at 13:33, 1/15/01 ..................... 36

4.17 CST bed of downstream column during Mode A at 11:40, 1/19/01 ..................... 36

4.18 Pressure drop across the downstream column during the first portion of Mode B ...... 38

4.19 CST bed of downstream column during Mode B at 12:30, 1/21/01 ...................... 38

5.1 Liquid flow rates measured during startup of Mode C .................................. 42

5.2 Pressures measured in tall column during startup of Mode C .............................. 42

5.3 Pressures measured in short column during startup of Mode C ............................ 43

5.4 Liquid flow rates and GDE liquid levelmeasured during startup of Mode A ........... 44

5.5 Pressures measured in tall column during startup of Mode A ............................... 44

5.6 Pressures measured in short column during startup of Mode A ............................. 45

5.7 Liquid flow rates and GDE liquid level measured during startup of Mode B ........... 46

6.1 Concentrations of selected metals in simulant solution and $\mathrm{H}_{2} \mathrm{O}_{2}$ feed over course of experiment

6.2 Mass of selected metals in the simulant solution as a function of time .................... 49

6.3 Concentration and mass of aluminum in solution over course of experiment ............ 49

6.4 Photograph of top of the CST bed in the tall column .................................... 50

6.5 SEM photomicrograph of CST removed from top of tall column $\ldots \ldots \ldots \ldots \ldots \ldots \ldots \ldots \ldots \ldots \ldots \ldots \ldots \ldots$

6.6 Fractured CST granules from tall column .................................................

6.7 Surface of particle from tall column, showing nodules of aluminum and silica ........ 52

6.8 CST removed from top of the short column ................................................... 53

6.9 Various-shaped CST particles removed from top of short column ........................ 53

6.10 Surface of CST particle taken from the short column ..................................... 54 


\section{LIST OF TABLES}

Table Page

3.1 Relative elevations of pressure transducers in the tall column ............................. 6

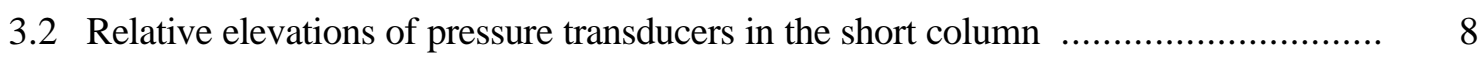

3.3 List of data points recorded by data acquisition system ................................... 14

3.4 Composition of SRS high-nitrate supernatant waste ..................................... 15

4.1 Average entrained-gas flow rates during each method of operation ....................... 29

4.2 Average gas accumulation rates in the top-of-column gas tubes ......................... 33

4.3 Average operating pressures at selected locations during each method of operation . 39 


\section{ACKNOWLEDGMENTS}

This work was sponsored by the U.S. Department of Energy's Environmental Management (EM-50) Program-Tanks Focus Area under U.S. Government contract DE-AC05-00OR22725 with UT-Battelle, LLC. The work was performed at the Oak Ridge National Laboratory under the auspices of the Chemical Technology Division.

The authors wish to thank their colleagues at the Westinghouse Savannah River Company and Savannah River Technology Center who provided assistance to the Oak Ridge National Laboratory Team in planning, designing, and testing of the equipment and instrument systems.

Conduct of the test campaign was supported by Kim Anderson, Bill Chase, Jim Hewitt, Hal Jennings, Steve Richardson, Paul Taylor, and Jim Travis - all of the Chemical Technology Division. Their efforts are highly appreciated.

Chemical analyses of liquid samples were performed by the Radioactive Materials Analysis Laboratory. Microscopic analyses of crystalline silicotitanate materials were performed by the Metals and Ceramics Division. The efforts of these organizations in providing excellent and timely results are gratefully acknowledged. 


\section{EXECUTIVE SUMMARY}

Removal of radiolytically produced gas is an important operating aspect of flow-through ion-exchange columns designed to remove and concentrate cesium-137 $\left({ }^{137} \mathrm{Cs}\right)$ from Savannah River storage tank waste solutions. In an evaluation of the short list of salt-waste treatment alternatives, the conceptual design of ion-exchange columns suggested that the dimensions should be $5 \mathrm{ft}$ in diameter and $20 \mathrm{ft}$ tall, with a $16-\mathrm{ft}$ bed depth. The use of crystalline silicotitanate (CST) ion-exchange columns at such a large scale has not been demonstrated previously and raises a number of issues. Among these are the design and operation considerations associated with a large, CST ion-exchange column which, when fully loaded with cesium, will generate radiolytic gases that must be removed. The accumulation of these gases, mostly hydrogen and oxygen, creates a hazard due to the potential of forming an explosive mixture. In addition, void spaces in the bed caused by accumulated gas cause additional resistance to liquid flow. It has been proposed that the gas entrained with the effluent be separated from the liquid prior to feeding downstream columns. A gas disengagement device designed for this purpose was evaluated using the existing ORNL tall-column test system, which consists of a 3-in.-diam, 20-fttall column originally designed to evaluate the flow-through hydraulic characteristics of CST ionexchange systems.

The gas disengaging equipment (GDE) designed for this evaluation supported four fundamental separation methods : (1) passive settling, (2) gas sparging to strip entrained gas or gas bubbles, (3) subatmospheric pressure separation, and (4) injection of ultrasonic waves to induce coalescence of bubbles with attendant settling. To simulate the generation of radiolytic gas with the flow-through CST column, gas was supplied to a simulated salt-waste liquid stream by adding a dilute hydrogen peroxide $\left(\mathrm{H}_{2} \mathrm{O}_{2}\right)$ solution. The $\mathrm{H}_{2} \mathrm{O}_{2}$ decomposed and produced oxygen bubbles within the CST bed. Once the bed was saturated with oxygen, the bubbles began passing through the bed and into the column effluent stream. The $\mathrm{H}_{2} \mathrm{O}_{2}$ feed rate was adjusted to control the amount of bubbles exiting in the CST column effluent to the equivalent rate expected for radiolytic gas generation. The GDE, which was installed between the tall column and a shorter lag column, was evaluated during a 24-h/day, 10-day operating campaign. In general, the GDE was operated in two different modes. When the GDE is operated under low pressures, a transfer pump is used to feed the downstream column. If the pump is not used, the GDE must operate under the upstream column-system pressure with the use of a control valve to maintain the appropriate operating level in the GDE separation chamber. This necessarily means that the 
downsteam column must operate at a lower pressure than the GDE. In addition, the GDE is bypassed in the third mode of tall-column operation.

During the tests, the GDE could be operated and controlled successfully in any of the defined modes of operation. In one mode, the GDE could be operated at atmospheric, or lower, pressure. The effluent from the tall column enters the GDE for gas separation with the GDE settling tank vented to the atmosphere. A pump, which is part of the GDE, is used to feed degassed simulant to the second column. The control system maintains the liquid level in the GDE settling tank at a given setpoint. At steady state, the GDE pump feeds the second column at the same rate that the simulant enters the GDE from the first column. During operation in this manner, the GDE performance was evaluated while using three of the four separation methods mentioned above (passive settling, nitrogen sparging, and reduced pressure). Combinations of these methods were not used in any of the tests. The GDE was also operated in an elevatedpressure mode, where the tall-column feed pump provided the necessary pressure to maintain flow through the columns and the GDE. The nitrogen (or $\mathrm{CO}_{2}$-free air) supply to the GDE provided the sweep gas for removal of radiolytic gases (in this case, $\mathrm{O}_{2}$ from the decomposition of $\mathrm{H}_{2} \mathrm{O}_{2}$ to simulate radiolysis) and also facilitated control of the liquid level in the GDE. The control system maintained a constant flow of pressurized gas to the GDE settling tank. A venting valve was manipulated to adjust the gas pressure in the headspace to a given setpoint. The liquid discharge valve was controlled to maintain the specified operating level in the GDE settling tank. During operation in this manner, three methods of separation (passive settling, nitrogen sparging, and ultrasonic-enhanced) were evaluated.

Control of the gas-generation rate proved to be more difficult than expected. The $\mathrm{H}_{2} \mathrm{O}_{2}$ used to generate the gas is both absorbed and decomposed by the CST. Absorption equilibria result in transients caused by absorption or desorption as the concentration of the $\mathrm{H}_{2} \mathrm{O}_{2}$ feed changes. Overlaid with large residence time in the column due to the relatively low liquid feed rates, this made control of the effluent gas rate at steady state very difficult. The mass feed rate of $\mathrm{H}_{2} \mathrm{O}_{2}$ was greatly increased at times to ensure saturation, then decreased when gas-generation rates were too high. Consequently, there were times throughout operations when the gas generation rate was either zero or up to 40 times the rate that could be expected from radiolysis. Despite this difficulty, however, steady-state generation of gas could be achieved over prolonged time periods to facilitate evaluation of GDE performance.

The results of the testing indicate that the gas disengaging equipment can effectively remove gas to a level that prevents bulk accumulation in the bed of downstream columns when the GDE is operated at atmospheric (or lower) pressures. Foregoing gas separation or operating 
the GDE at pressures higher than those in the downstream column can cause accumulation of gas in the downstream column. When the GDE operates at a pressure lower than that of the downstream column, gas does not accumulate in the downstream column. If the liquid is saturated with gas at this pressure and the pump elevates the pressure of the liquid before feeding it to the downstream column, the degree of gas saturation for the liquid entering the downstream column is reduced. No gas evolves from the liquid because the liquid has the capacity to absorb more gas. Conversely, when the GDE operates at a high pressure and the liquid is throttled through a control valve to a lower pressure, the liquid becomes supersaturated with gas. Gas evolves from the liquid and is accumulated in the downstream column. Gas volume measurements obtained on the influent and effluent of the GDE, along with the measurement of pressure drop across the tall column and downstream column, support these observations. It was further found that the separation method tested (passive, sparging, ultrasonic) was not as important as the general operating mode (pressurized or atmospheric) under which the GDE was operating. In each operating mode, the liquid stream was video-taped both upstream and downstream of the GDE to measure bubble size. When bubbles were present in the tall-column effluent, they tended to range from 0.1 to $2 \mathrm{~mm}$ in diameter. Bubbles downstream of the GDE were usually sparse and very small (i.e., around $0.1 \mathrm{~mm}$ in diameter).

Based on these tests, it is recommended that column design include gas vents at tops of columns to permit the release of gas that will accumulate slowly over time. Gas separation between columns should be performed at lower pressures than will be encountered within the downstream column; otherwise, gas will evolve from the liquid and accumula te in the column. It is recommended that additional tests be performed in two primary areas. First, equipment that supports a falling film to permit entrained gas to separate from the liquid could be very effective and reduce the inventory of simulant in the GDE. Second, additional tests of the ultrasonicenhanced separation at higher power levels would be prudent. Ultrasonic equipment could be operated in the pulsed mode if equipment capable of continuous operation cannot be identified. The results of such tests would help define the most effective gas-separation techniques.

Samples of the simulant were obtained on a daily basis throughout the operating campaign. Analysis indicated that some niobium and titanium were leached from the CST. The concentrations of these metals in the simulant appeared to increase in response to feed of concentrated $\mathrm{H}_{2} \mathrm{O}_{2}$. Later, the concentrations would decrease, indicating that the metals had precipitated from solution. Scanning electron microscopic analysis of CST samples showed deposition of globular nodules and cubic crystals on the particle surface. Energy-dispersive $\mathrm{X}$-ray spectroscopy identified these deposits as being rich in aluminum, silicon, and titanium. 
Sluicing of the CST from the column proved difficult. Probing of the beds revealed a crusty consistency, which was particularly hard at the top of the tall column where $\mathrm{H}_{2} \mathrm{O}_{2}$ was introduced. It was concluded that the deposition of an aluminosilicate-rich precipitate acted as a binder. The introduction of $\mathrm{H}_{2} \mathrm{O}_{2}$ may have increased the leaching of titanium and silicon from the CST which, when combined with the aluminum in the simulant, resulted in increased deposition rates. The CST in the tall column was effectively immobilized but remained porous so that liquid flow could continue. Some binding was also observed in the short column, but backflushing with simulant and nitrogen gas broke up the CST so that it could be removed by sluicing. 


\section{BACKGROUND AND INTRODUCTION}

Removal of radiolytically produced gas is an important operating aspect of flow-through ion-exchange columns designed to remove and concentrate cesium-137 $\left({ }^{137} \mathrm{Cs}\right)$ from Savannah River storage tank waste solutions. In an evaluation of the short list of salt waste treatment alternatives, ${ }^{1}$ the conceptual design of ion-exchange columns suggested that the dimensions should be $5 \mathrm{ft}$ in diameter and $20 \mathrm{ft}$ tall, with a $16-\mathrm{ft}$ bed depth. A bed of this size is expected to accumulate $\sim 3 \times 10^{6} \mathrm{Ci}$ of ${ }^{137} \mathrm{Cs}$ and to have a decay heat of $\sim 4.95 \mathrm{~W} / 1000 \mathrm{Ci}$; thus, the column will require cooling. The use of crystalline silicotitanate (CST) ion-exchange columns at this large scale has not been demonstrated previously and raises a number of questions and concerns. Among these are the design and operation issues associated with a large CST ion-exchange column which, when fully loaded with cesium, will generate substantial quantities of decay heat and radiolytic gases that must be removed. ${ }^{2}$ Tests in a 16 -ft-tall test bed operated with the liquid in a downflow pattern have demonstrated that gases generated within the bed accumulate to an estimated $7 \%$ of the bed volume, but without apparent bed disruption. Once the gas inventory has reached steady state, the gases are swept out with the liquid effluent at the same rate as they are formed (ORNL/TM-1999/103). ${ }^{3}$ However, in a three-column processing train, the gases swept from the lead column will likely accumulate in the headspace of the next column. The accumulation of these gases, primarily hydrogen and oxygen, would create a hazard due to the potential for forming an explosive mixture. Void spaces in the bed caused by accumulated gas causes additional resistance to liquid flow and impacts the loading of the CST with cesium. It has been proposed that the gas entrained with the effluent be separated from the liquid prior to feeding downstream columns. Methods for removing this gas between columns should be evaluated and demonstrated. The effect of entrained gas on downstream columns needs to be understood. 


\section{OBJECTIVES}

The objective of this experimental program was to evaluate the effectiveness of gasdisengaging equipment (GDE) to separate gas from the liquid effluent of CST ion-exchange columns. The GDE designed for this evaluation supports four fundamental separation methods : (1) passive settling, (2) gas sparging to strip entrained gas or gas bubbles, (3) subatmospheric pressure separation, and (4) injection of ultrasonic waves to induce coalescence of bubbles with attendant settling. These methods may be used separately or in combination, provided that the selections are not mutually exclusive (e.g., passive settling and gas sparging are mutually exclusive by definition). The method using ultrasonic waves is limited because the acoustic actuator cannot be used on a continuous basis; only intermittant bursts are recommended to prevent overheating and subsequent failure.

Each separation method was evaluated to determine which, if any, would be suitable for application to CST ion-exchange columns. The GDE supports two general modes of column operation. In one mode, the GDE operates at an elevated pressure and the feed pump must push fluid through the series of columns. In the other mode, operation proceeds in a vented condition and an interstage pump is required to reelevate the liquid pressure to feed the downstream column. In the third mode, the GDE may be bypassed to obtain base-line data in the absence of gas removal. Again, the feed pump must overcome the frictional losses and elevation differences associated with both columns.

The efficiency/effectiveness of the GDE is based on the fraction of undissolved gas removed in the unit and on the size of the gas bubbles carried into and out of the unit with the liquid stream. Optimization of combinations of the fundamental separation methods is beyond the scope of the tests reported here. Pressure drop (caused by resistance to flow) in the second column was measured since increases can be used as an indirect indicator of gas accumulation in the column. Gas accumulation was also detected through visual observation. The results of these tests provided information on the separation of undissolved gas from liquid salt solution in accordance with the requirements of the technical task plan. ${ }^{4}$ 


\section{EXPERIMENTAL APPARATUS AND REAGENTS}

\subsection{TALL-COLUMN SYSTEM}

The existing tall column at Oak Ridge National Laboratory (ORNL) was modified to support this experimental program. The lower section of the column [ 65 in. $(165 \mathrm{~cm})$ long] was replaced to accommodate a vertically oriented, rather than a horizontally oriented, Johnson screen. This modification also permitted effluent to flow upward, rather than horizontally, when exiting the column. A gas-disengaging system was placed on the platform above the tall column. The effluent from the tall column flows through a vertical riser pipe and into the GDE. The liquid stream is then fed to a second column, which was built to simulate the upper section of a downstream column.

A simplified schematic diagram of the test system is shown in Fig. 3.1. [ORNL Piping and Instrumentation Diagram (P\&ID) J3E-020638-A001 provides greater detail.] The test system

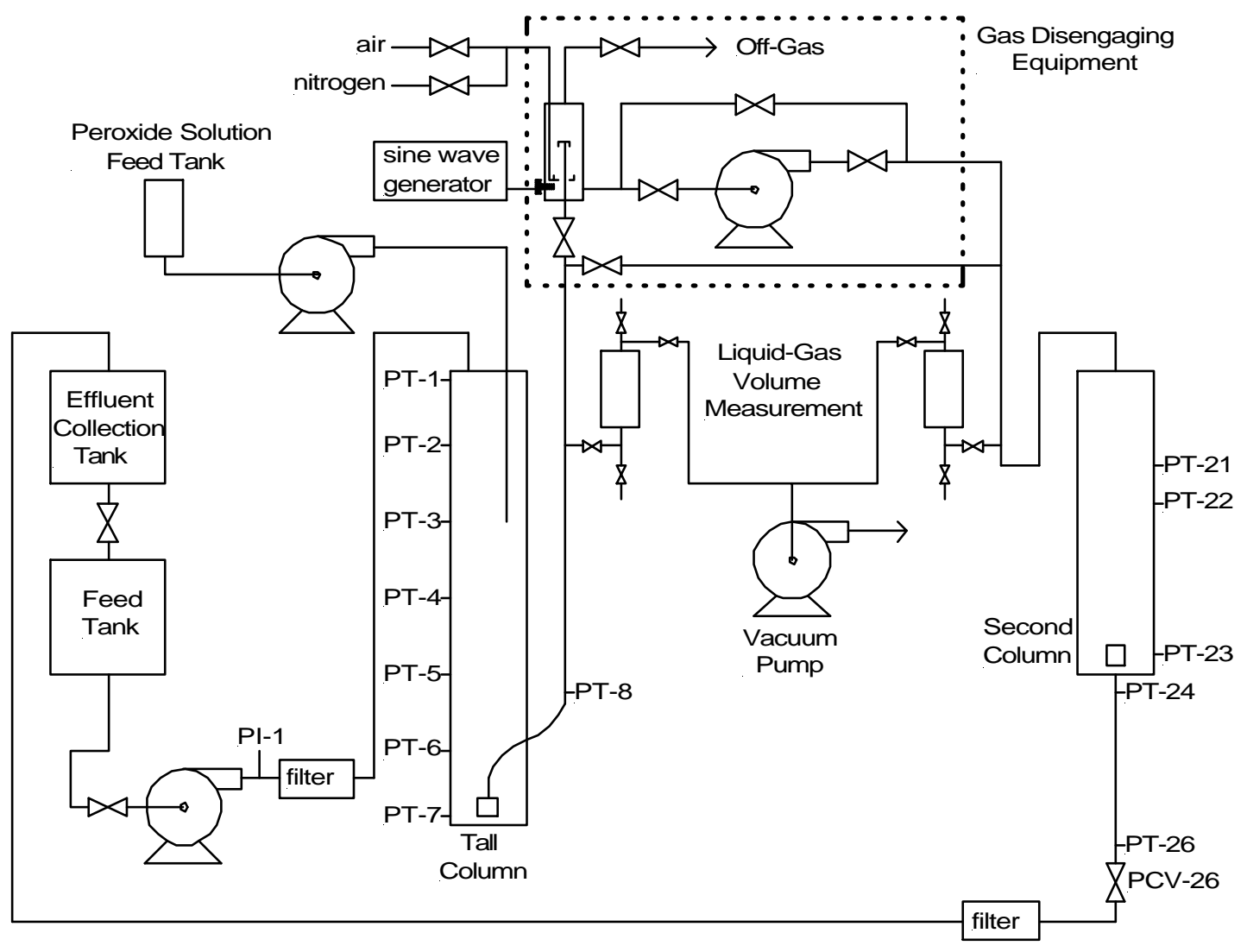

Fig. 3.1. Simplified schematic of test system. 
includes tanks, piping, valves, and instrumentation and controls needed to load both columns with CST, operate the columns in a recirculating mode with aqueous caustic salt solution (simulant) feed, perform gas accumulation and disengagement tests, and to unload the columns. During operation, simulant is pumped from a feed tank located near the bottom of the tall column through an in-line filter to the top of the tall column. Simulant moves through the column in a downflow configuration. Fluid exits the tall column through a Johnson screen at the bottom of the column and is then fed to the GDE located above the column. From the GDE, the fluid moves in a downflow configuration through a second (lag) column. The effluent is filtered and collected in a receiving tank. The contents of the receiving tank can be drained into the feed tank to support recycle operation.

\subsubsection{Columns and Ancillary Devices}

The ORNL tall column is located on the second floor of Building 4505 (Laboratory 22A) and extends vertically to a level just below the elevated platform built upon the third floor. ${ }^{5}$ This column was fabricated from 3-in.-diam clear polyvinyl chloride (PVC) pipe and is $20 \mathrm{ft}$ tall to model the proposed full-size SRS columns. The latter columns were designed with tentative dimensions of $5 \mathrm{ft}$ diam and $20 \mathrm{ft}$ tall and containing a 16- $\mathrm{ft}$ absorbent bed. The much smaller diameter of the columns in the test system permits smaller throughputs and simulant inventory for evaluation purposes. At a flow rate of $190 \mathrm{~mL} / \mathrm{min}$, the test system achieved a superficial velocity equivalent to that expected for the proposed full-size columns.

For test purposes, the tall column simulates a system of appropriate hydraulic characteristics (e.g. hydrostatic pressures) and provides a source stream of simulant containing dissolved and undissolved gases of appropriate total volume for the tests. Gas was supplied to the liquid stream by the decomposition of $\mathrm{H}_{2} \mathrm{O}_{2}$ as described in ORNL/TM-1999/103. ${ }^{3}$ The decomposition produced only oxygen; no hydrogen was present.

The lower portion of the column was modified to eliminate dead zones where gas can accumulate in the flow path of the effluent. The effluent line rises vertically from a Johnson screen near the bottom of the bed and passes through a short section of the bed. The tube then bends at an angle of $30^{\circ}$ from the horizontal and passes through a machined PVC plug welded into the side of the column. Once outside the column, the tube bends back to the vertical. The effluent passes through a viewing cell on its way to the elevated GDE. A photograph of the new lower section is shown in Fig. 3.2.

In an effort to cause the undissolved exiting gases to form bubbles of prototypical sizes, the Johnson screen in the column was modified so as to obtain a filtering area properly scaled to the diameter of the column. Appendix A describes the design of a shortened Johnson screen 
having the appropriate filtering area. Figure 3.3 shows a photograph of a standard unit with 3/4in. normal pipe thread (NPT) connection alongside custom fabricated 5-slot and 2slot units with fittings to mate with tubing connectors. The 2-slot unit was the smallest the vendor (U.S. Filter) could make with existing tooling. The 5-slot unit was selected for use in the tall column.

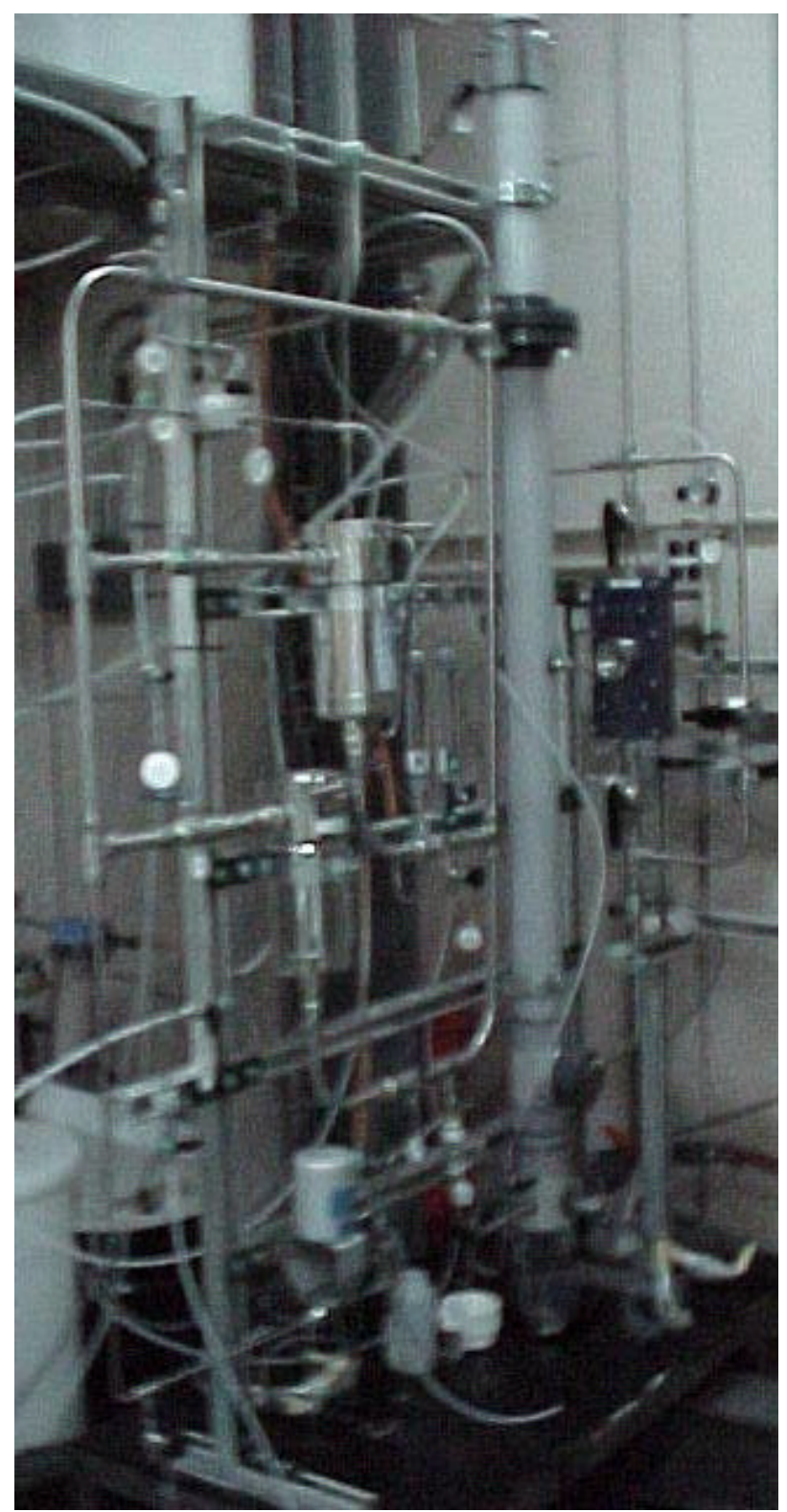

Fig. 3.2. Lower section of tall column following modifications.

Pressure sensors were located at intervals along the length of the tall column. The elevation of each sensor is given in Table 3.1. The bed height was $467 \mathrm{~cm}$, placing the surface of the bed between sensors PT-2 and PT-3. The centerline of the Johnson screen was at the same 
elevation as PT-7. Data from PT-7 and PT-8 may be used to infer the pressure drop across the Johnson screen.

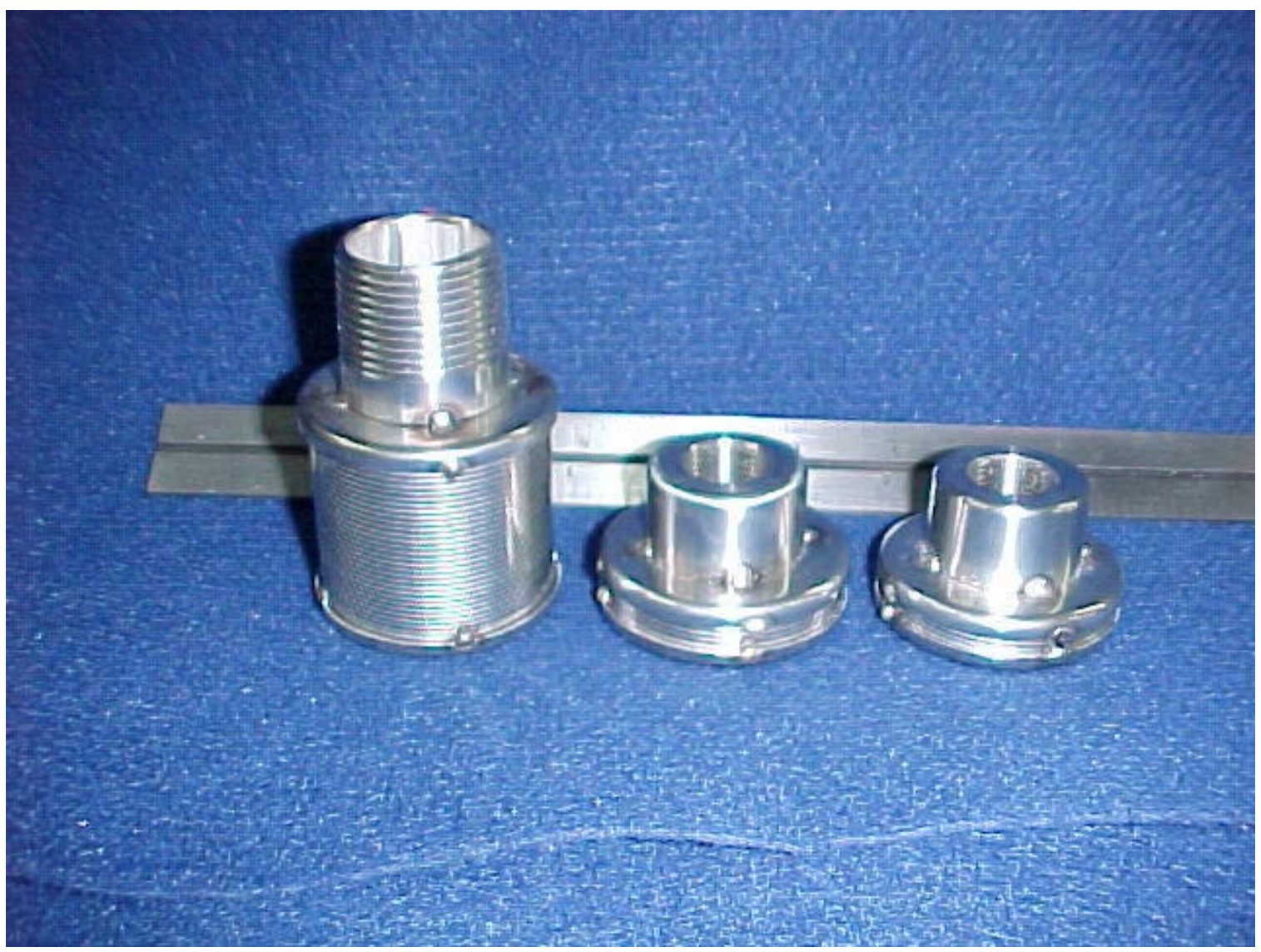

Fig. 3.3. Standard Johnson screen (left) shown alongside custom 5-slot (center) and 2-slot (right) units.

Table 3.1. Relative elevations of pressure transducers in the tall column

\begin{tabular}{cc}
\hline Pressure transducer & Height $[\mathrm{cm}(\mathrm{ft})]^{a}$ \\
\hline PT-1 & $604 .(19.8)$ \\
PT-2 & $502 . \quad(16.5)$ \\
PT-3 & $402 .(13.2)$ \\
PT-4 & $302 .(9.9)$ \\
PT-5 & $202 . \quad(6.6)$ \\
PT-6 & $100 .(3.3)$ \\
PT-7 & $8.5(0.3)$ \\
PT-8 & $62 . \quad(2.0)$ \\
\hline
\end{tabular}

${ }^{a}$ The weld line, just above the threaded base plug, was selected as the zero reference. 
A short column, 5ft tall, was fabricated of 3-in. schedule 80 PVC pipe (see Fig. 3.4) to simulate the upper section of a downstream column. It is located on the third floor of Building 4505 adjacent to the tall column. The surface of the CST bed is at approximately the same elevation as the CST bed in the tall column. ${ }^{5}$ Four pressure sensors (see relative elevation of each sensor in Table 3.2) were installed to monitor the short column. The surface of the bed was at $100 \mathrm{~cm}$, placing that interface between PT-21 and PT-22. The column was equipped with a standard Johnson screen (see Fig. 3.3, left-most unit), the centerline of which is at a relative elevation of $4 \mathrm{~cm}$. Both sensor PT-24, which is located in the effluent line just below the column, and PT-23 provide pressure drop-information about the Johnson screen.

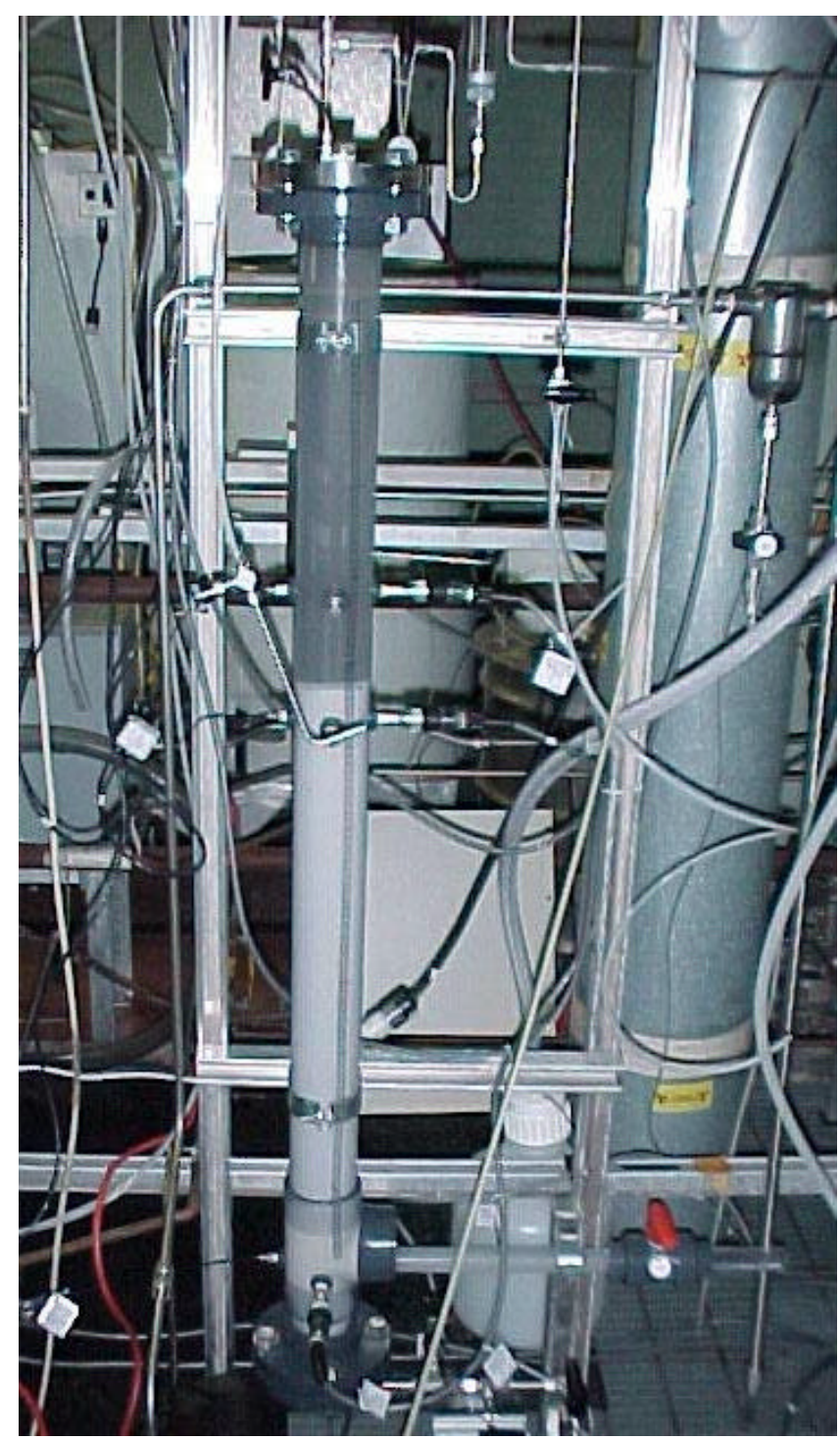

Fig. 3.4. Short downstream column. 
A valve downstream of the short column was used to restrict flow and to simulate pressure drop across two 16-ft-tall columns in series. Using estimations by Pike $^{6}$ as a guide, the pressure immediately upstream of the valve is normally around 20 psig.

Table 3.2. Relative elevations of pressure transducers in the short column

\begin{tabular}{cc}
\hline Pressure transducer & Height $[\mathrm{cm} \text { (in.) }]^{a}$ \\
\hline PT-21 & $107 .(42)$ \\
PT-22 & $91 .(36)$ \\
PT-23 & $15 .(6)$ \\
PT-24 & $-6 .(-21 / 4)$ \\
\hline
\end{tabular}

${ }^{a}$ The inside bottom of the column, or top surface of the lower flange, was selected as the zero reference.

Each column was equipped with a gas-collection tube attached to its top. The tubes were sections of 1-in., clear PVC pipe oriented vertically to collect gas that would normally collect in the headspace of the column. Periodic measurements of the heights of the liquid level in these tubes provided information concerning the accumulation rate of gas in the tops of the columns.

Instruments to measure undissolved gas in the liquid feed and effluent of the GDE (essentially a liquid-gas settling chamber) were designed and fabricated. These instruments included (1) a separation chamber to measure the gas volume that is separated from a volume of liquid and (2) viewing chambers used in conjunction with photographic equipment to measure the sizes of bubbles entrained in a flowing liquid stream. ${ }^{7}$

The liquid-gas volume measurement chambers were used to collect a fixed volume of simulant solution. These units were fabricated of sections of 3-in. schedule 80 clear PVC pipe and were equipped with valves, gauges, and burets as shown in Fig. 3.5. Liquid was sampled and held in these chambers to permit the gas and liquid to separate, and the gas buret was then used to measure the volume of gas collected. (The nominal volume of the sampling chambers is $1 \mathrm{~L}$.) A vacuum pump was used to evacuate the chamber prior to sampling to ensure that all gas measured was that entrained with the simulant.

Viewing cells were designed and fabricated to facilitate a photographic method of measuring the sizes of bubbles in the liquid streams exiting the tall column and the GDE. The unit in the tall-column effluent line is shown in Fig. 3.6. Each unit was machined from solid PVC plate stock and assembled with stainless steel fasteners. The front cover was clear PVC to improve lighting, and both sides were equipped with 1-in.-diam optical flats for viewing the interior from either side. A stainless steel insert was placed inside the viewing cell to provide 
both flow directing vanes and support for a measurement reference. The measurement reference is a 0.020 -in.-diam stainless steel wire fixed within the field of view of the camera.

Additional detail on the design and layout of this equipment may be obtained by referring to the design documentation. ${ }^{5,7}$

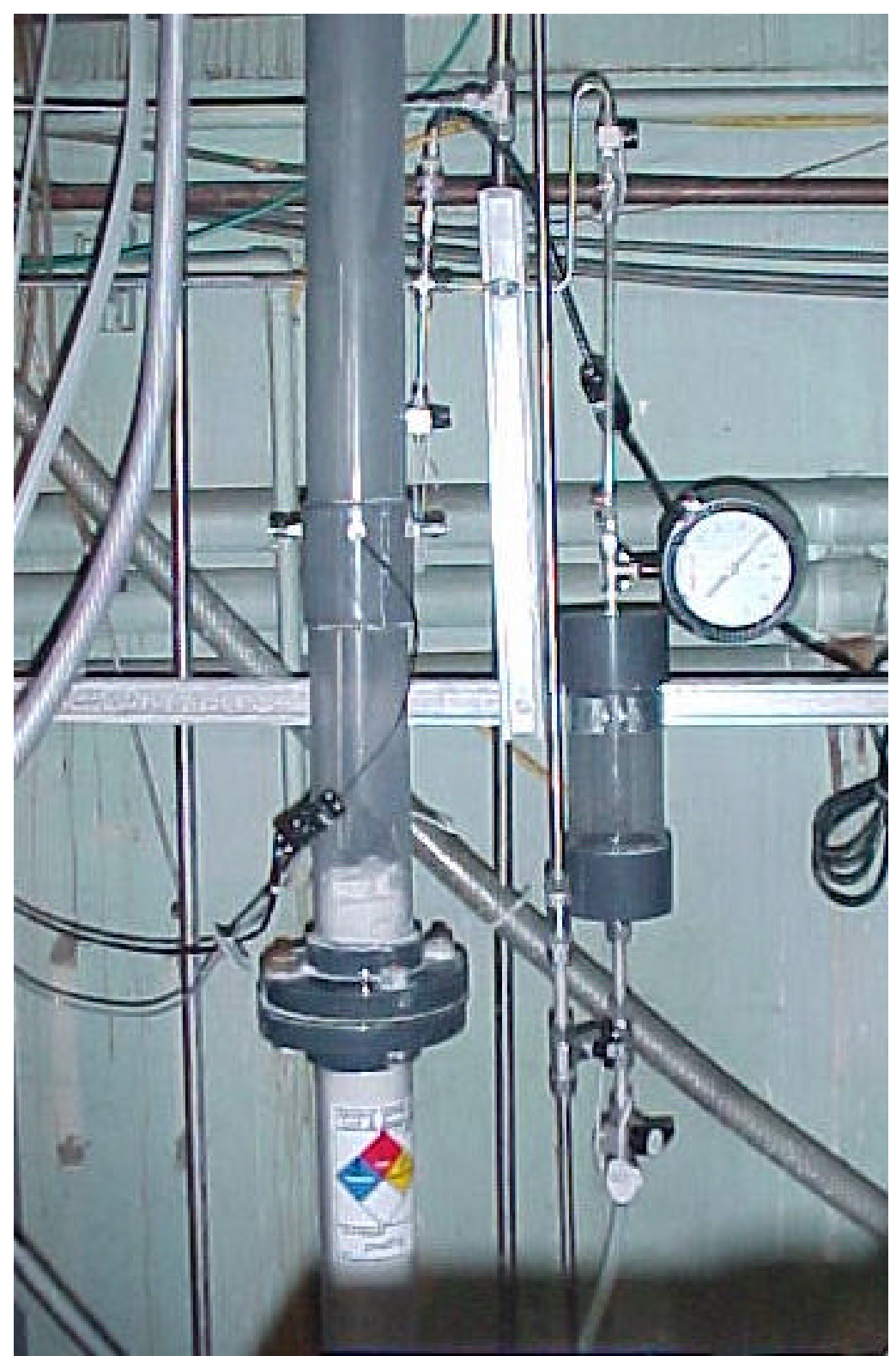

Fig. 3.5. Gas separation and measurement chamber shown plumbed to tall-column effluent riser pipe (with tall column to the left). 


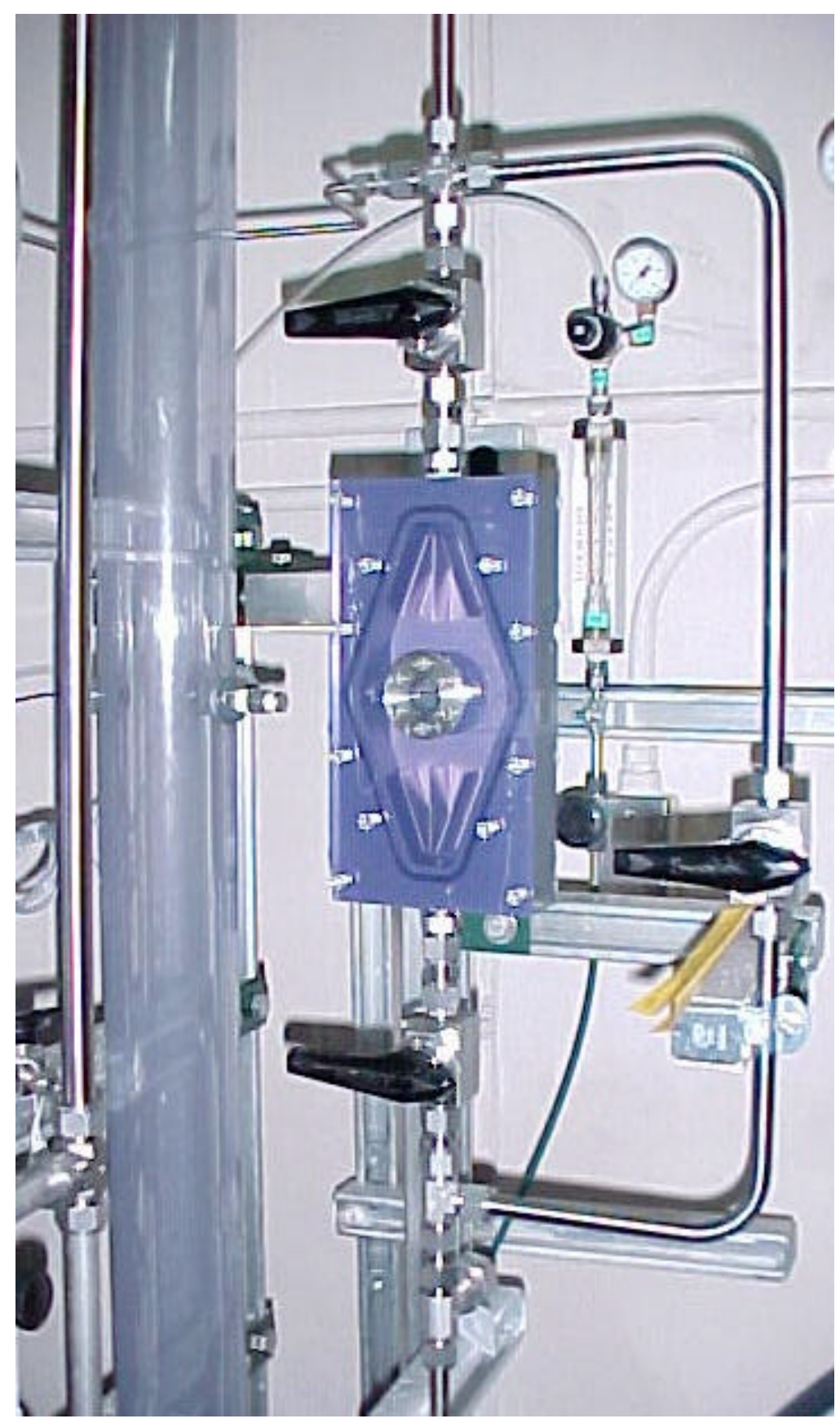

Fig. 3.6. Bubble -viewing cell. 


\subsubsection{Gas -Disengaging Equipment}

The GDE was specified by Savannah River Design Engineering. ${ }^{8,9}$ [Details are shown in P\&ID M-M6-G-0731 and assembly drawing M-PM-G-0008.] A fabrication contractor to ORNL built the unit as a plate-mounted assembly for ease of transport and installation. The primary components are a settling chamber with sparger and ultrasonic horn that induces coalescence of the small gas bubbles entrained in the liquid stream. The larger bubbles then separate readily in the settling chamber. Ancillary equipment includes a pump, control valves, and fluid flow measurement devices. The equipment is located on the platform at the third floor of Building 4505 over the tall column. A photograph of the equipment is shown in Fig. 3.7.

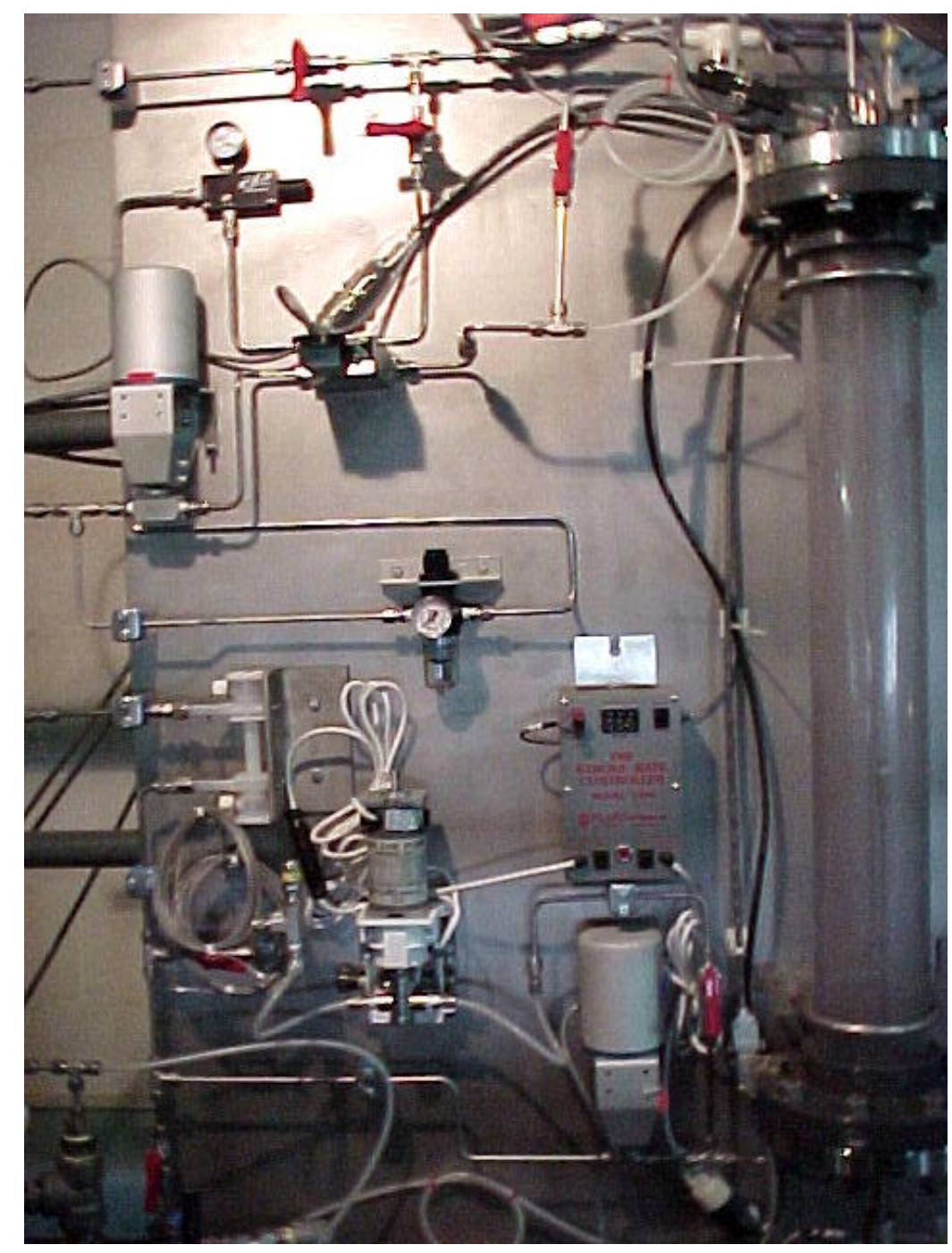

Fig. 3.7. Gas disengaging equipment. 
The GDE designed for this evaluation supports four fundamental separation methods: (1) passive settling, (2) gas sparging to strip entrained gas or gas bubbles, (3) separation under reduced pressure, and (4) injection of ultrasonic waves to induce coalescence of bubbles with attendant settling. It is possible to use these methods separately or in combination, provided that the selections are not mutually exclusive. The method using ultrasonic waves is limited because the acoustic actuator cannot be used on a continuous basis; only intermittent bursts are recommended to prevent overheating and subsequent failure. The settling-separation chamber is equipped with a feed nozzle that introduces salt solution and a sparger nozzle that introduces sparge gas $\left(\mathrm{CO}_{2}\right.$-free air or nitrogen). The vertical position of each of these nozzles within the chamber is adjustable. The flow rate of the sparge gas is also an adjustable parameter. By use of an eductor (venturi vacuum pump), the equipment is also capable of operation at pressures less than atmospheric.

The GDE may be operated in two general modes. However, since the GDE may also be bypassed, the column system can actually be operated in three different modes. These three modes can be described as follows.

Mode A: The GDE operates at atmospheric, or lower, pressure in this mode. The effluent from the tall column enters the GDE for gas separation. When operating at atmospheric pressure, the GDE is simply vented. A pump, which is part of the GDE, is used to feed degassed simulant to the short column. The control system maintains the liquid level in the GDE settling tank at a given setpoint. At steady state the GDE pump feeds the short column at the same rate as the feed pump does the tall column. There are four possible separation methods: passive settling, nitrogen (or $\mathrm{CO}_{2}$-free air) sparging, reduced pressure, and injection of ultrasonic waves. Combinations of these methods were not used in any of the tests.

Mode B: The GDE operates at elevated pressure. In this mode, the feed pump for the tall column provides the necessary pressure to maintain flow through the columns and the GDE. The nitrogen (or $\mathrm{CO}_{2}$-free air) supply to the GDE provides the sweep gas for removal of radiolytic gases (in this case, $\mathrm{O}_{2}$ from decomposition of $\mathrm{H}_{2} \mathrm{O}_{2}$ to simulate radiolysis) and also facilitates control of the liquid level in the GDE. The control system maintains a constant flow of pressurized gas to the GDE settling tank. A venting valve is manipulated to adjust the gas pressure in the headspace to a given setpoint. The liquid discharge valve is controlled to maintain the liquid level in the GDE settling tank. At steady state the liquid flow through both columns is equivalent. There are three possible methods: passive settling, nitrogen (or $\mathrm{CO}_{2}$-free air) sparging, and ultrasonic-enhanced separation. The reduced-pressure method is ruled out by definition. 
Mode C: In this mode of operation, the GDE is bypassed; the effluent from the tall column (first column) is fed directly to the short column. The feed pump must overcome the pressure losses through both columns and meet the requirements of hydrostatic head associated with the overall system. The control system maintains the feed rate of simulant to the tall column.

\subsubsection{Control and Data Acquisition System}

The control system consists of an IBM-compatible personal computer (PC) connected to a National Instruments (NI) SCXI data acquisition and control system (see Fig. 3.8). The PC is a Pentium ${ }^{\circledR}$ III-class machine running under the Windows ${ }^{\circledR}$ NT 4.0 operating system. It was equipped with an NI PCI-MIO-16XE-10 serial interface card, which permits communication with the SCXI data acquisition system, and a NI 5401 sine wave generator (45 to 20,000 Hz) circuit card. Data acquisition and control are implemented using the LabView software from NI (Version 6.0, full development system) with custom programming for this experimental setup. Control screens showing the column and GDE system layout were developed. This setup gave the operator an overview of the system and an interface through which the system could be controlled.

The data acquisition system consists of the following major components:

$\begin{array}{lll}\text { SCXI-1101 } & \text { 12-slot chassis } \\ \text { SCXI-1100 } & \text { 32-channel analog input card } & \text { (2) } \\ \text { SCXI-1124 } & \text { 6-channel analog output card } & \text { (2) } \\ \text { SCXI-1163R } & \text { 32-channel relay card } \\ \text { SCXI-1162HV } & \text { 32-channel digital input card }\end{array}$

To reduce noise and improve accuracy, various shielded cables and terminal blocks were used as required to assemble and connect the system. Field sensors consisting of thermocouples, pressure transmitters, flow transmitters, valve position sensors, and level switches comprised the data input. Output signals to actuators included those for control valves, pumps, and power relays. Table 3.3 lists the data points recorded during operations. The logging frequency is user selectable. Each data point was recorded at 10-s intervals over the course of the tests. 


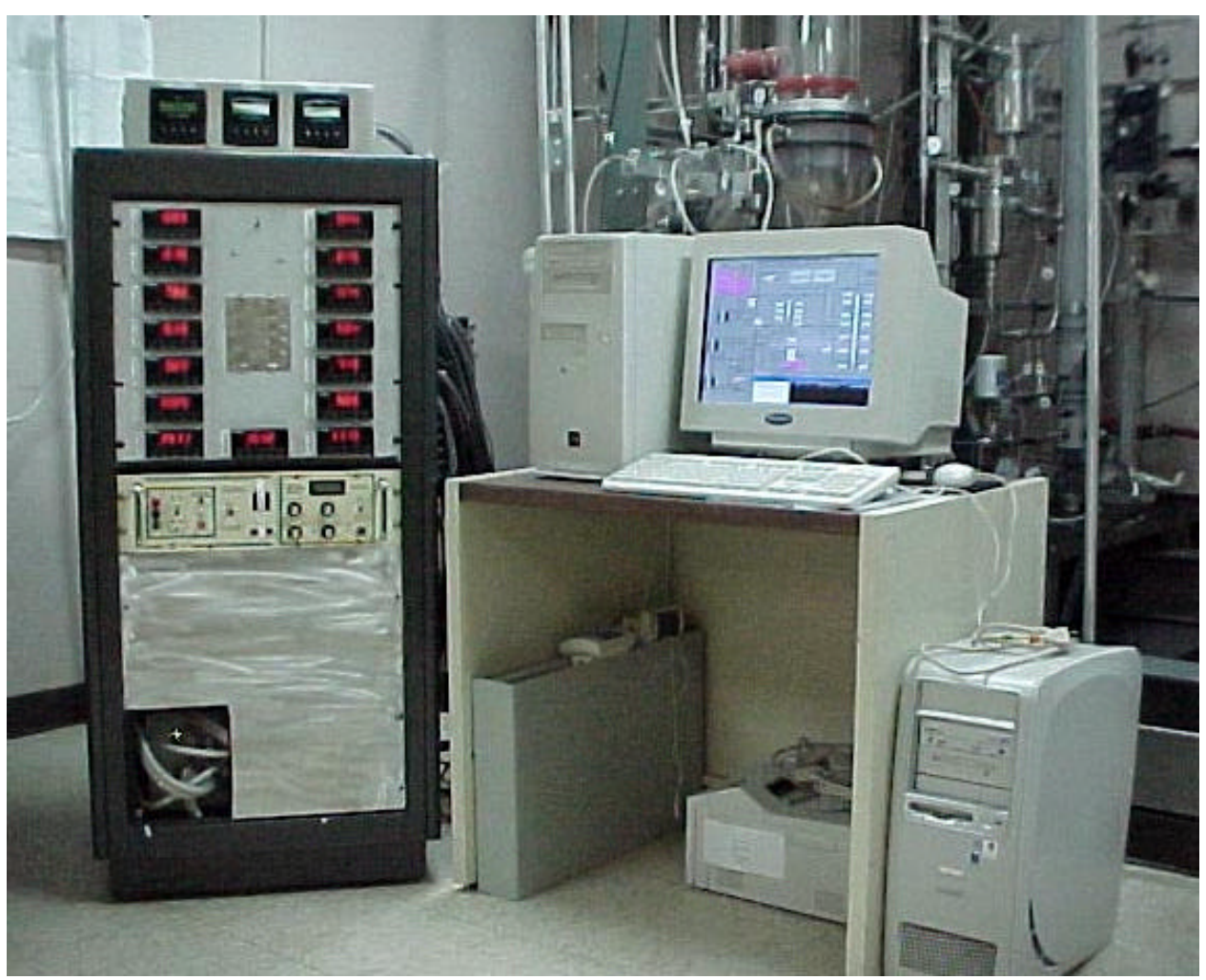

Fig. 3.8. Control system.

Table 3.3. List of data points recorded by data acquisition system

\begin{tabular}{cl}
\hline Point name & Definition \\
\hline Date & Date in mm/dd/yy format \\
Time & Time in hh:mm:ss AM/PM format \\
PT-1 through PT-8 & Pressure in tall column at positions $1-8$ (see Table 3.1), psig \\
PT-25 & Headspace pressure in GDE vessel, psig \\
LT-21 & Liquid level in GDE, in. \\
PT-26 & Back pressure on second column, psig \\
TE-1 through TE-7 & Temperature in tall column at positions $1-7$ (see Table 3.1), ${ }^{\circ} \mathrm{C}$ \\
FT-21 & Hydrogen peroxide solution flow rate, $\mathrm{mL} / \mathrm{min}$ \\
PT-21 through PT-24 & Pressure in second column at positions $1-4$ (see Table 3.2), psig \\
TE-21 through TE-24 & Temperature in second column at positions $1-4$ (see Table 3.2), ${ }^{\circ} \mathrm{C}$ \\
PCV-25 & Position of GDE gas vent valve, \% \\
FCV-23 & Position of GDE nitrogen feed valve, \% \\
FCV-22B & Position of GDE liquid discharge valve (Mode B), \% \\
PCV-26 & Position of second column back-pressure control valve, \% \\
FIT-1 & Simulant feed rate to tall column, mL/min \\
FIT-2 & Simulant return rate to feed or effluent tank, $\mathrm{mL} / \mathrm{min}$ \\
FIT-22 & Simulant feed rate to second column, $\mathrm{mL} / \mathrm{min}$ \\
FT-23 & Nitrogen feed rate to GDE, mL/min \\
\hline &
\end{tabular}




\subsection{MATERIALS}

\subsubsection{Supernatant Simulant}

Supernatant simulant was prepared using a recipe supplied by Savannah River Site (SRS) personnel $^{10}$ and is similar to simulant used in previous tests at ORNL (see Table 3.4). Deionized water was used to prepare the solution. Because of the undesired reactions between nitrite ion and hydrogen peroxide, nitrite was replaced with nitrate. Oxalate interferes with the analysis of peroxide concentration in the simulant and was omitted. Reagent-grade chemicals purchased from commercial sources were used in the preparation of the supernatants.

Table 3.4. Composition of SRS high-nitrate supernatant $^{a}$ waste

\begin{tabular}{lc}
\hline Component & Average concn. $(M)$ \\
\hline $\mathrm{Na}^{+}$ & 5.6 \\
$\mathrm{Cs}^{+}$ & 0.00014 \\
$\mathrm{~K}^{+}$ & 0.0041 \\
$\mathrm{OH}^{-}$ & 1.17 \\
$\mathrm{NO}_{3}{ }^{-}$ & 2.84 \\
$\mathrm{NO}_{2}{ }^{-}$ & $0.37^{b}$ \\
$\mathrm{AlO}_{2}{ }^{-}$ & 0.32 \\
$\mathrm{CO}_{3}{ }^{2-}$ & 0.16 \\
$\mathrm{SO}_{4}{ }^{2-}$ & 0.22 \\
$\mathrm{Cl}^{-}$ & 0.040 \\
$\mathrm{~F}^{-}$ & 0.050 \\
$\mathrm{PO}_{4}{ }^{3-}$ & 0.010 \\
$\mathrm{C}_{2} \mathrm{O}_{4}{ }^{2-}$ & $0.008^{c}$ \\
$\mathrm{SiO}_{3}{ }^{2-}$ & 0.004 \\
$\mathrm{MoO}_{4}{ }^{2-}$ & 0.0002 \\
\hline
\end{tabular}

${ }^{a}$ Source: Walker, WSRC-TR-99-00116 (ref. 10).

${ }^{b}$ Replaced with nitrate to prevent side reactions with hydrogen peroxide.

${ }^{c}$ Omitted to prevent interference with analysis of perioxide concentration.

\subsubsection{Granulated CST}

CST used for these tests is the commercial, granular form of the sorbent IONSIV $^{\circledR}$ IE-911 ${ }^{\mathrm{TM}}$ (UOP, LLC, Mt. Laurel, NJ). The as-received CST was pretreated using the steps recommended by SRS. ${ }^{11}$ This included treatment with dilute sodium hydroxide to adjust the $\mathrm{pH}$ to $\sim 13$ followed by backwashing to remove fines prior to use. The material was then drained and air-dried. Material from lot 999098810006 (receipt drum 3A) was used to charge the tall column. The particle size distribution of the dried material was measured prior to loading it into the 
column. Four samples were subjected to sieve analysis with good repeatability. The weight fraction is presented in Fig. 3.9 as a function of median particle diameter. The distribution indicates that $(62.1 \pm 2.1) \%$ of the particles, by mass, fall within the 350- to 840-ì m-diam range. Low quantities of material below about $250 \mathrm{ìm}$ causes the truncated distribution, which is expected of materials that have been classified and backwashed to remove fines.

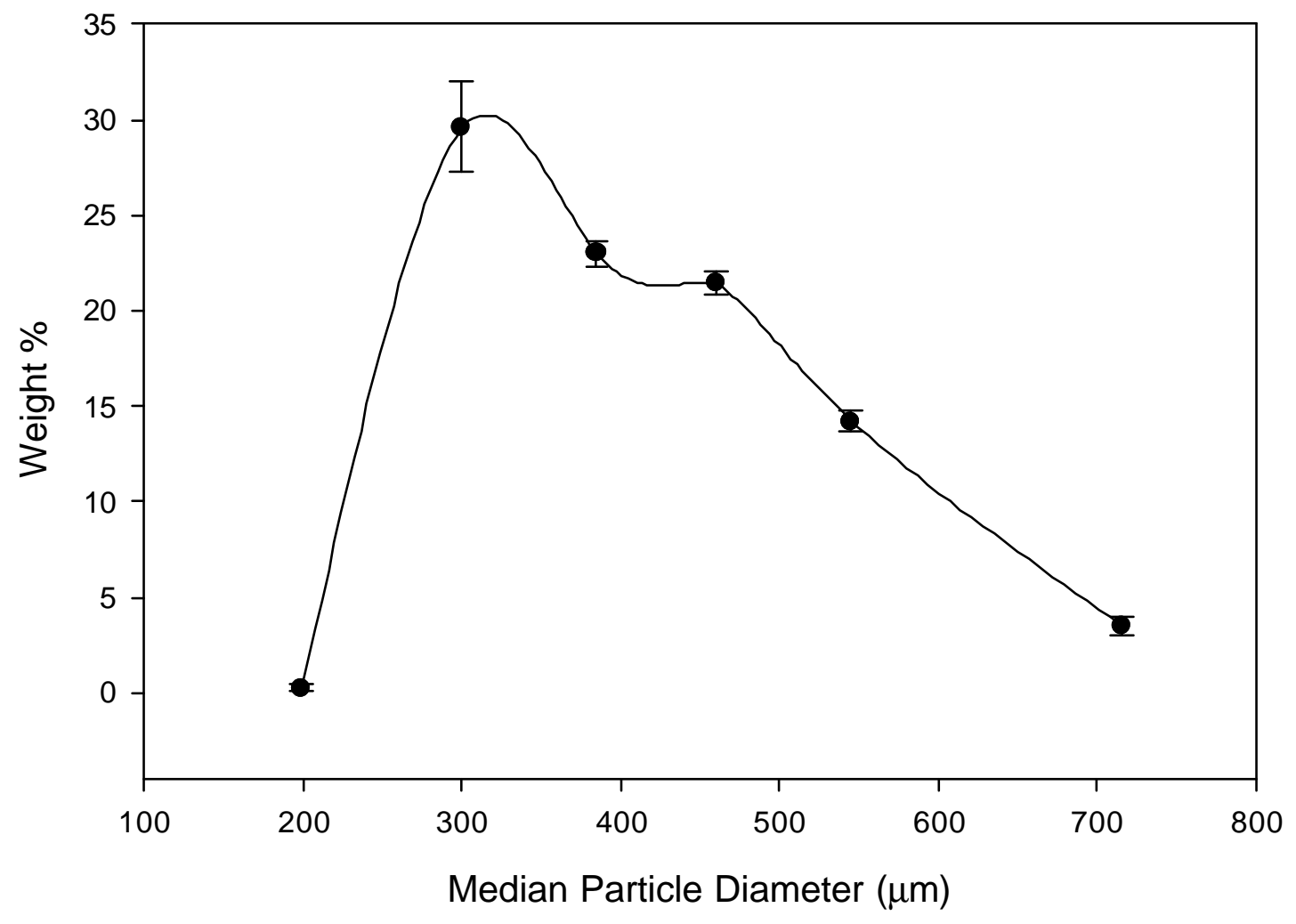

Fig. 3.9. Particle size distribution of CST, lot 99909881006 , us ed to charge the tall column.

The bulk density of the dried CST was also measured. A 50-mL graduated cylinder was weighed before and after being filled with CST. Three replicate measurements indicated a bulk density of $1.127 \pm 0.006 \mathrm{~g} / \mathrm{mL}$. 


\section{PERFORMANCE OF GAS DISENGAGING EQUIPMENT}

The GDE is designed to support three modes of system operation: (1) Mode C, where the GDE is bypassed; (2) Mode A, where the GDE operates at a vented condition; and (3) Mode B, where the GDE operates at pressurized conditions. Modes C and B do not use an interstage pump and require that the simulant feed pump force the liquid stream (waste simulant) through the series of columns. Mode A requires the use of an interstage pump at the GDE to feed the liquid through the short (downstream) column. Gas-separation methods supported by the GDE include passive settling, sparging, reduced-pressure, and ultrasonic-enhanced coalescence of gas bubbles. The tests reported here were meant to assess the effect of the primary separation methods - not to optimize combinations of separation methods. In addition, the GDE supports variation in other operational parameters. These include the position or elevation of both the inlet liquid nozzle and the sparge tube nozzle, as well as the liquid level in the GDE. These latter parameters were fixed at specific values for the duration of the tests. The liquid level was set to 15 in. (GDE vessel, approximately half full), the inlet nozzle was adjusted to about one-half the vessel height (15 in.), and the sparge nozzle adjusted to about one-fourth the vessel height (7.5 in.).

Decomposition of hydrogen peroxide $\left(\mathrm{H}_{2} \mathrm{O}_{2}\right)$ was used to generate gas (oxygen) in the tall column (sometimes referred to as the upstream, or first, column). Hydrogen peroxide is both absorbed and decomposed by the CST. Absorption equilibria result in transients caused by absorption or desorption as the concentration of the $\mathrm{H}_{2} \mathrm{O}_{2}$ feed changes. Overlaid with a long residence time in the column, due to the relatively low liquid feed rates, this made control of the effluent gas rate at steady state very difficult.

The primary purpose of the GDE is to prevent gas generated in the upstream CST column from being introduced to the downstream column. To meet this need, the GDE removes entrained gas from the effluent of the upstream column. The experimental GDE supports various methods (discussed above and in Sect. 3.1.2) of separating the gas from the liquid. The purpose of the testing program is to determine how effectively the GDE performs this separation.

The experimental system provides three methods for assessing the effectiveness of the GDE. First, a direct method is used for sampling the liquid stream and measuring the volume of gas that separates from the liquid. If the gas is not completely separated from the liquid by the GDE, then it can accumulate in the downstream column, either in the headspace above the CST bed or in the CST bed itself. The second method involves monitoring the volumetric accumulation of gas in the headspace of the second column. The third method involves 
monitoring the pressure drop (resistance to flow) across the column, a parameter that is expected to increase with increasing accumulation of gas in the solids bed. Even though the last two methods are based on indirect measurements, the results are very useful.

Each method of evaluation was used to assess the different operating modes of the GDE. The efficacy of each mode was compared with that of the others. Finally, qualitative data on the effect of ultrasonic waves to induce coalescence of gas bubbles in the GDE were obtained and are presented here.

\subsection{ENTRAINED-GAS MEASUREMENTS}

Gas-separation and gas-measurement chambers were designed with a nominal volume of $1 \mathrm{~L}$ each to take samples of liquid from the system, hold the sample while the free gas separates from the liquid, and permit measurement of the gas volume collected with a gas buret (see Sect. 3.1.1 for details). The range of gas-volume measurements was 3.1 to $11.6 \mathrm{~mL}$ for the downstream unit and 3.4 to $11.9 \mathrm{~mL}$ for the upstream unit. Because the nominal liquid flow rate through the system is $190 \mathrm{~mL} / \mathrm{min}$, these measurement chambers are capable of collecting the entire liquid stream for a period of $\sim 5.3 \mathrm{~min}$. This represents a significant disturbance to the system, impacting system pressure, flow downstream of the measurement point, and liquid level in the GDE. To minimize the effect of disturbances on the gas measurements, the sampler downstream of the GDE and the sampler upstream of the GDE were operated sequentially. Measurements were made at approximately 2 -h intervals to permit the system to recover. Smaller sampling chambers were predicted to be ineffective. At nominal gas-generation rates of $80 \mathrm{std} \mathrm{mL} / \mathrm{h}$ and the sample collection period mentioned above, a 1-L sample contains only $7 \mathrm{~mL}$ of gas.

Operation of the gas-separation and gas-measurement chambers consisted of evacuating the chamber with a vacuum pump, isolating the chamber with the associated valves, verifying that the chamber did not leak, and then slowly opening the valve connecting the chamber to the line being sampled. It was observed that as the chamber filled, bubbling and frothing of the fluid occurred and large numbers of bubbles adhered to the inside surface. The pressure inside the chamber remained constant at the evacuation pressure until the chamber was nearly full; then it rapidly increased to system pressure. Once at system pressure, the valve was closed to isolate the chamber from the system. It was observed that at system pressure, the bubbles adhering to the inside surface of the vessel disappeared. It is thought that these bubbles were composed of water vapor and that the "boiling" caused the gas, both dissolved and undissolved, to be stripped from 
the liquid. After settling, the gas volume was measured at system pressure. The vessels were then vented at the bottom to allow the gas to expand and to encourage additional separation at atmospheric pressure. After initial expansion, the gas volume did not change, indicating that no additional desorption of gas from the liquid was occurring.

Gas volumes measured at atmospheric pressure were used to calculate the entrained-gas flow rate. When the reading was off scale at atmospheric pressure, bit on scale at system pressure, the gas volume measured at system pressure was used to calculate the equivalent volume at atmospheric pressure. The entrained-gas flow was calculated by

$$
V_{g}=60 f \frac{V_{c}}{V}
$$

where $V_{g}=$ volumetric gas flow rate, $\mathrm{mL} / \mathrm{h}$;

$f=$ liquid (simulant) flow rate, $\mathrm{mL} / \mathrm{min}$;

$V=$ volume of separation-measurement chamber, $\mathrm{mL}$;

$V_{c}=$ measured volume of gas collected, $\mathrm{mL}$; and

$60=$ a conversion factor, $\min / \mathrm{h}$.

Equation (4.1) is valid only when the volume of gas is much smaller than the volume of liquid collected (which is the usual case). The total volume of the downstream unit is $944.8 \mathrm{~mL}$, while that of the upstream unit is $955.1 \mathrm{~mL}$.

\subsubsection{Mode C}

The system was started in Mode $\mathrm{C}$, in which the GDE is bypassed, to obta in baseline data in the absence of gas disengagement. Data collected under steady-state operating conditions (i.e., as close as could be achieved) were used to calculate the entrained-gas flow rate. The results are shown in Fig. 4.1. The gas rate upstream of the GDE position (i.e., effluent from the first column) is close to constant. However, the entrained-gas flow rate at the downstream position (i.e., feed into the second column) is less smooth and, on average, is of larger magnitude. Because the bypass mode is a closed circuit, the upstream and downstream readings should be equivalent. There are two likely causes for the difference observed in our experiments. First, there could be a bias in the downstream unit caused by leakage of air into the system around one of the valves or fittings. Second, gas bubbles might adhere to the piping upstream of the measurement station. Disturbances in the flow caused by sampling may dislodge the bubbles, which are subsequently collected. Obviously, there are also other explanations for the difference. For example, differences in the quantity of gas dissolved in the liquid could account for the bias, but the similar pressure reduction encountered at each station during sampling should mitigate this effect. The average upstream gas rate was calculated from the data as $71.6 \mathrm{~mL} / \mathrm{h}$; the average 
downstream rate was calculated as $92.6 \mathrm{~mL} / \mathrm{h}$. Thus, a value of $21 \mathrm{~mL} / \mathrm{h}$ may be considered the error with which these measurements can be made. Since the error appears to favor a larger value at the downstream position, a positive bias of $21 \mathrm{~mL} / \mathrm{h}$ on the downstream unit will be assumed for the purposes of subsequent analysis.

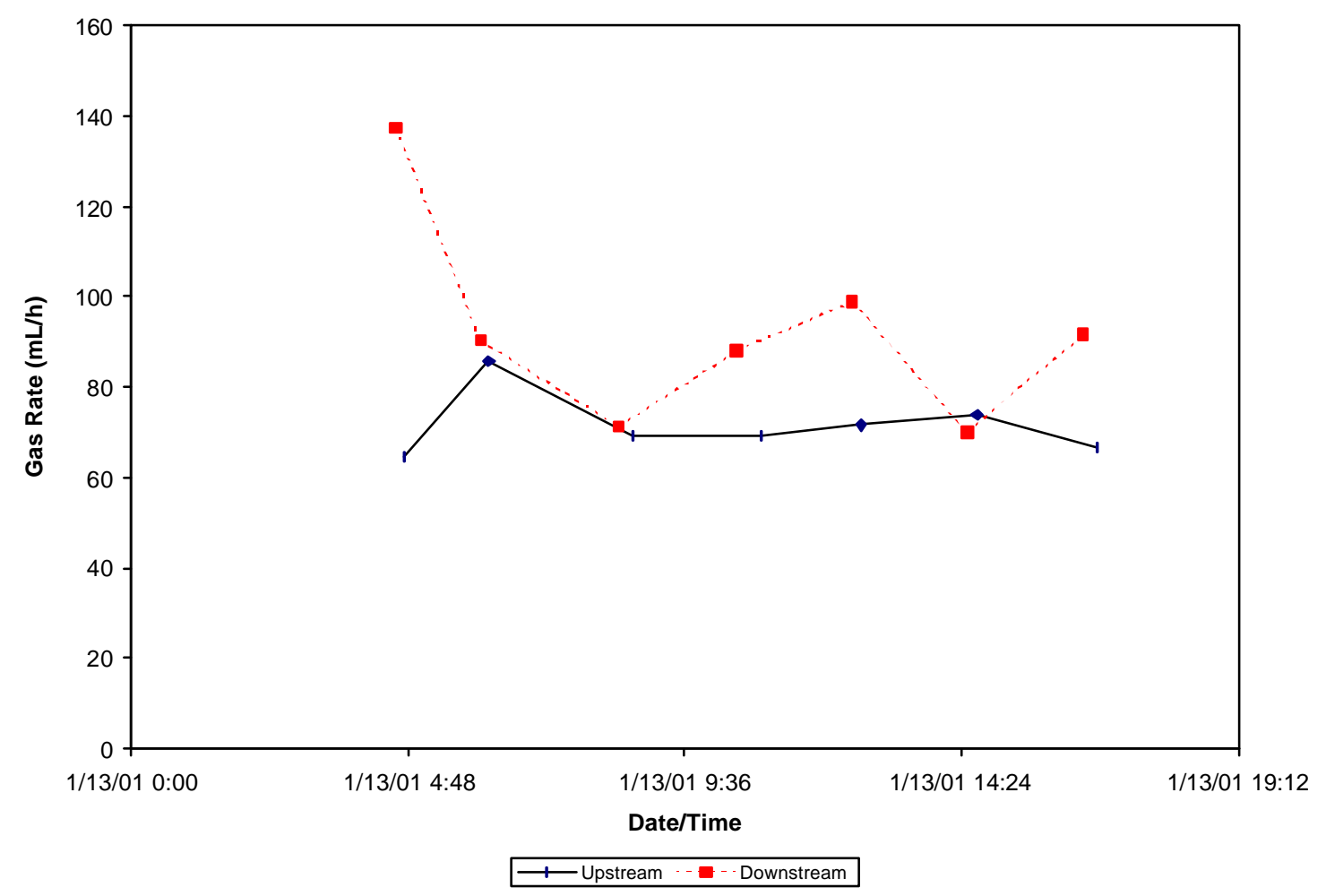

\section{Fig. 4.1 Entrainedgas flow rates measured during experiments conducted using Mode $\mathbf{C}$.}

As discussed in Sect. 3.1.1, bubble-viewing cells were placed in the lines both upstream and downstream of the GDE. A stainless steel wire with a diameter of $0.020 \mathrm{in}$. $(0.51 \mathrm{~mm})$ was installed in the flow path as a reference. At intervals throughout the experimental campaign, videotape recordings were made using a close-focus camera to obtain images of the bubbles. A photograph of a bubble in the effluent from the first column (upstream of the GDE) is shown in Fig. 4.2. The diameter of the bubble was $\sim 0.070$ in. $(1.8 \mathrm{~mm})$. As can be seen, some small particles are adhering to the surface of the wire. Bubbles were rarely observed in either the upstream or downstream units during Mode $\mathrm{C}$, possibly due to the small sizes of the bubbles or the dissolution of most of the gas. 


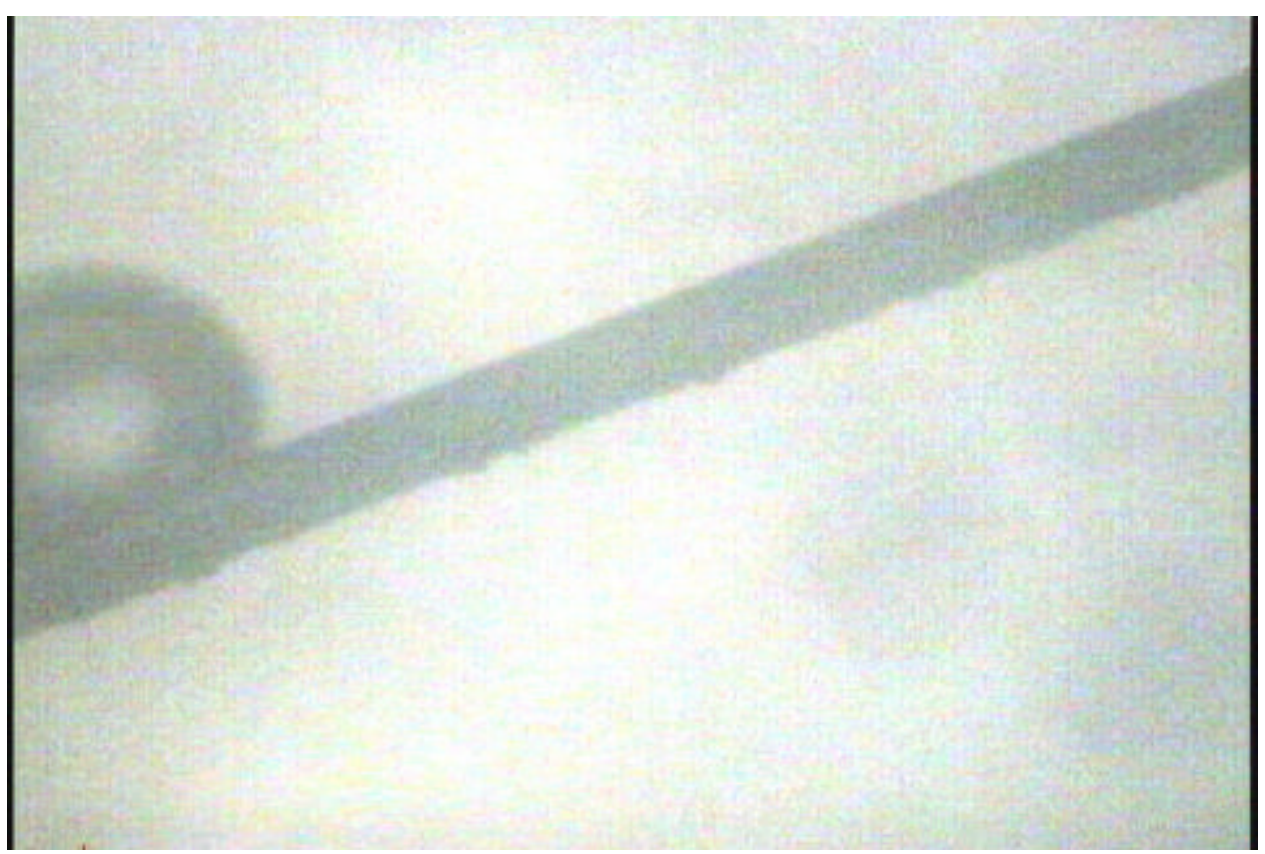

Fig. 4.2. Bubble upstream of the GDE, Mode C (1/12/01, 18:30).

The diameter of the bubble is $\sim 0.070$ in. $(1.8 \mathrm{~mm})$.

\subsubsection{Mode A}

Operation of the column system was switched from Mode C to Mode A by manually valving the GDE into the loop and by selecting the Mode A controls option at the PC console. Because the GDE is vented to the atmosphere in Mode A, the operating pressure in the first column changed significantly. At steady-state conditions, the pressure in the downstream column was not significantly different from that observed for Mode $\mathrm{C}$ because the back pressure on the downstream column was controlled at the same set point. The pressure reduction did not initiate an outgassing of the first column as one might expect. Rather, the effluent gas rate decreased, which led to the suspicion that flow channeling at low pressure could be different from that observed at high pressure. This could expose additional fresh CST to the $\mathrm{H}_{2} \mathrm{O}_{2}$, causing the peroxide to be absorbed instead of generating gas by decomposition. In any case, efforts were made to reestablish steady gas-generation rates by adjusting the $\mathrm{H}_{2} \mathrm{O}_{2}$ feed rate and concentration.

On two occasions the gas flow rate was so high that the capability for measuring the gas in the buret was exceeded; however, the rate could be estimated. The system was fed $\mathrm{H}_{2} \mathrm{O}_{2}$ at the concentration of $30 \mathrm{wt} \%$ to quickly load the CST, as compared with the nominal concentration of $0.2 \mathrm{wt} \%$ needed to achieve prototypical gas-generation rates. When breakthrough occurred at the high concentration, large quantities of gas were being produced. When the volume of gas produced was large enough, the liquid-gas interface in the separation and measurement vessels could be observed in the clear portion of the vessel body. The gas rate could be estimated from measurements of the distance between the top of the vessel and the liquid level, with knowledge 
of the physical dimensions of the vessel. At one point prior to establishing stable conditions in Mode A (passive settling method) the gas rate upstream of the GDE was $3440 \mathrm{~mL} / \mathrm{h}$ while the measured downstream rate was $130 \mathrm{~mL} / \mathrm{h}$. At another time prior to achieving stable conditions in Mode A (the reduced-pressure method), the upstream gas rate was $1920 \mathrm{~mL} / \mathrm{h}$ while the downstream rate was $19 \mathrm{~mL} / \mathrm{h}$. This illustrates that very large gas entrainments can be readily handled by the GDE.

Establishing a steady rate of gas flow in the effluent of the upstream column proved to be very difficult. Entrained-gas flow rates were obtained over a period of time that included passiveseparation, sparging, and reduced-pressure methods of operation. Figure 4.3 shows the gas rates both upstream and downstream of the GDE throughout the period. Superimposed on this graph is the concentration of $\mathrm{H}_{2} \mathrm{O}_{2}$ fed to the system. Intervals when $15 \mathrm{wt} \%$ and $30 \mathrm{wt} \% \mathrm{H}_{2} \mathrm{O}_{2}$ were used are evident. The low values range from 0.52 to $0.82 \mathrm{wt} \% \mathrm{H}_{2} \mathrm{O}_{2}$. Flow rates (not shown) were adjusted between 1.0 and $3.0 \mathrm{~mL} / \mathrm{min}$ to obtain the desired gas generation rate. Generation rates exceeding the capacity of the gas measurement vessels could be obtained with feeds having concentrations much less than $30 \mathrm{wt} \% \mathrm{H}_{2} \mathrm{O}_{2}$. Figure 4.4 shows the gas rates for the individual methods during periods when the system was declared to be in stable operation. When the gas flow rate in the effluent of the upstream column was high, as illustrated in Fig. 4.3, less gas was entrained in the effluent of the GDE and the rates lay within a narrower, albeit "noisy," band than that for the incoming stream. High gas rates in the input stream do not significantly increase the gas rate in the GDE effluent stream. When the input stream was lean in entrained gas, the GDE effluent often exhibited higher gas entrainment. These observations illustrated effective gas removal at high entrainment levels but appeared to support the need to adjust the downstream gas rate values to eliminate a bias that becomes significant at low values.

Figure 4.4 shows the best data obtained for each of the different separation methods. These data have not been corrected for any bias in the downstream measurement. The results for Mode A (passive settling method) show that gas entrainment in the GDE inlet stream was initially high but then settled to a fairly constant value. The outlet stream was leaner in gas than it was when the inlet gas rate was high. However, for most of the interval, the outlet was higher than the inlet. Corrections to eliminate a measurement bias, and thus this contradiction, are discussed in Sect. 4.1.4

Switching to Mode A (sparging method) only required that the nitrogen flow control be enabled to feed the sparger. In this mode, nitrogen sparging is expected to strip both bubbles and dissolved gas from the liquid. However, the nitrogen also dissolves in the liquid, but with a different saturation value than that of oxygen. Nitrogen bubbles could also be introduced. In either case, the measurement apparatus only determines volume and cannot distinguish between the two gases. 


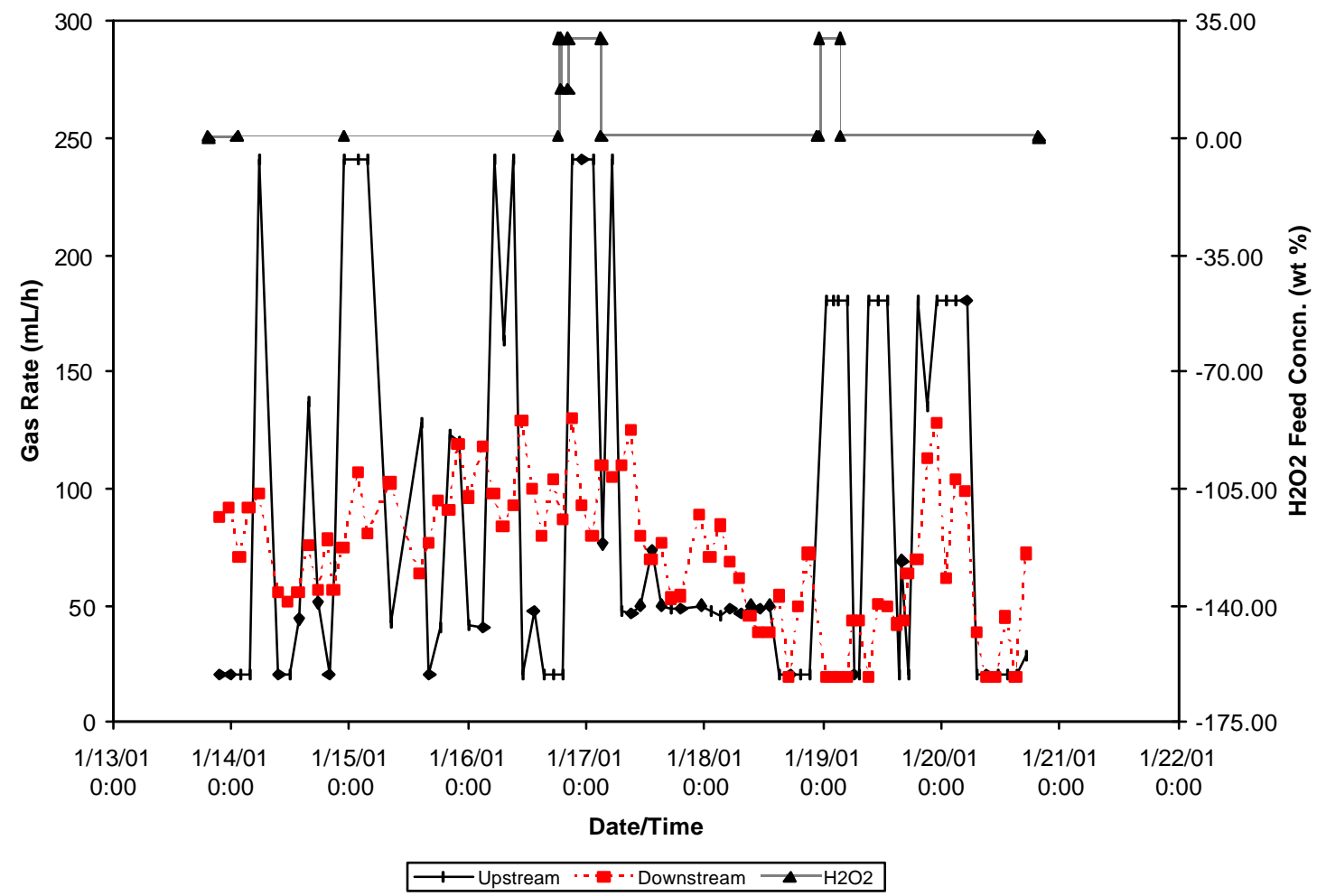

Fig. 4.3. Entrainedgas flow rates measured during Mode A.

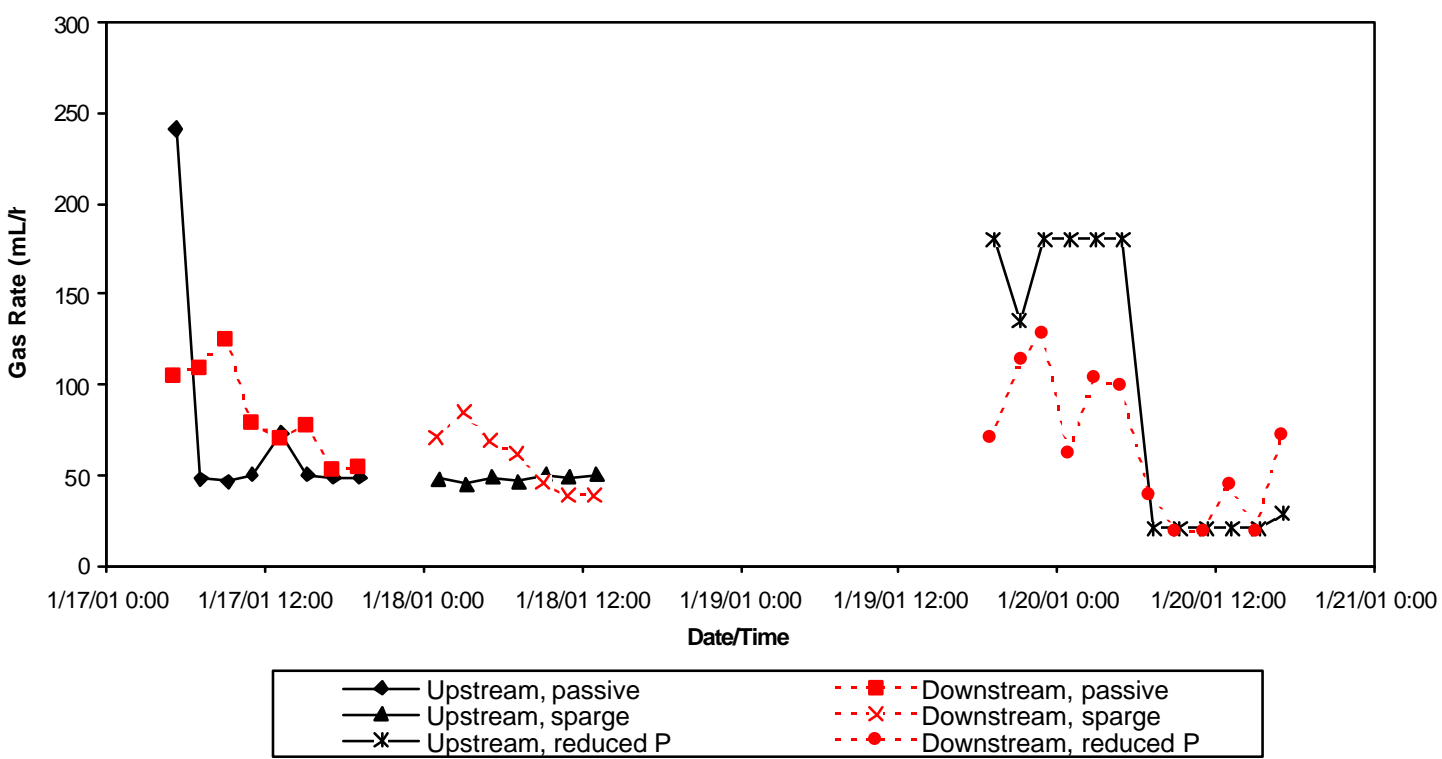

Fig. 4.4. Entrained-gas flow rates measured during steady-state methods of Mode A. 
Various nitrogen flow rates were tried, relying on visual observations of the turbidity of the liquid in the GDE and observation of bubbles in the GDE effluent line viewport as a guide in selecting an appropriate flow rate. Nitrogen flow rates of 1500, 1200, 900, 600, 300, and $150 \mathrm{~mL} / \mathrm{min}$ were used. At flows of $600 \mathrm{~mL} / \mathrm{min}$ or higher, bubbles were observed near the fluid exit at the bottom of the GDE where the effluent line was connected. However, no bubbles were apparent to the unaided eye in the downstream sight glass. At flow rates of $300 \mathrm{~mL} / \mathrm{min}$ or less, the turbidity of the liquid in the GDE was clearly reduced but still present. Due to an apparent low mixing intensity at the lowest flow rate, a value of $300 \mathrm{~mL} / \mathrm{min}$ was selected for the sparging method. Data for the stable operating period are shown in Fig. 4.4. The gas rate in the GDE inlet stream was steady at $\sim 50 \mathrm{~mL} / \mathrm{h}$, whereas the rate in the GDE effluent was higher at first but then decreased to values lower than the input. Although this trend has the appearance of a first-order lag (e.g., a mixed tank), the variation is probably similar to the fluctuations noted earlier. Again, the bias in the downstream measurement is dealt with in Sect. 4.1.4.

Tall-column operations were then switched to Mode A (reduced-pressure method). A vacuum of $-11 \mathrm{in} . \mathrm{Hg}$, gauge, was the target and was readily achieved with the vacuum venturi eductor. An immediate decrease in the gas measurement in the tall-column effluent stream was observed, which was contrary to expectations (generally, gas solubility decreases with decreasing pressure). A similar pattern occurred when the system was switched from Mode $\mathrm{C}$ to the lowerpressure Mode A (passive settling while vented to the atmosphere). It was presumed that the CST was still not fully loaded with $\mathrm{H}_{2} \mathrm{O}_{2}$, perhaps as the result of some unknown effect of channeling enhanced by higher pressure. A 4- to 5-h period of feed with $30 \mathrm{wt} \% \mathrm{H}_{2} \mathrm{O}_{2}$ was used to load the CST. Then the $\mathrm{H}_{2} \mathrm{O}_{2}$ feed was returned to the previous concentration. Tests showed that the venturi would operate reliably at the lower pressure of $-15 \mathrm{in} . \mathrm{Hg}$, gauge. Because this lower pressure was anticipated to improve gas separation, it was used for the remainder of the Mode A operations. The amount of gas in the column effluent remained high for several hours after returning to the low-concentration $\mathrm{H}_{2} \mathrm{O}_{2}$. At $\mathrm{H}_{2} \mathrm{O}_{2}$ input rates near the planned nominal rate, gas in the column effluent continued to exceed the capacity of the gas volume measurement apparatus for $\sim 24 \mathrm{~h}$. This is illustrated in Fig. 4.4, where the plotted gas rate is at the upper limit of the device. As shown, smaller quantities of gas were measured downstream of the GDE. The $\mathrm{H}_{2} \mathrm{O}_{2}$ rate was decreased to about $60 \%$ of nominal. After $\sim 6 \mathrm{~h}$, the measured gas upstream of the GDE decreased to a level below the reliable limit of the measurement chamber. A small increase in the hydrogen peroxide feed was initiated, and gas began to reappear in $\sim 10 \mathrm{~h}$ (see Fig. 4.4). The measured quantity of gas in the GDE effluent again often exceeded that measured in the inlet stream. 
Figures 4.5 through 4.7 show photographs of bubbles taken during operation in Mode A. Figure 4.5 shows a pair of bubbles observed in the upstream unit during experiments based on use of the passive settling method. The bubble diameter was $\sim 0.08$ in. $(2.0 \mathrm{~mm})$.

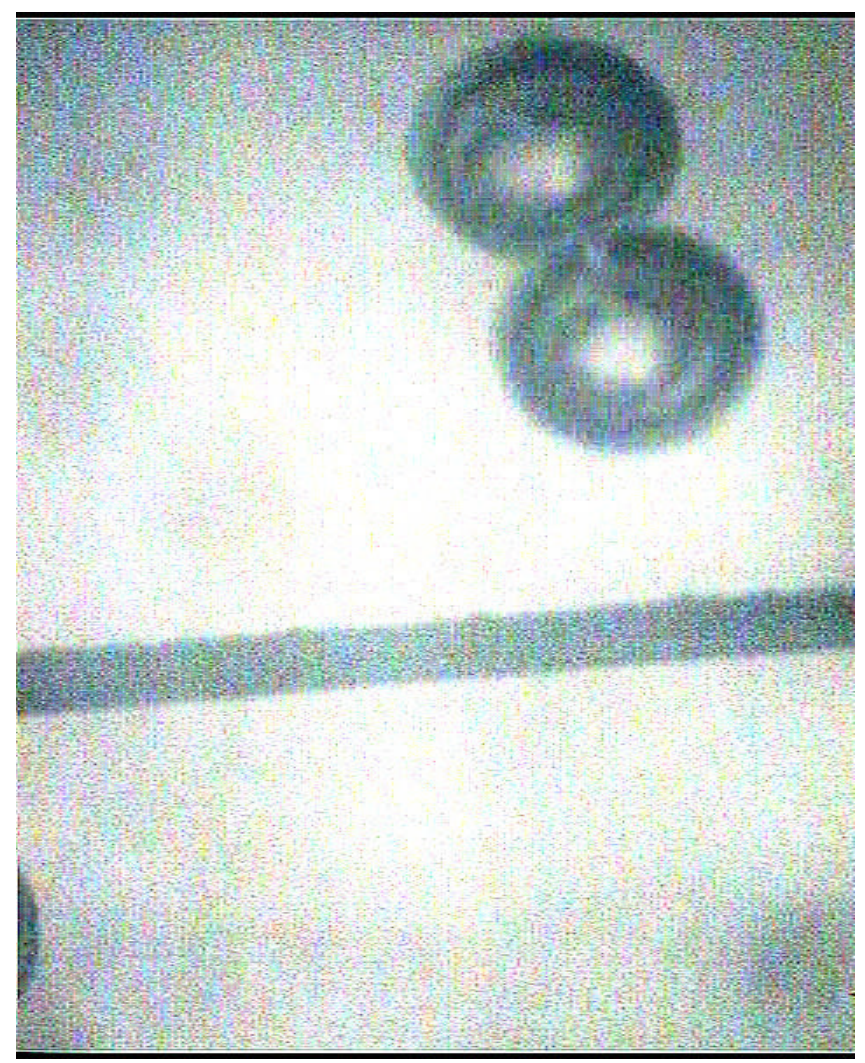

Fig. 4.5. Bubbles upstream of the GDE, Mode A, passive settling method $(1 / 14 / 01,23: 00)$.

Bubble diameter is $\sim 0.08$ in. $(2.0 \mathrm{~mm})$.

Figure 4.6 was taken downstream of the GDE during the sparging method. The photograph shows some very small bubbles and particulate matter $\sim 0.001 \mathrm{in}$. $(0.025 \mathrm{~mm})$ in diameter. This was typical of observations made downstream of the GDE during all methods of Mode A.

A photograph of bubbles upstream of the GDE is shown in Fig. 4.7, which was taken during the reduced-pressure method of operation. The bubbles shown had diameters ranging from 0.006 in. $(0.16 \mathrm{~mm})$ to $0.025 \mathrm{in} .(0.64 \mathrm{~mm})$. These data indicate that the bubbles passing through the CST bed and the Johnson screen are small and that significant coalescence does not occur immediately upon exit from the column. 


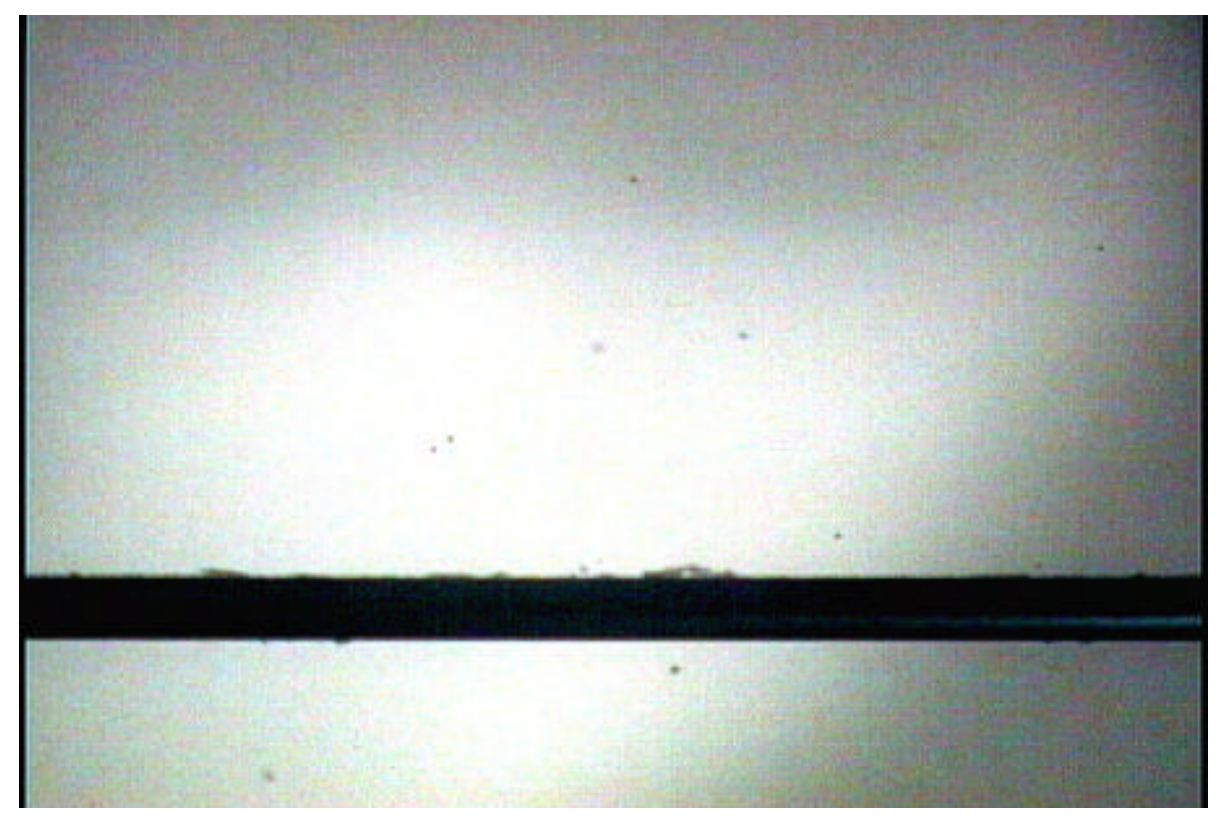

Fig. 4.6. Bubbles downstream of the GDE, Mode A, sparging method (1/18/01, 08:30). Very small bubbles and particulate matter $\sim 0.001$ in. $(0.025 \mathrm{~mm})$ in diameter.

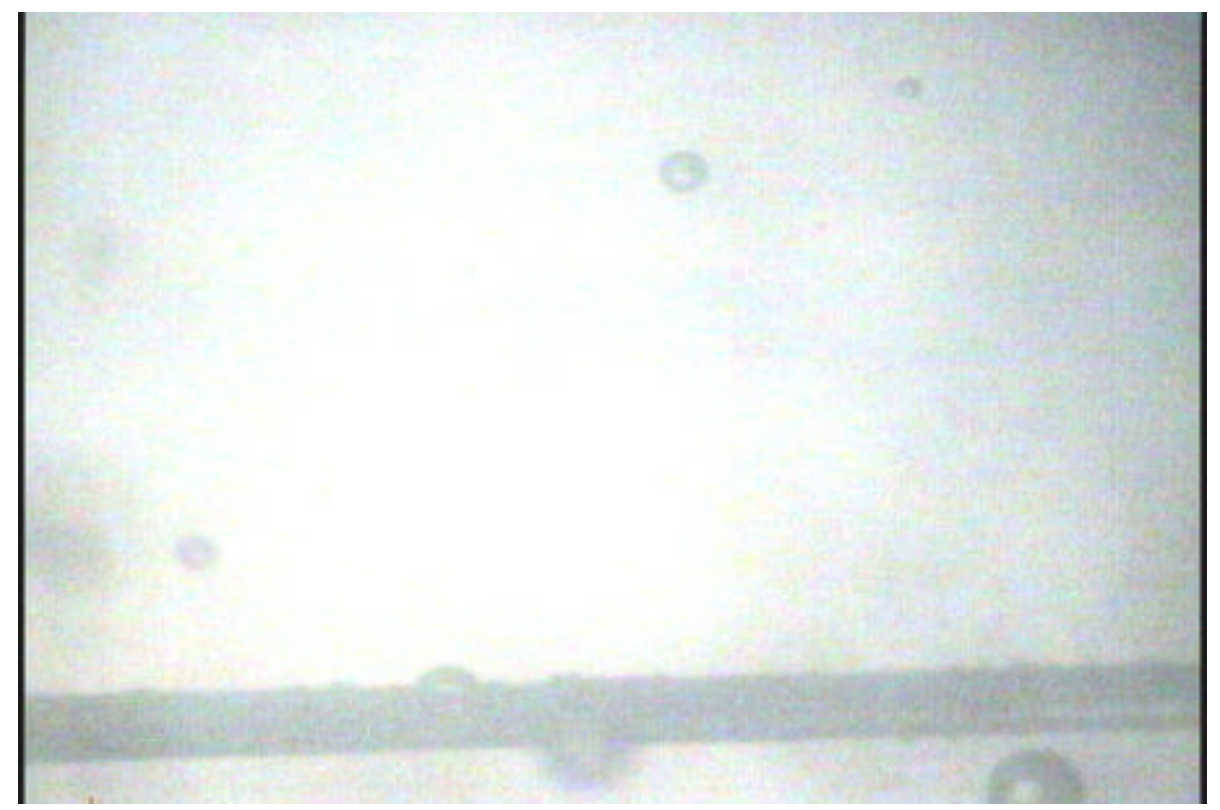

Fig. 4.7. Bubbles upstream of the GDE, Mode A, reduced-pressure method

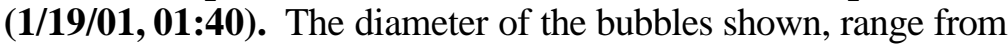
0.006 in. $(0.16 \mathrm{~mm})$ to 0.025 in. $(0.64 \mathrm{~mm})$. 


\subsubsection{Mode B}

Mode B (passive settling method) operates at a higher pressure than does Mode A. Thus, it was anticipated that uptake of $\mathrm{H}_{2} \mathrm{O}_{2}$ by the bed would occur. For this reason, the $\mathrm{H}_{2} \mathrm{O}_{2}$ feed rate was increased to more rapidly saturate the bed. After $\sim 3 \mathrm{~h}$ of operation, the measured quantities of gas in the effluent of the upstream column ranged from 70 to $80 \mathrm{~mL} / \mathrm{h}$ (adjusted to atmospheric pressure). Even so, no bubbles were observed in the stream after $\sim 10 \mathrm{~h}$ of operation. Measurements of the entrained gas both upstream and downstream of the GDE are illustrated by the two left-most curves in Fig. 4.8. In this mode, the quantity of entrained gas downstream of the GDE was always lower than in the inlet stream, with an average difference of $\sim 14 \mathrm{~mL} / \mathrm{h}$.

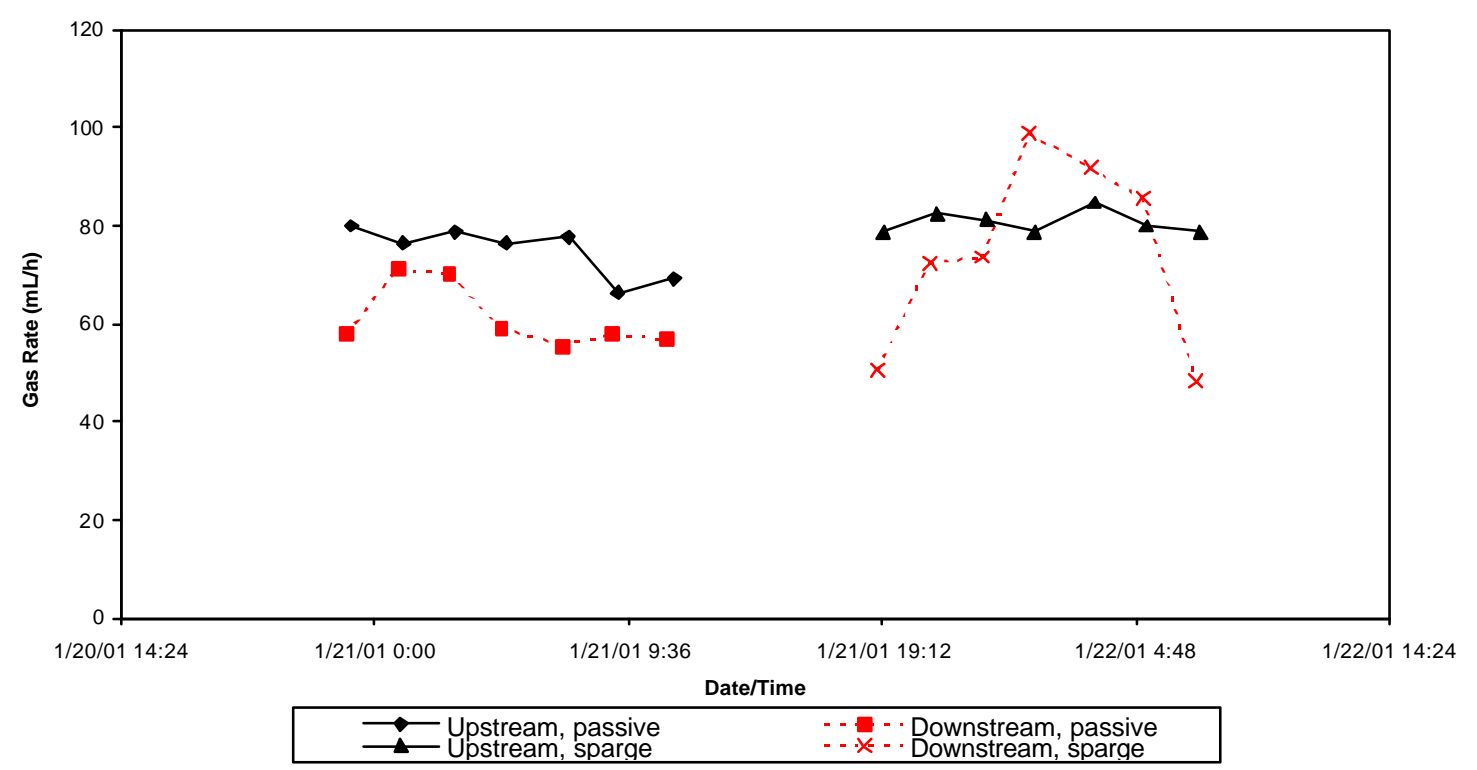

Fig. 4.8. Entrained-gas flow rates measured during specific methods of Mode B.

The sparging method was initiated by simply closing one valve and opening another to divert the nitrogen flow from the line feeding the headspace of the GDE to the sparge line. The nitrogen flow was adjusted to $300 \mathrm{~mL} / \mathrm{min}$ since that rate was previously found to be satisfactory. The system was permitted $6 \mathrm{~h}$ to stabilize. Results of entrained-gas measurements made at steady-state conditions are shown in the right-hand portion of Fig. 4.8. As shown, the upstream gas rate was relatively constant but the downstream measurements fluctuated more. On average, the gas rate downstream of the GDE was slightly lower than the rate in the inlet stream. 
A photograph of bubbles taken during the passive settling method of Mode B is shown in Fig. 4.9. Diameters of the bubbles ranged from $0.003 \mathrm{in}$. $(0.08 \mathrm{~mm})$ to $0.10 \mathrm{in}$. $(0.25 \mathrm{~mm})$. The gas rates in this mode were similar to those in Mode A; however, observation of the bubbles was more difficult without the magnification of the camera. The higher pressure of Mode B could possibly provide an explanation for compression of the bubbles, but the reason why similar-sized bubbles do not stream from the column requires further investigation.

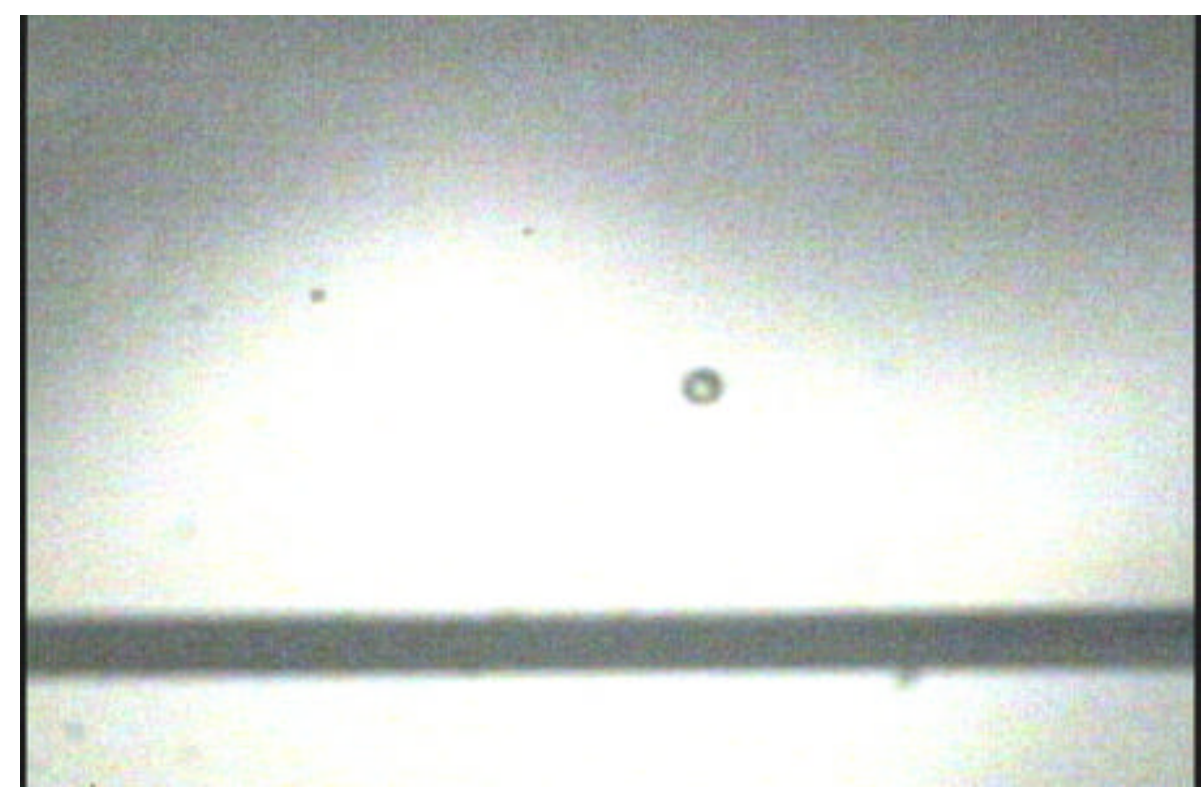

Fig. 4.9. Bubbles upstream of the GDE, Mode B, passive settling method $(\mathbf{1 / 2 1 / 0 1 , 0 8 : 3 0 )}$. Diameters of the bubbles range from 0.003 in.

$(0.08 \mathrm{~mm})$ to $0.10 \mathrm{in} .(0.25 \mathrm{~mm})$.

\subsubsection{Summary}

Gas entrained in the upstream column effluent and in the GDE effluent was measured with the gas-separation and gas-measurement vessels. These data were used to calculate a flow rate of the entrained gas. Because the data were scattered and only a few points were obtained, the results are somewhat dependent on which points are chosen to represent stable, or steadystate, operation. In the preceding analysis, a consistent approach was used to determine the point at which steady-state operation existed. Table 4.1 summarizes the average gas flow rates for each mode and method of operations. Because data from Mode $\mathrm{C}$ represent a closed-loop measurement, a positive bias in the downstream measurement unit was assumed. That quantity was subtracted from each of the measured downstream values to obtain a "corrected" gas flow rate in the GDE effluent stream. The "corrected" GDE performance data are shown in Table 4.1. 
The upstream gas rates are noted to exceed the downstream gas flow rates in every case. Thus, the gas removal rate in the GDE is always positive.

Table 4.1. Average entrained-gas flow rates during each method of operation

\begin{tabular}{lcccc}
\hline Mode, method & $\begin{array}{c}\text { Upstream, } \\
\text { GDE }(\mathrm{mL} / \mathrm{h})\end{array}$ & $\begin{array}{c}\text { Downstream, } \\
\text { GDE }(\mathrm{mL} / \mathrm{h})\end{array}$ & $\begin{array}{c}\text { "Corrected" downstream } \\
(\mathrm{mL} / \mathrm{h})\end{array}$ & $\begin{array}{c}\text { Removal } \\
(\mathrm{mL} / \mathrm{h})\end{array}$ \\
\hline C & 71.6 & 92.6 & 71.6 & 0 \\
A, passive & 75.9 & 84.3 & 63.3 & 12.6 \\
A, sparging & 48.2 & 58.4 & 37.4 & 10.8 \\
A, reduced & 97.2 & 65.8 & 44.8 & 52.4 \\
$\quad$ pressure & & & & \\
B, passive & 74.9 & 61.2 & 40.2 & 34.7 \\
B, sparging & 80.7 & 74.5 & 53.5 & 27.2 \\
\hline
\end{tabular}

${ }^{a}$ The corrected value equals the measured value minus 21 (the estimated bias).

${ }^{b}$ The removal rate is calculated by subtracting the corrected downstream value from the upstream value.

Although a fractional gas removal can be easily calculated from the data in Table 4.1, the results would prove to be of little value. Based on the data and the physical observations, the quantity of gas in the effluent from the GDE does not vary significantly, whereas that in the input stream can vary widely. Basically, a small amount of gas remained in the GDE effluent stream under almost all conditions, because of the solubility of the gas in the solution. Better indicators of the effectiveness of the GDE in protecting the downstream column are those that can be integrated over time, such as gas accumulation in the downstream column. These indicators are discussed in Sect. 4.2.

\subsection{ACCUMULATION OF GAS IN COLUMN HEADSPACE}

Gas was expected to accumulate in the headspace of each of the CST columns. To facilitate measurement of the quantity of gas accumulated, the top of each column was equipped with a gas-accumulation and gas-measurement tube. A groove was machined into the inside surface of the top flange on each column to collect the gas. The flange was bored through into that collection ring, and a threaded fitting was attached to the flange. A short section of tube was connected to this fitting, and a section of 1-in. schedule 40 clear PVC pipe was attached to the tubing. This clear section served as the gas-collection tube. A valve on each side of the gascollection tube permitted manual venting of the accumulated gas as required. On the tall column, $3 / 8$-in. tubing connected the gas-collection tube to the column; on the short column, $1 / 4$ in. tubing 
was used to make the connection. Although functional, the smaller-diameter tubing permitted a greater accumulation of gas in the column before the gas would percolate into the gas-collection tube. In general, the gas that would normally accumulate in the headspace of the column would be expected to accumulate in the gas-collection tube.

Measurements of the liquid level in the gas-collection tubes were made on an hourly basis. Changes in the liquid level together with knowledge of the inside diameter of the tube permitted the volumetric gas-collection rate to be calculated. Measurements of the pressure in the system, along with necessary corrections for the liquid head, permitted the volumes to be corrected to atmospheric pressure. Data for all three modes of operation are shown in Figs. 4.10 through 4.12 .

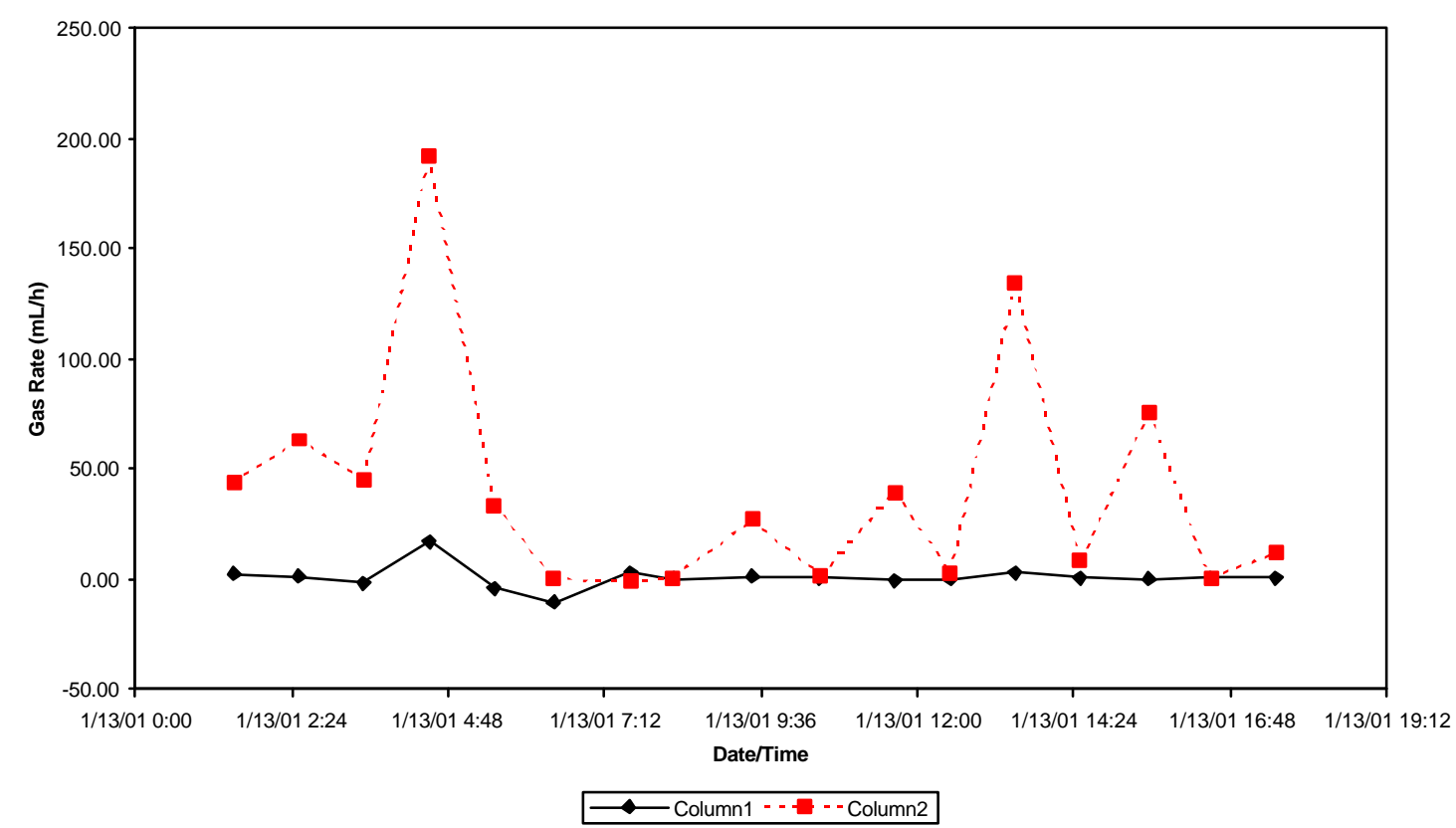

Fig. 4.10. Gas accumulation in the headspace of columns during Mode $C$.

In each of the three modes of operation, the data showed that little gas accumulated in the headspace of the upstream (or tall) column. This implies that the $\mathrm{H}_{2} \mathrm{O}_{2}$ solution was effectively fed into the CST bed. Since gas was measured in the effluent of the upstream column (see Sect. 4.2), the $\mathrm{H}_{2} \mathrm{O}_{2}$ decomposed, at least partially, within the bed and was swept out, at least partially, with the effluent. 
The data in Fig. 4.10 show an obvious accumulation of gas in the headspace of the downstream column when the GDE was bypassed in Mode C. Scatter in the data is exaggerated because of the discrete time derivative implicit in the calculation of rate. Because there was no mechanism in Mode $\mathrm{C}$ to remove the gas between the columns, accumulation was expected.

Figure 4.11 shows that there was little or no accumulation of gas in the headspace of the downstream column during any operational method of Mode A. In this mode of operation, the GDE either effectively removed gas from the liquid or the operation itself inhibited accumulation of gas in the downstream column.

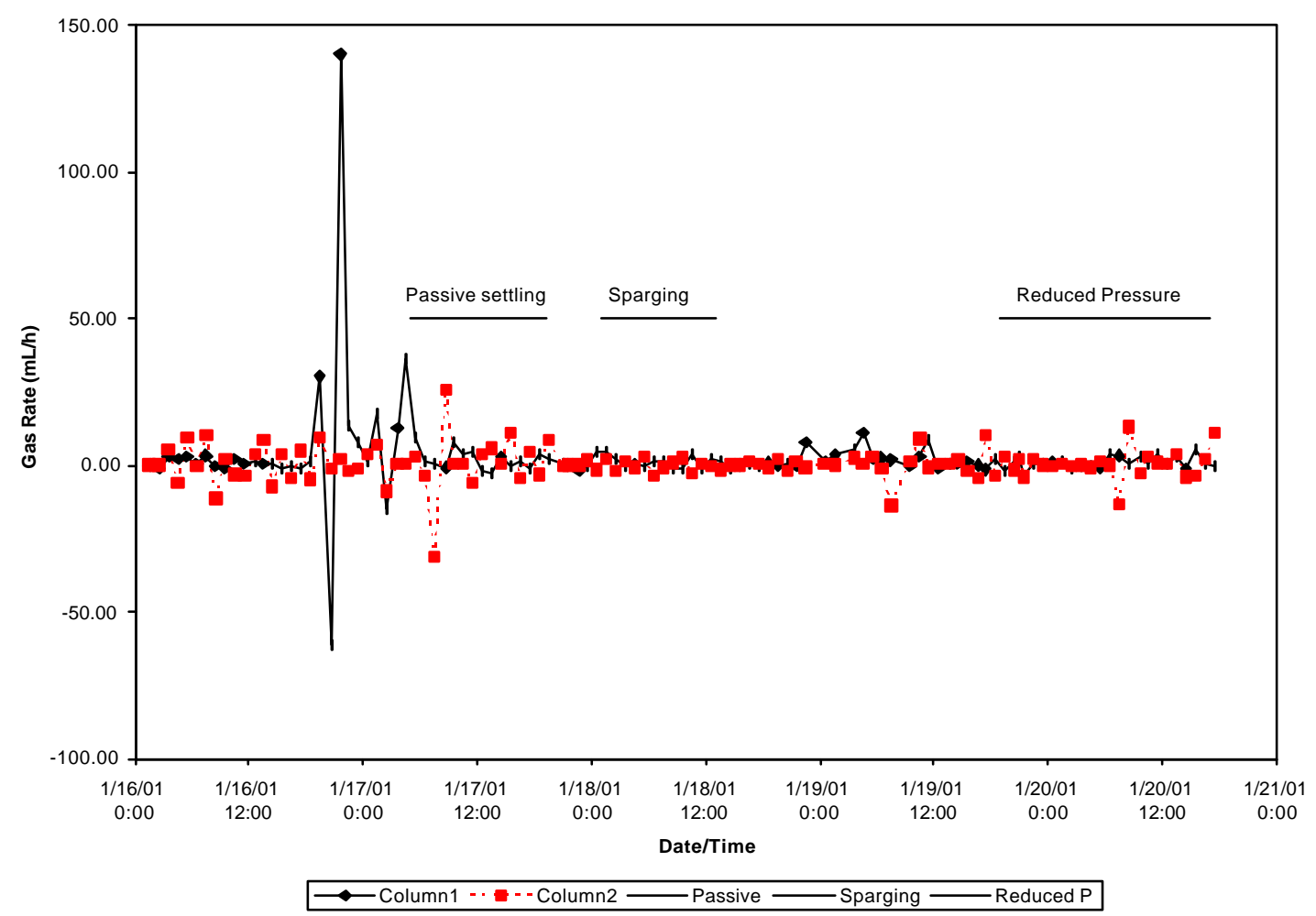

Fig. 4.11. Gas accumulation in the headspace of columns during Mode A.

Gas accumulated in the headspace of the downstream column during each method of Mode B. Little difference was observed between the average rates of accumulation for the passive and sparging methods. One point showed a very high accumulation rate during sparging; however, this was insufficient to deduce that carryover of the sparge gas was occurring. The higher pressure in the GDE during Mode B, as compared with Mode A, could have two effects; 
(1) keeping the bubbles compressed to a smaller size so that separation was more difficult, particularly via settling; and (2) increasing the solubility of the gas that might have desorbed from the solution within the downstream column. These effects will be discussed further in Sect. 4.4.

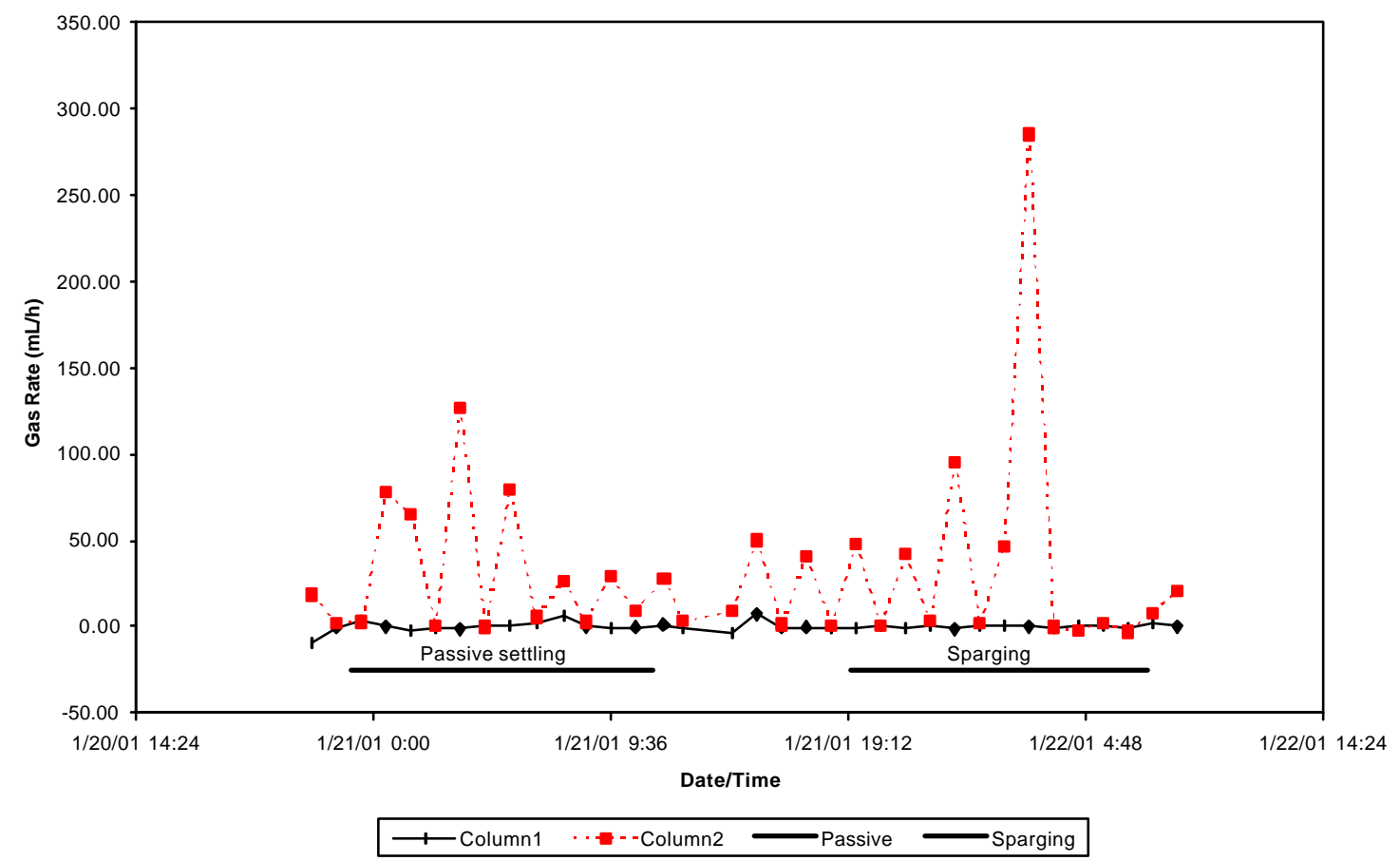

Fig. 4.12. Gas accumulation in the headspace of columns during Mode B.

Table 4.2 summarizes the average gas accumulation rates measured in the headspace of the downstream column. These data provide convincing evidence that Mode $\mathrm{A}$ is superior in preventing accumulation of gas in the downstream column. The accumulation rates in the upstream column are so small as to make the modes indistinguishable. 
Table 4.2. Average gas accumulation rates in the top-of-column gas tubes

\begin{tabular}{lcc}
\hline & \multicolumn{2}{c}{ Accumulation rate $(\mathrm{mL} / \mathrm{h})$} \\
\cline { 2 - 3 } Mode, phase & Upstream column & Downstream column \\
\hline C & 0.8 & 40.8 \\
A, passive settling & 1.3 & 0.6 \\
A, sparging & 0.6 & 0.0 \\
A, reduced pressure & 1.0 & 0.0 \\
& & \\
B, passive settling & 0.4 & 38.8 \\
B, sparging & 0.1 & 43.0 \\
\hline
\end{tabular}

\subsection{ACCUMULATION OF GAS IN THE CST BEDS}

Accumulation, or the lack thereof, of gas in the bed of the CST column downstream of the GDE served as a good indicator of which operational mode was best. An indirect indication was also provided by the pressure drop throughout the column. As gas accumulated in the bed, the pressure drop was expected to increase. Pressure drop across the bed of the short column, free from end effects such as the Johnson screen and bed surface, was measured by the difference between pressure sensors PT-22 and PT-23. The depth of the bed between these points, $2.49 \mathrm{ft}$, was needed to correct for the fluid head between the two points and to calculate the pressure difference per unit length of bed. Qualitative information on the accumulation could be obtained through visual observation.

\subsubsection{Mode C}

The pressure drop per unit length of bed during the first few hours of operation in Mode $\mathrm{C}$ is shown in Fig. 4.13. These data indicate that there was an accumulation of gas in the bed, as would be expected since the GDE was bypassed in this mode.

Figure. 4.14 shows a photograph of the upper portion of the CST bed in the downstream column. Bubbles are clearly visible and appear to have displaced the CST. Measurements of the bed height, however, did not indicate a significant overall expansion of the bed (expansion of $\sim 0.5 \mathrm{~cm}$ or less). It was observed that, at the time that the photograph was taken, the first $15 \mathrm{~cm}$ (bed height between 100 and $85 \mathrm{~cm}$ ) of the bed contained a large concentration of bubbles of sizes up to $0.5 \mathrm{~cm}$ in diameter. Over the next $15 \mathrm{~cm}$ of bed (bed height between 85 and $70 \mathrm{~cm}$ ), the concentration and the size of the bubbles decreased to what appeared to be an unaffected, or original, bed. The pressure-drop data and visual observations were consistent. 


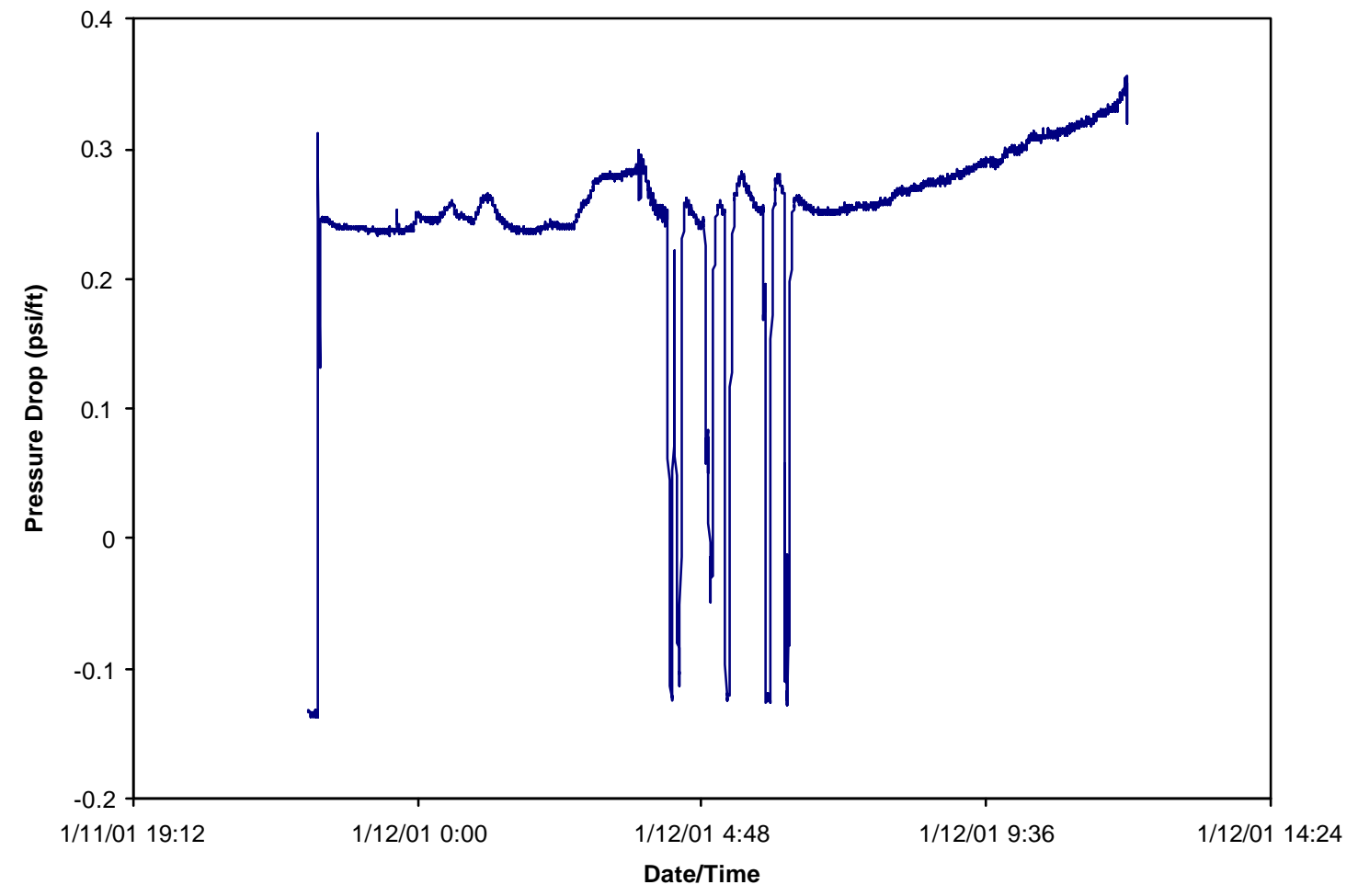

Fig. 4.13. Pressure drop across the downstream column during startup of Mode $\mathrm{C}$.

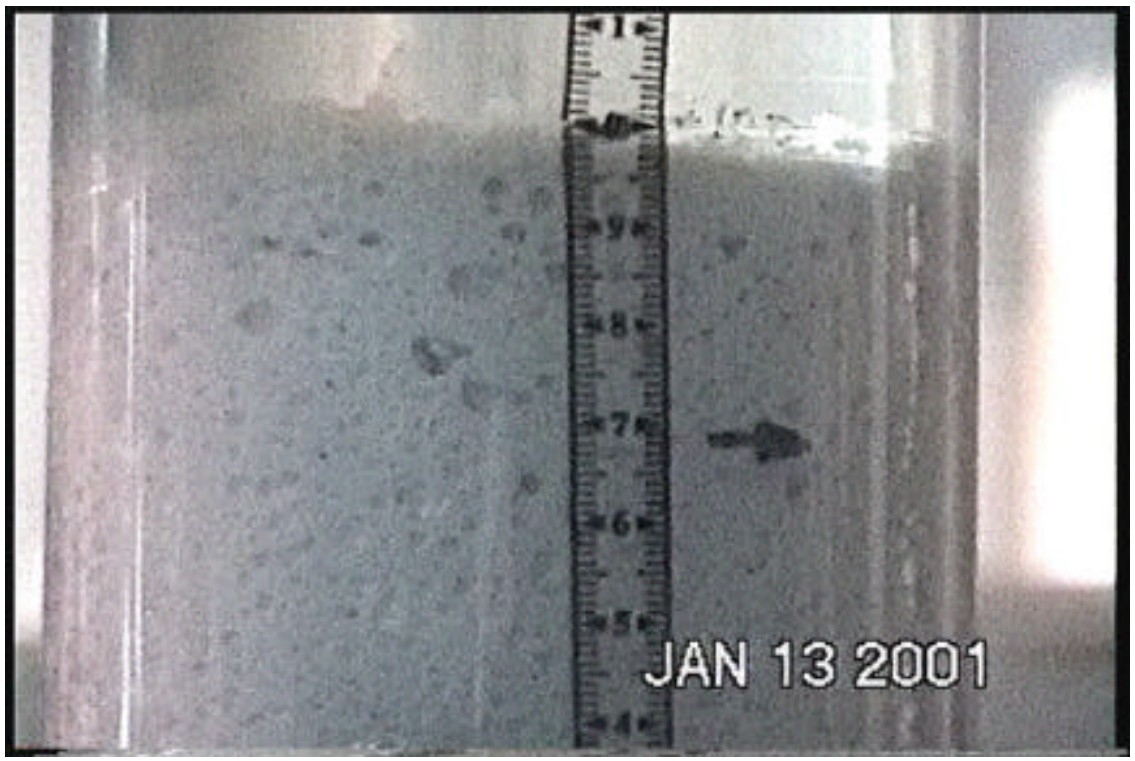

Fig. 4.14. CST bed of downstream column during Mode $\mathrm{C}$ at 09:25, 1/13/01. Bubbles sizes are up to $0.5 \mathrm{~cm}$ across. 


\subsubsection{Mode A}

The column system was switched from Mode C to Mode A operations with little downtime. Efforts were made to ensure that the short column did not de-pressurize during the switch, which could cause it to degas. Although some bubbles were noted to rise from the bed when the column was slowly vented to release gas in the gas collection tubes, the bed appeared to be unaffected. Figure. 4.15 shows the pressure drop across the second column during the first few hours of Mode A. A slight decrease was noted in the pressure drop, which might indicate that accumulated gas was being removed from the column.

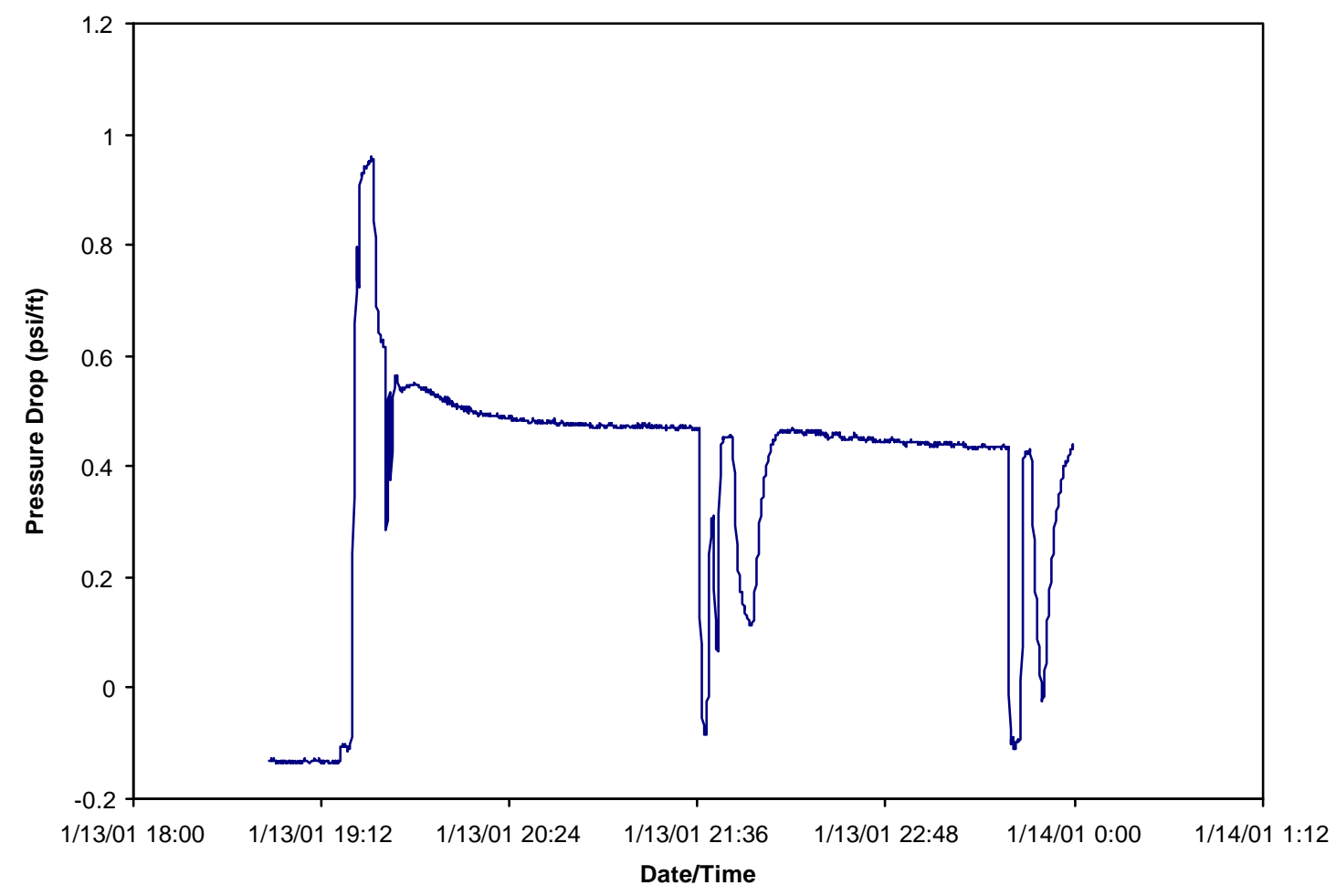

Fig. 4.15. Pressure drop across the downstream column during the first portion of Mode A.

After $\sim 40 \mathrm{~h}$ of operation in Mode A, the bubbles in the downstream column had dramatically decreased. Figure 4.16 shows that the large bubbles or voids had disappeared, but many smaller bubbles were still visible. Figure 4.17 shows the bed after another 4 days of operation in Mode A. The bed was visually free from bubbles and has appeared to return to 
preoperation status. A comparison of Figures 4.16 and 4.14 shows that bubbles trapped in the bed during Mode $\mathrm{C}$ apparently caused an $\sim 0.5 \mathrm{~cm}$ expansion of the bed height.

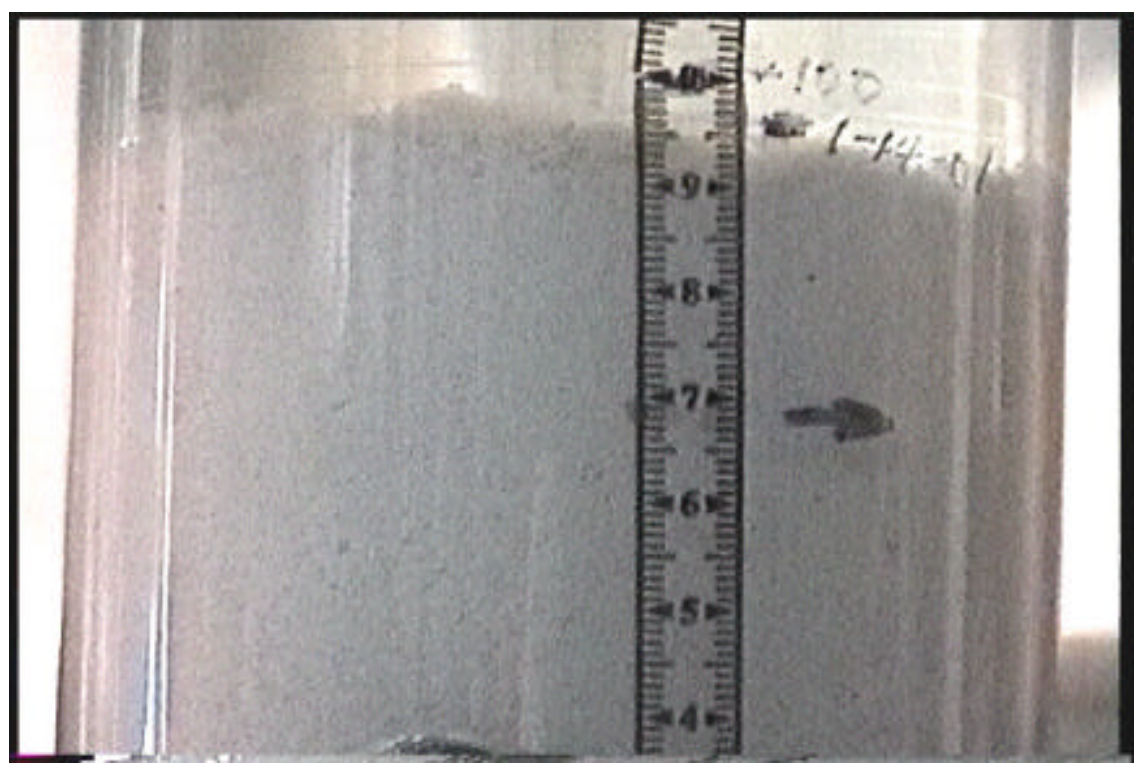

Fig. 4.16. CST bed of downstream column during Mode A at 13:33, 1/15/01.

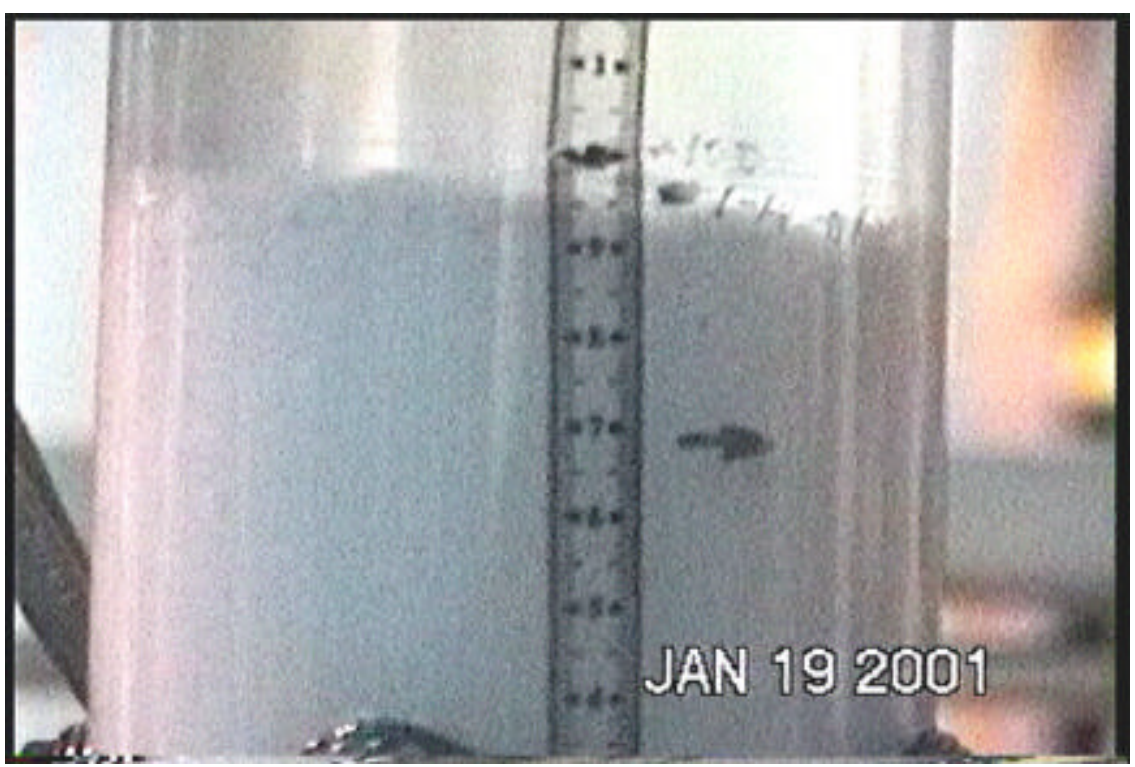

Fig. 4.17. CST bed of downstream column during Mode A at 11:40, 1/19/01. 
The degassing of the short column in Mode A was a slow process that took place over several days of operation. Because of the qualitative nature of the data, relating the degassing to a particular method of separation (passive settling, etc.) did not seem fruitful. These data and observations could indicate that the gas (presumably oxygen) was redissolved in the simulant. It is unlikely that the gas was merely pushed through the column; otherwise, it would not have accumulated during Mode C. Use of the pump in Mode A to elevate the fluid pressure well above that in the GDE caused the solution to be unsaturated in dissolved gas, giving it the capacity to dissolve the gas in the second column.

\subsubsection{Mode B}

When the tests conducted using Mode A were completed, the system was switched to operation in Mode B. The auxiliary pump at the GDE was not used in Mode B. Nitrogen was fed to the GDE to maintain an elevated pressure in the headspace of the GDE. A control valve in the effluent line was manipulated to feed the liquid to the downstream column and to control the liquid level in the GDE. The original plan was to operate the GDE with a headspace pressure of 27 psig with a set point for the back pressure on the short column of 22 psig. However, a small leak in the tall column developed around one of the pressure sensors during Mode A operations. Although a repair was made, reduction of the stress on the column seemed prudent to keep the seepage low. Thus, the GDE was operated with a headspace pressure of $7 \mathrm{psig}$ and the set point for the back pressure on the short column was fixed at $5 \mathrm{psig}$.

Figure 4.18 shows the pressure drop through the short column during the first portion of Mode B operations. A trend of increasing pressure drop indicates accumulation of gas in the second column.

Figure 4.19 shows that gas bubbles accumulated significantly in the second column after $16 \mathrm{~h}$ of operation in Mode B. The GDE operated at a higher pressure than in Mode A. If it is assumed that the liquid was saturated at the higher pressure, then more gas was available for deposition in the second column. This situation could exist if the pressure in the second column was lower than the pressure in the GDE (see Sect. 4.4). 


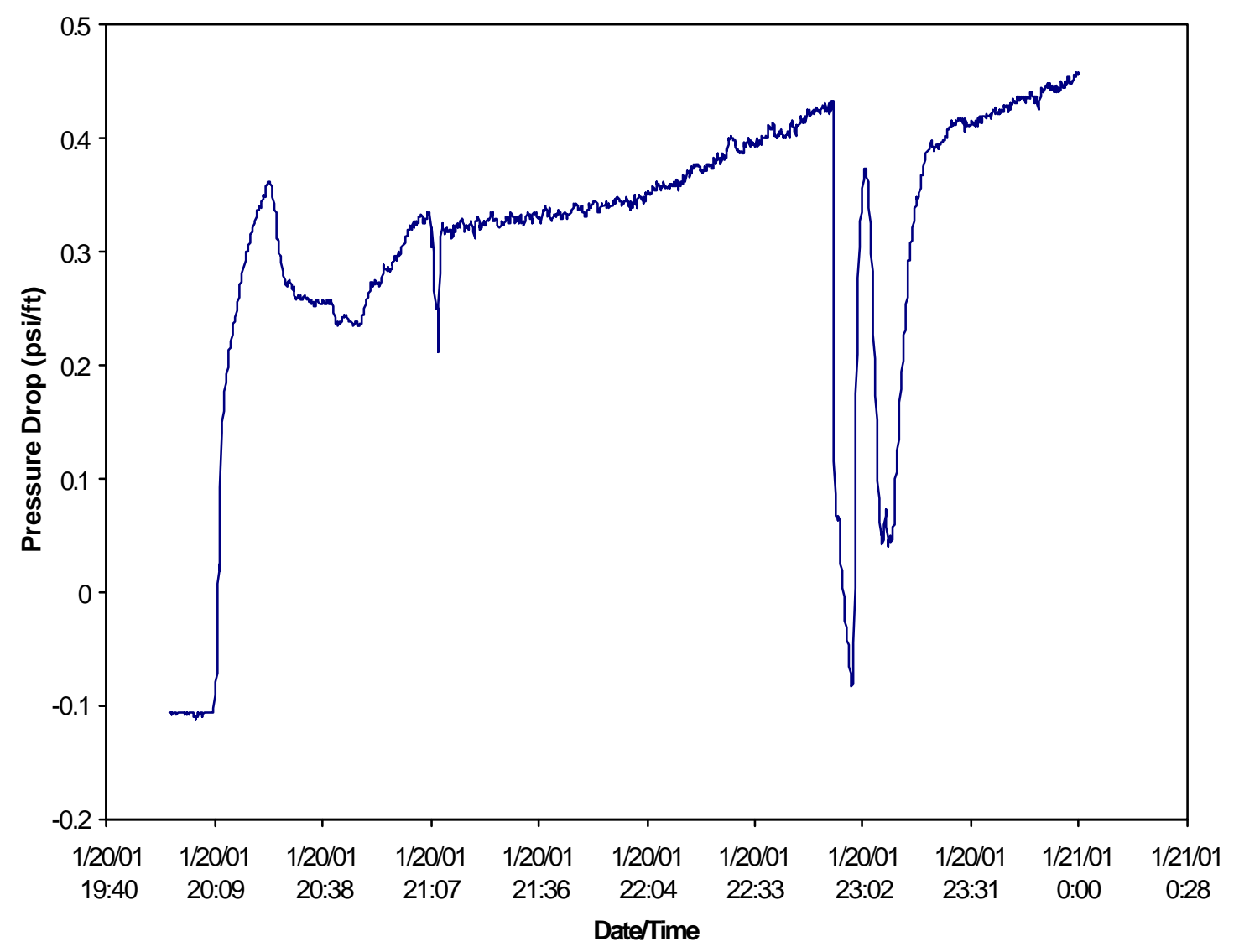

Fig. 4.18. Pressure drop across the downstream column during the first portion of Mode $B$.

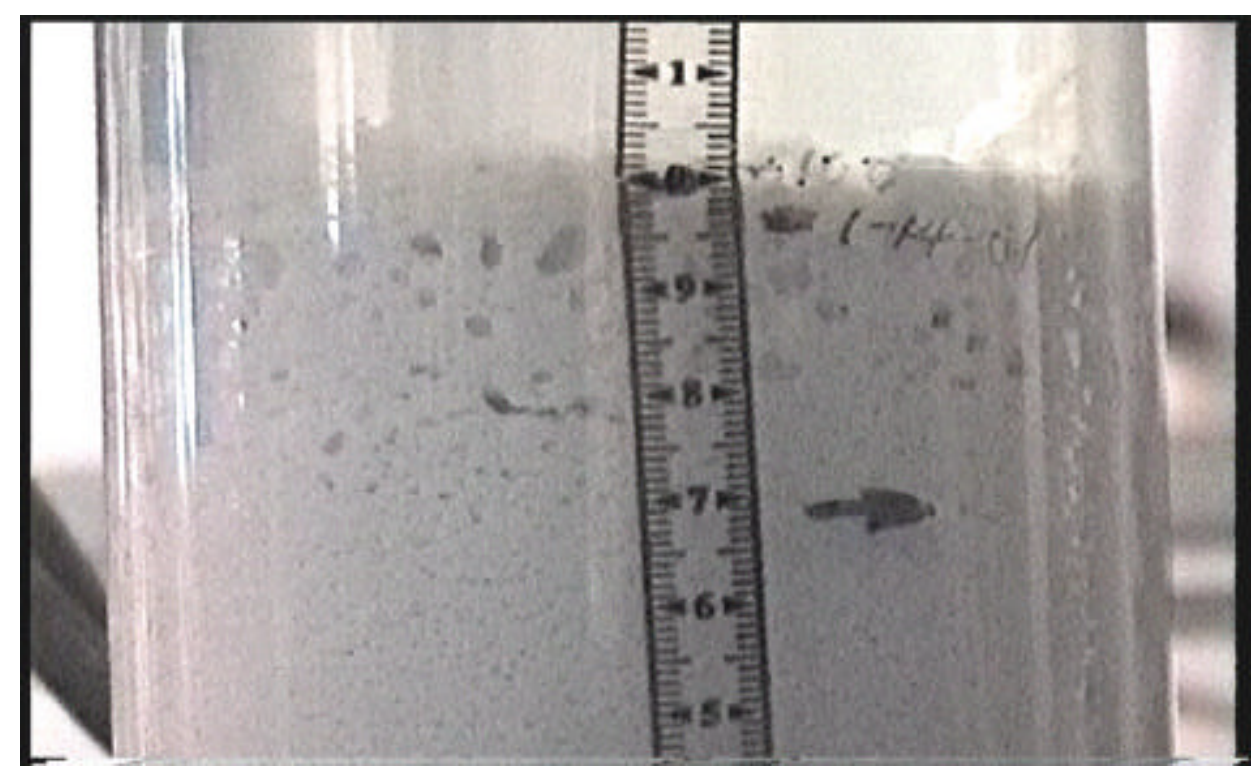

Fig. 4.19. CST bed of downstream column during Mode $B$ at 12:30, 1/21/01. 


\subsection{DISCUSSION OF GAS-MEASUREMENT DATA}

Operation of the two-column train without interstage gas separation, as in Mode $\mathrm{C}$, led to an accumulation of gas in the headspace and in the CST bed of the downstream column. In longterm operations, the quantity of gas accumulated in the bed could degrade the performance of the ion-exchange process. At a minimum, the gas in the headspace would need to be vented periodically.

Interstage gas separation was performed during both Mode A and Mode B operations. Measured quantities of gas entrained in the effluent of the GDE were nearly equivalent in both modes. However, in Mode A, no accumulation of gas in the CST bed was noted; there was actually a clearing of the gas deposited in the bed during the previous Mode $\mathrm{C}$ operations. In addition, there was a very small accumulation of gas in the headspace of the downstream column. In Mode B, gas accumulated in both the CST bed and the column headspace. The primary difference between Mode A and Mode B was the pressure at which the GDE operated relative to the pressure in the downstream column.

In Mode A the pressure in the GDE was at atmospheric ( 0 psig) or lower (refer to Table 4.3). The pump that fed the downstream column elevated the pressure in the liquid effluent from the GDE. If the liquid in the GDE were saturated with the gas in the headspace, then this pressurization would cause the gas concentration to be lower than the saturation value at the new, higher pressure. The liquid stream just above the bed of the short column had a pressure of $>16$ psig, or $>2$ atm on the absolute scale. If the system obeys Henry's law, then the gas concentration in the liquid at a point above the bed of the short column would be about half the saturation value of the liquid at atmospheric pressure. This could explain how the gas that accumulated in Mode C could be slowly removed from the bed during subsequent Mode A operations.

Table 4.3. Average operating pressures at selected locations during each method of operation

\begin{tabular}{lccc}
\hline & \multicolumn{3}{c}{ Pressure } \\
\cline { 2 - 4 } Mode, method & $\begin{array}{c}\text { Outlet of column 1 } \\
(\mathrm{psig})\end{array}$ & $\begin{array}{c}\text { GDE headspace } \\
(\mathrm{psig})\end{array}$ & $\begin{array}{c}\text { Above bed of column 2 } \\
\text { (psig) }\end{array}$ \\
\hline C & 25.3 & N/A & 17.0 \\
A, passive & 13.2 & 0 & 16.6 \\
A, sparging & 13.2 & 0 & 16.3 \\
A, reduced pressure & 6.2 & $-7.4^{a}$ & 16.2 \\
B, passive & 20.3 & $7.0^{b}$ & 5.8 \\
B, sparging & 20.2 & $7.0^{b}$ & 6.4 \\
\hline \multicolumn{1}{c}{ Headspace } & & \\
\hline
\end{tabular}

${ }^{a}$ Headspace pressure controlled to -15 in. $\mathrm{Hg}$, gauge (-7.4 psig).

${ }^{b}$ Headspace pressure controlled to $7.0 \mathrm{psig}$. 
In Mode B, as shown in Table 4.3, the GDE operated at pressures above atmospheric pressure. This was necessary because the pump at the GDE was not used to feed the short column. The fluid pressure must be sufficient to overcome frictional losses and fluid head associated with the short column. There was a significant pressure drop across the control valve at the GDE, which was used to adjust the flow rate to the short column. As shown in Table 4.3, the pressure above the bed of the short column was less than that in the headspace of the GDE. The liquid level in the GDE was $\sim 8.5 \mathrm{ft}(259 \mathrm{~cm})$ higher than the position of the sensor in the column. Based on the density of the simulant $(\sim 1.27 \mathrm{~g} / \mathrm{mL})$, the pressure immediately downstream of the control valve was $\sim 1.1$ to $1.7 \mathrm{psig}$. Thus, there was a decrease of $\sim 5.3$ to $5.9 \mathrm{psi}$ across the control valve. If the liquid were saturated with gas in the GDE, the lower pressures in the line from the control valve down to the bed in the short column would promote desorption of the gas. The undissolved gas would then accumulate in the headspace and CST bed as observed.

\subsection{EFFECT OF ULTRASONIC WAVE-ENHANCED COALESCENCE}

Some brief testing of the ultrasonic-enhanced coalescence and gas-separation method was performed following the Mode B (sparging method) operations. The system was first returned to the passive settling phase of Mode B to ascertain if ultrasonic vibrations in the liquid would enhance the gas-liquid separation. The tests were then performed by operating the acoustic actuator and visually observing the effect, if any, on the coalescence of bubbles in the GDE. Frequencies between 10 and $20 \mathrm{kHz}$ were tested in 1-kHz increments. Low-power settings were used to prevent overheating and failure of the ultrasonic actuator. The output voltage was set to $3 \mathrm{~V}$. The current output was $5 \%$ of full scale, which is low as compared with the maximum output of the power supply of $120 \mathrm{~V}$ and $500 \mathrm{~W}$. The ultrasonic actuator was operated for a duration of $30 \mathrm{~s}$ and then allowed to cool for $5 \mathrm{~min}$ before proceeding to the next frequency. Even so, the actuator became warm to the touch. Because there were few visible bubbles in the GDE liquid holdup, it was not possible to observe an effect.

The system was then operated in the sparging method of Mode B, which produced very small bubbles throughout the liquid. When the test protocol was repeated, an effect was observed at $19 \mathrm{kHz}$. On energizing the device, noticeably larger bubbles rose from the vicinity of the ultrasonic horn. When the device was deenergized, the larger bubbles ceased and the system returned to the previous state. Frequencies were varied to determine if a particular value would give improved results. Only in the narrow frequency band of 18.8 to $19.1 \mathrm{kHz}$ was coalescence of bubbles observed. Testing at $0.1-\mathrm{kHz}$ increments within this band did not result in the identification of a best frequency. 


\section{PERFORMANCE OF CONTROL SYSTEM}

An important factor in the selection of the operating mode of the column system is the issue of system control. Some experience was obtained during the shakedown period, before the experimental campaign, while the control loops were being tuned. Operation of the column system provided the opportunity to observe both system response at startup and long-term stability in each mode. Startup of Modes A and B was somewhat nonrepresentative because the system was charged with solution and pressurized during the previous mode of operation.

The primary interest was in the transient response of the liquid flow rates, liquid level in the GDE, and pressure in the columns. A detailed mathematical analysis was not performed. The data are presented here with some of the attributes described. Pressure data are also useful for assessing the status of the Johnson screen (plugged or not) and buildup of material at the surface of the beds.

\subsection{MODE C}

Liquid flow rates measured during startup of the system in Mode $\mathrm{C}$ are shown in Fig. 5.1. The feed to the tall column rapidly approached the set point $(190 \mathrm{~mL} / \mathrm{min})$, as expected when using a positive-displacement pump. A valve in the effluent line from the tall column was initially closed; however, when it was opened, the interstage flow rate rapidly achieved steady state. The effluent flow rate (from the short column) took more time to reach steady state because of the need to compress the gas heel in the top-of-column gas tube to operating pressure and because of the response of the control loop that adjusts back pressure in the short column. Overall, the flow rates reached steady conditions in $\sim 5 \mathrm{~min}$. All the flow rates should be equal at steady state; however, errors in the flowmeters resulted in the differences shown in Fig. 5.1.

Figure 5.2 shows the pressure response in the tall column. The four pressures shown are those measured above the CST bed (PT-2); below the upper surface of the bed (PT-3); at the bottom of the bed, upstream of the Johnson screen (PT-7); and downstream of the Johnson screen (PT-8). Pressure response generally follows flow-rate response. The difference between the readings at PT-7 and PT-8 (adjusted for differences in fluid head) may be used to infer the pressure drop across the Johnson screen. The scaled Johnson screen at the bottom of the tall column showed no evidence of plugging during the entire experimental campaign. 


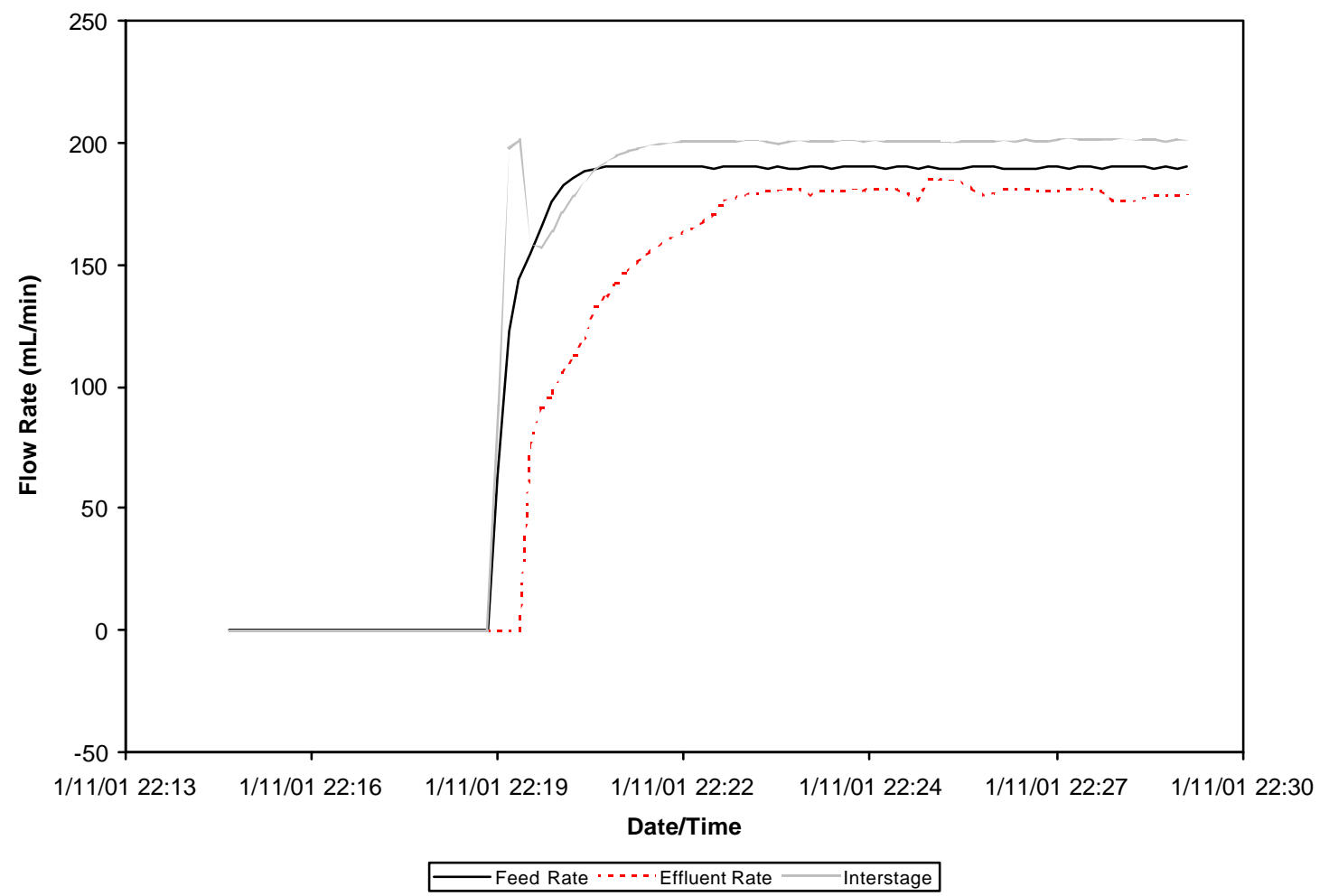

Fig. 5.1. Liquid flow rates measured during startup of Mode $C$.

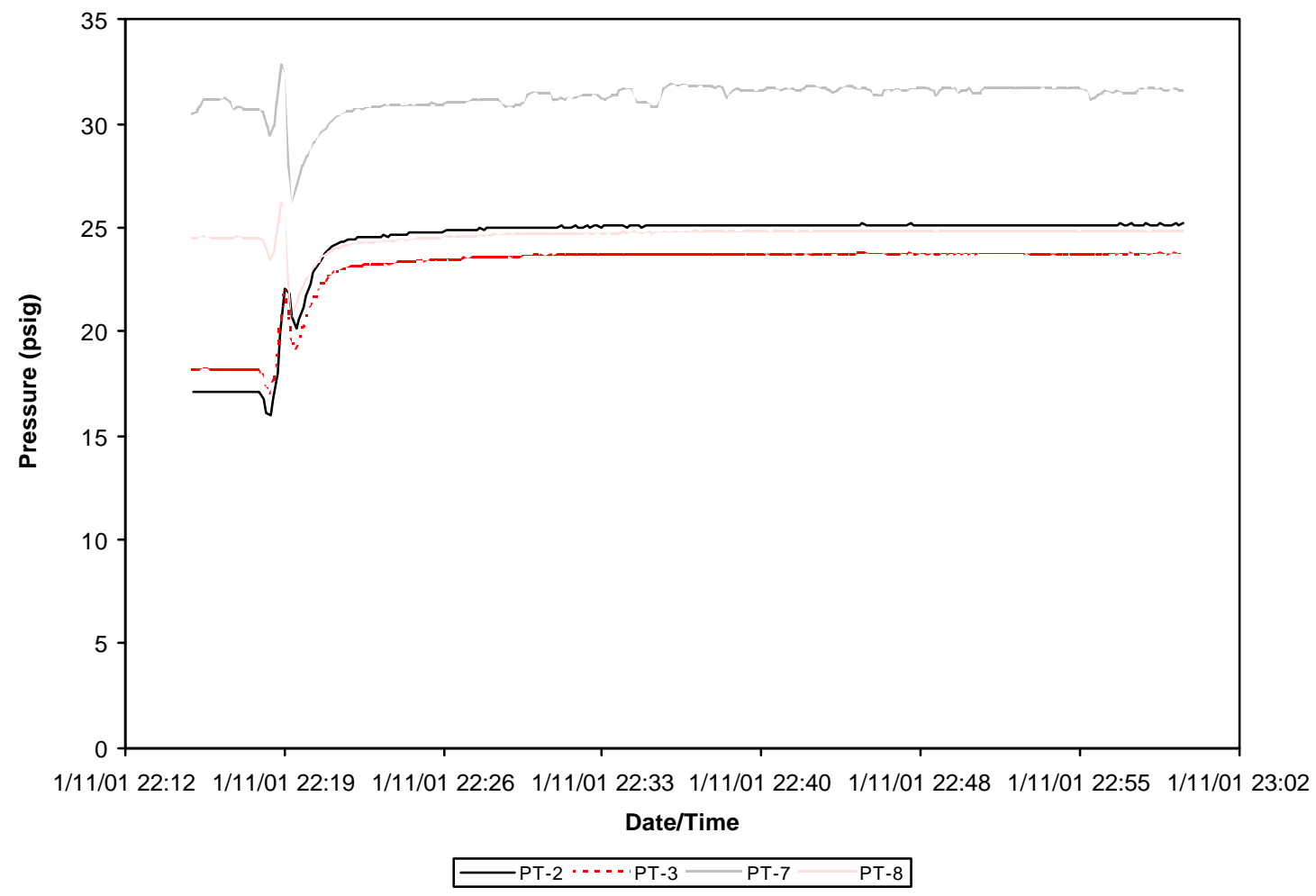

Fig. 5.2. Pressures measured in tall column during startup of Mode $C$. 
Figure 5.3 illustrates the pressure response of the short column. The pressures shown are those measured above the CST bed (PT-21); below the upper surface of the bed (PT-22); at the bottom of the bed, upstream of the Johnson screen (PT-23); and downstream of the Johnson screen (PT-24). Again, the pressures followed the flow-rate response.

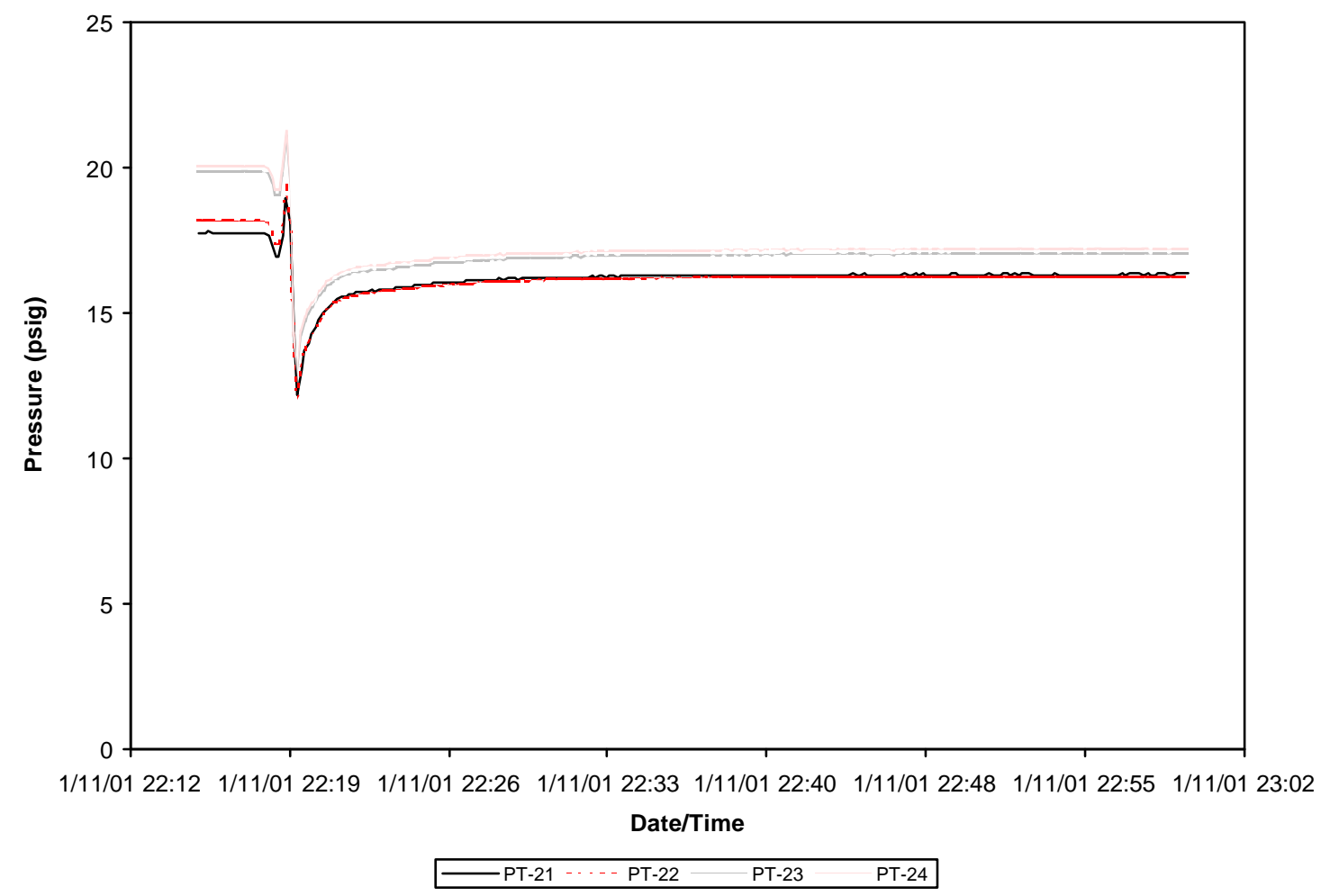

Fig. 5.3. Pressures measured in short column during startup of Mode C.

\subsection{MODE A}

In Mode A, the GDE decoupled the two columns; the holdup in the GDE acted as a lag between the two columns. The dynamics of adjusting the liquid level in the GDE contributed to slowing the overall system approach to steady state. Figure 5.4 illustrates the response of the measured flow rates and liquid level in the GDE. Steady state was achieved in $\sim 60 \mathrm{~min}$. Small differences between the flow rate into and out of the GDE caused the approach to steady state to be delayed. Pressure-response curves for the two columns are shown in Figs. 5.5 and 5.6. 


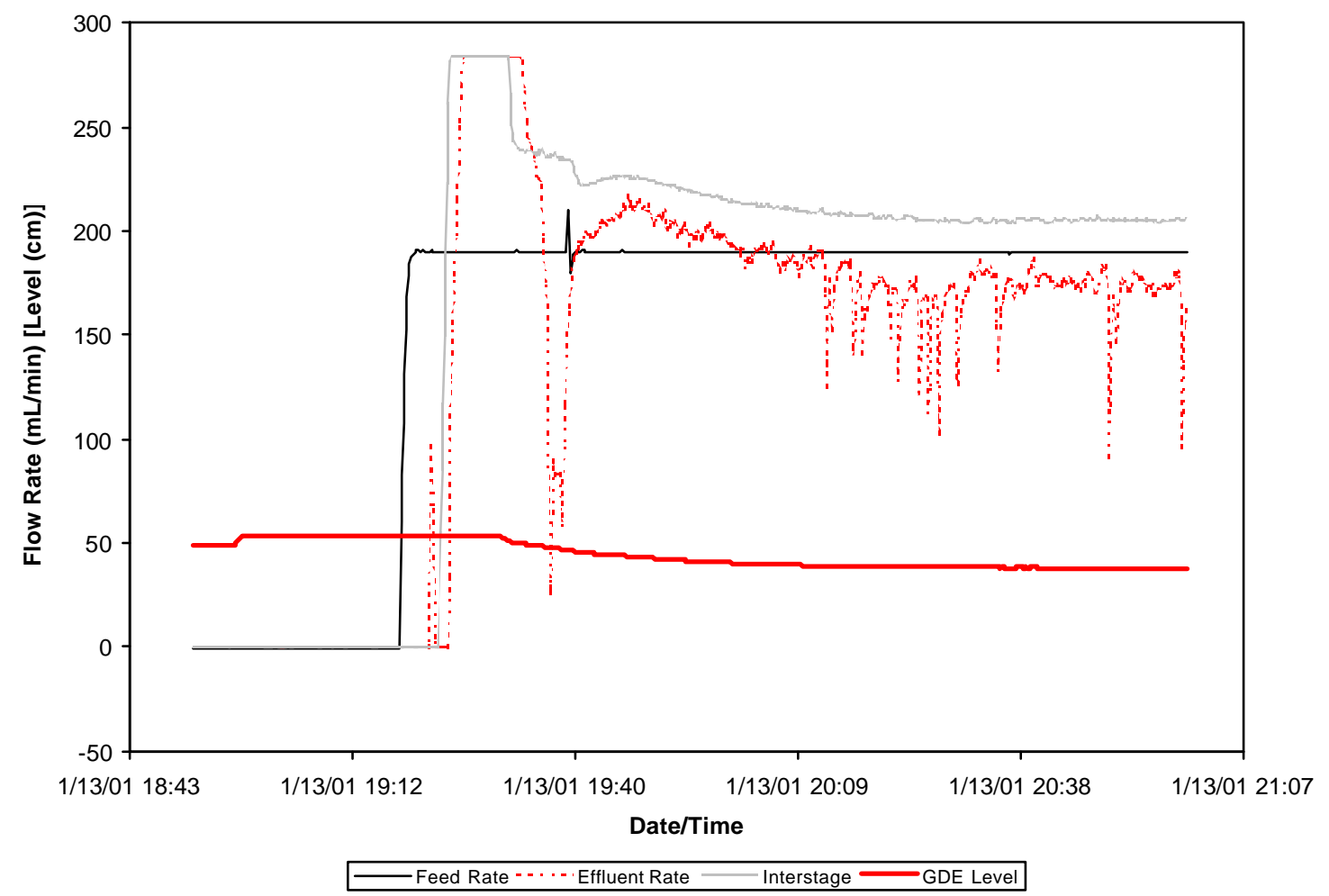

Fig. 5.4. Liquid flow rates and GDE liquid level measured during startup of Mode A.

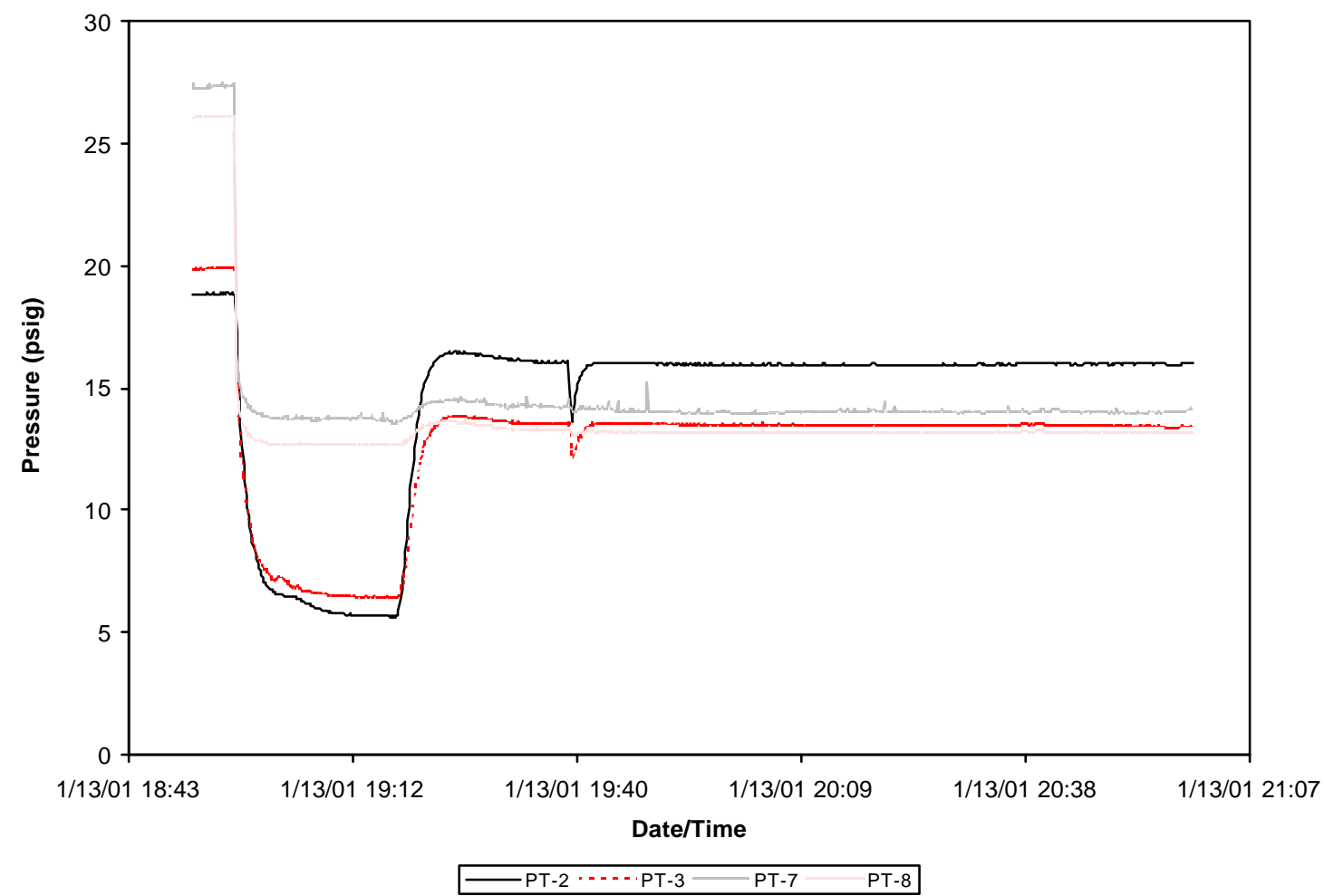

Fig. 5.5. Pressures measured in tall column during startup of Mode A. 


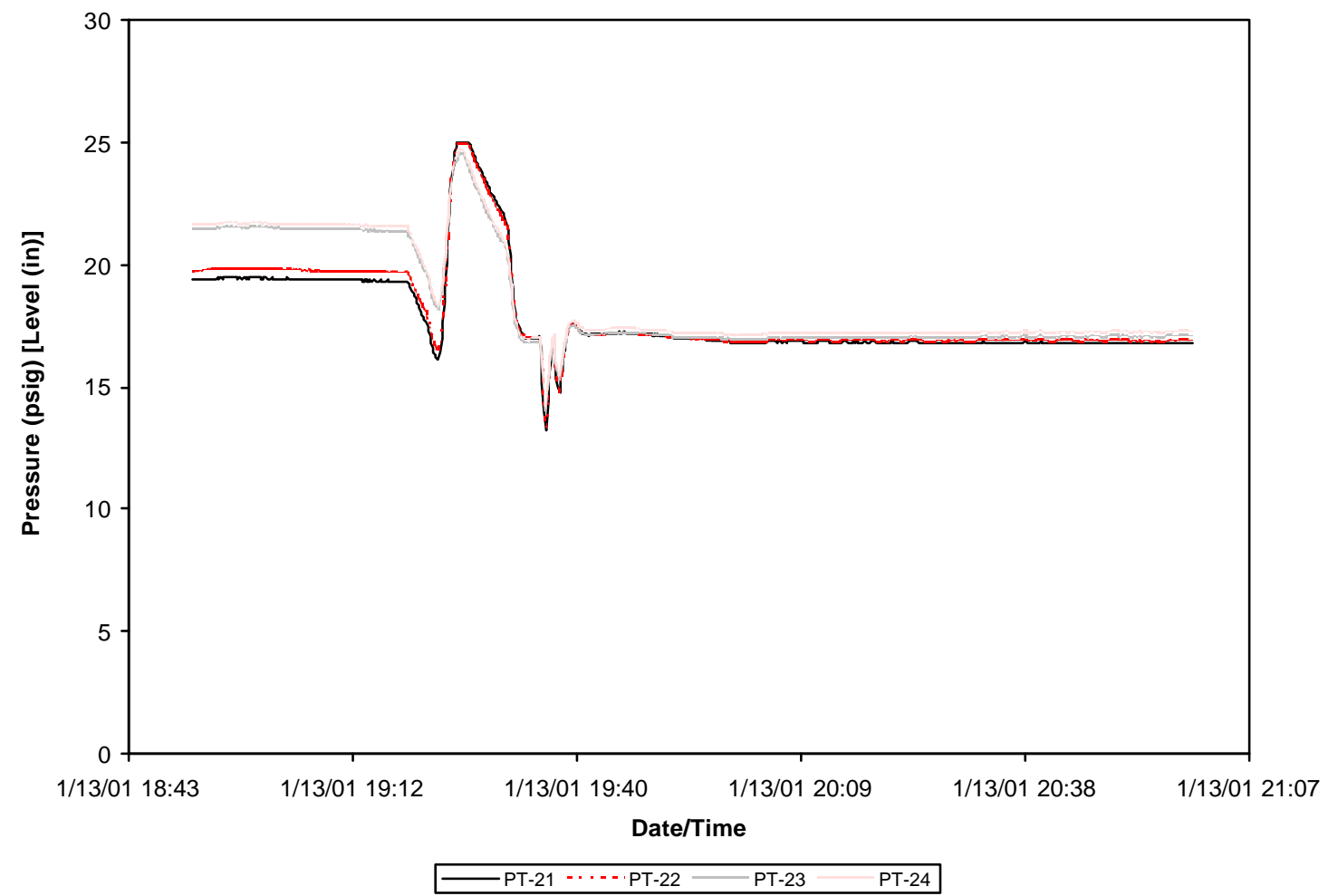

Fig. 5.6. Pressures measured in short column during startup of Mode A.

\subsection{MODE B}

The GDE also served to decouple the two columns in Mode B; however, instead of relying on a rapidly responding pump to feed the downstream column, the headspace pressure in the GDE had to be elevated. A control valve was used to feed the short column. In addition, another control valve was used to control the headspace pressure by venting the gas from the vessel. This control loop was purposely slow to prevent oscillation in the liquid discharge rate. Overall system response was limited by the adjustment of the liquid level in the GDE. Figure 5.7 shows the flow-rate and liquid-level responses during the startup of Mode B. Because a lag time was associated with pressurizing the headspace of the GDE (slow adjustment of the vent valve from full open), the GDE filled with fluid. Manual intervention was necessary to decrease the feed rate to permit the GDE to empty. Then the feed rate was increased incrementally over time as the level in the GDE approached the target value. A combination of automatic and manual actions permitted the system to achieve steady state in about $75 \mathrm{~min}$. Thereafter, the system was able to maintain steady state without interference and performed satisfactorily. 


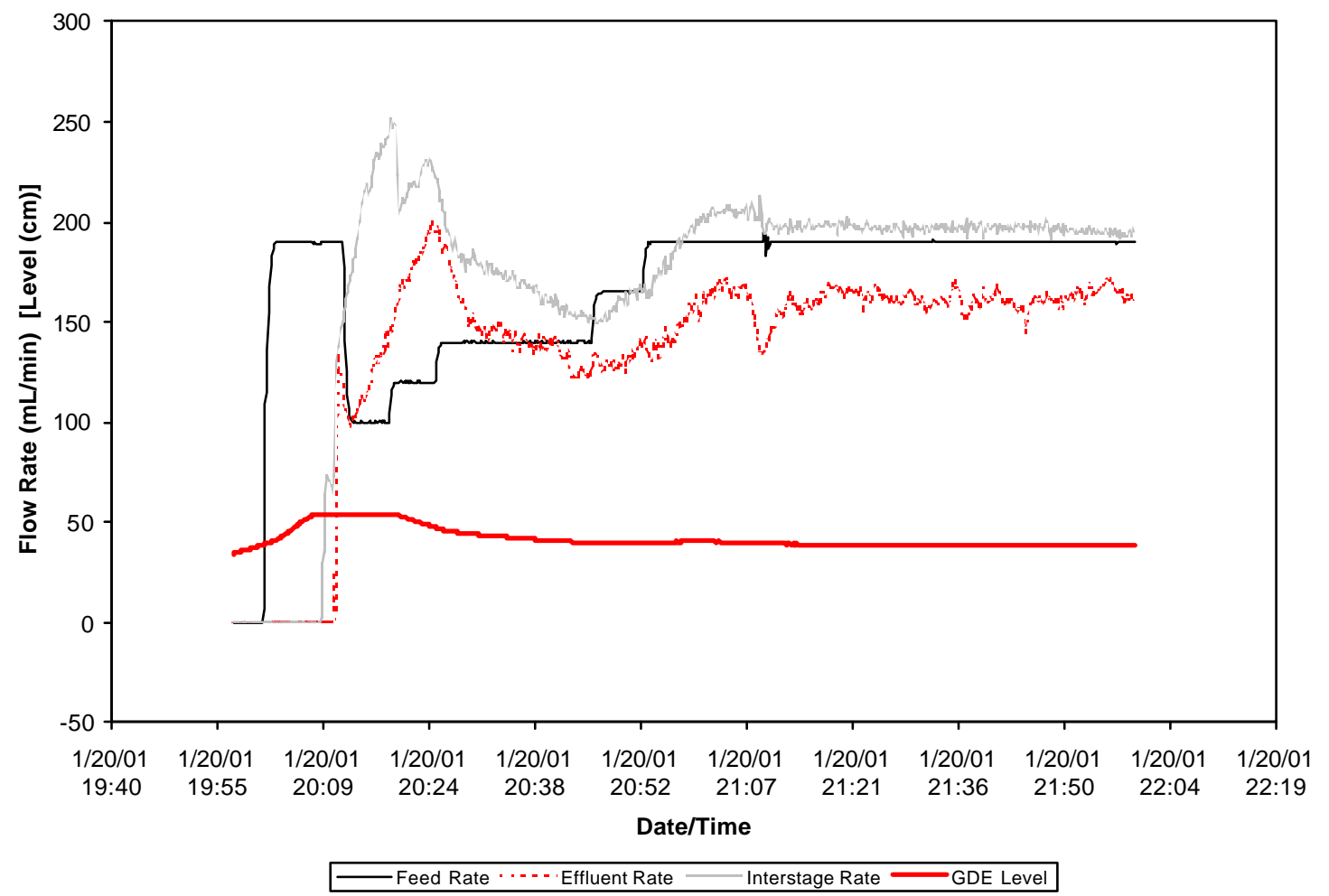

Fig. 5.7. Liquid flow rates and GDE liquid level measured during startup of Mode B.

\subsection{GENERAL OBSERVATIONS}

The two-column system, including the GDE, could be operated satisfactorily using automatic control in all three modes of operation. Small variations caused by different methods of separation (such as sparging) did not affect the system. Pressure-drop measurements across the Johnson screens indicated that the screens never plugged and, therefore, did not affect system operation. Sampling with the gas-separation chambers perturbed the system. Pressures fell in the upstream column and the liquid level in the GDE decreased when the upstream line was sampled. When the downstream line was sampled, the pressures decreased in the downstream column but little effect was noted at the GDE or further upstream. In all cases, the system recovered from these upsets within about $30 \mathrm{~min}$. Thus, no operating mode should be removed from consideration on the basis of control problems. 


\section{EFFECT OF OPERATIONS ON THE CST}

\subsection{LEACHING OF COMPONENTS FROM THE CST}

Liquid simulant samples were obtained, on a daily basis, during the 10-day experimental campaign. These samples were taken from the effluent stream of the second column, just upstream of the effluent collection tank. They were analyzed so as to monitor the leaching of components from the CST and dilution effects from the $\mathrm{H}_{2} \mathrm{O}_{2}$ addition. Analysis of anions $\left(\mathrm{NO}_{3}{ }^{-}\right.$, $\mathrm{Cl}^{-}, \mathrm{F}, \mathrm{SO}_{4}{ }^{2-}$, and $\mathrm{PO}_{4}{ }^{3-}$ ) was achieved using liquid chromatography in conjunction with titration for $\mathrm{OH}^{-}$and $\mathrm{CO}_{3}{ }^{2-}$. Analysis of dissolved metals was accomplished using ICP-AES.

The simulant was expected to exhibit slight decreases in the concentrations of some components because of dilution by the continuous small feed of $\mathrm{H}_{2} \mathrm{O}_{2}$ solution necessary to simulate gas generation in the column. As would be expected, the concentrations of the anions did not vary appreciably. Similarly, there were small changes in the concentrations of most of the metals. The concentrations of the primary metal components of the CST (silicon, titanium and niobium) are traced in Fig. 6.1. The $\mathrm{H}_{2} \mathrm{O}_{2}$ feed concentration is also shown in this figure. There were two periods of high concentration of niobium in the simulant, making it appear that niobium was leached from the CST and later precipitated from solution. The higher niobium concentrations roughly corresponded to periods of concentrated $\mathrm{H}_{2} \mathrm{O}_{2}$ feed. Silicon remained at a nearly constant concentration throughout the experiment, indicating saturation. An upward trend in the concentration of titanium is shown, particularly around January 19 when 30 wt $\% \mathrm{H}_{2} \mathrm{O}_{2}$ solution was again introduced. In the early portion of the experiment the 30 wt $\% \mathrm{H}_{2} \mathrm{O}_{2}$ had a lesser effect, presumably because much of the peroxide was being absorbed by the CST.

The mass of the metals in solution was calculated from the product of the concentration and liquid volume. The liquid volume was not constant because of the continuous addition of $\mathrm{H}_{2} \mathrm{O}_{2}$ solution (time-weighted average of $\sim 2.1 \mathrm{~mL} / \mathrm{min}$ over the duration of the experimental campaign). Under the assumptions that liquid volumes did not change upon mixing, the total liquid inventory was calculated from the sum of the starting volume of simulant and the volume of peroxide solution added up to the time each sample was taken. It was also assumed that the concentrations of the metals were uniform throughout the liquid simulant inventory (even though some liquid is in the column, some in the tank, etc.). The mass of the selected metals in solution is shown in Fig. 6.2. The mass of niobium in solution at any given time ranged up to $14 \mathrm{~g}$. An increasing mass of silicon that followed in lockstep with the increase in liquid volume inventory is shown. The quantity of silicon in solution was small, on the order of $12 \mathrm{~g}$. The starting mass of silicon in the solution was $\sim 8 \mathrm{~g}$; thus, only $\sim 4 \mathrm{~g}$ that was leached from the CST remained in 
solution. Titanium was slowly leached from the CST with a mass of $\sim 4 \mathrm{~g}$ in solution. As compared with the original mass of CST charged to the column $(\sim 24.3 \mathrm{~kg})$, the mass of components leached from the CST bed that remains in solution is small. Once-through processing of waste solutions could slowly leach the CST, resulting in chemical and physical changes throughout operating campaigns that last for several months.

Figure 6.3 shows the variation in the concentration and mass of aluminum in the simulant over the course of the campaign. These data indicate that precipitation of aluminum occurs early in the experiment, followed by a gradual uptake of aluminum by the simulant.

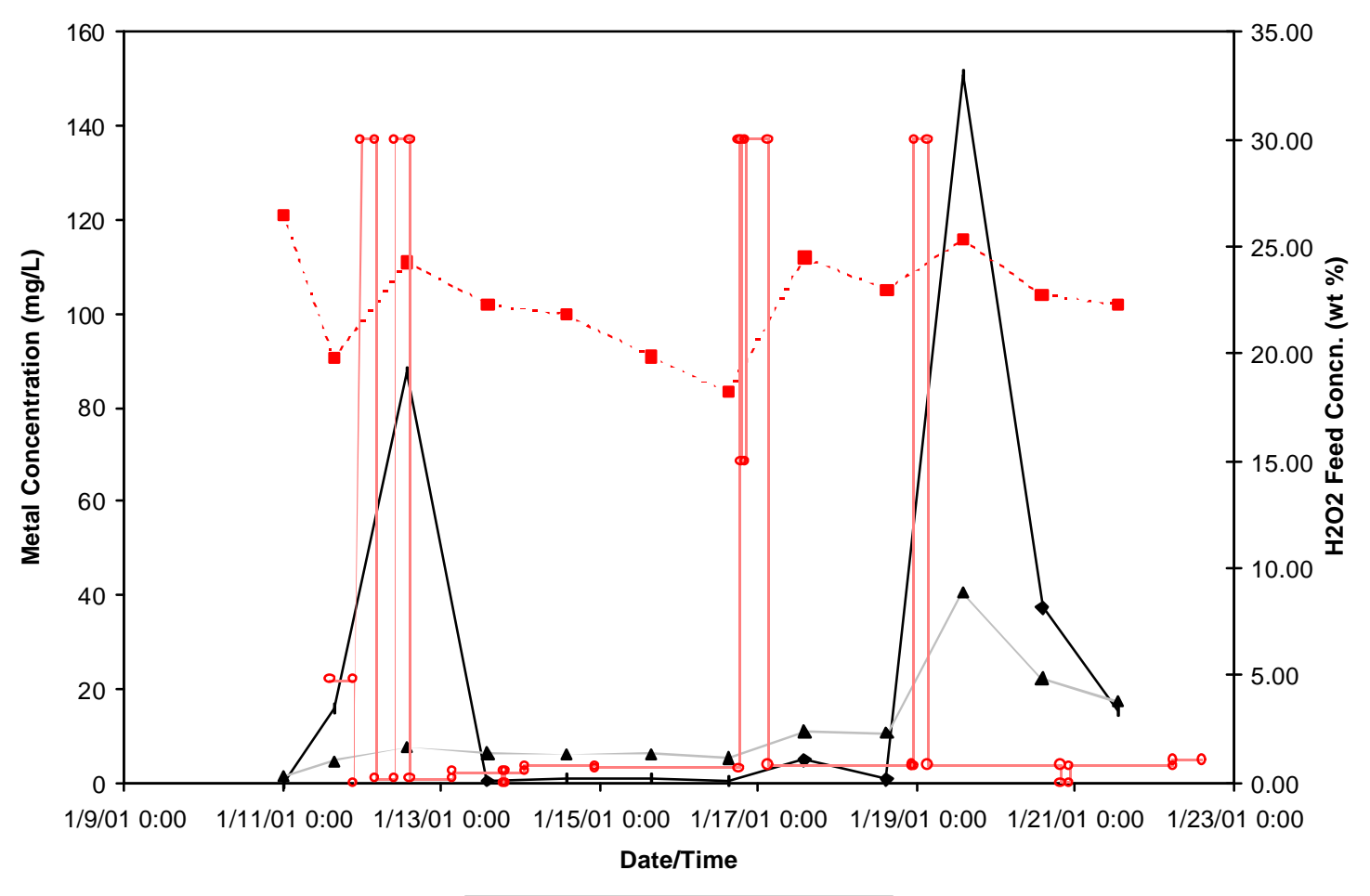

$\longrightarrow \mathrm{Nb}--\mathrm{E} \cdot \mathrm{Si} \triangle \mathrm{Ti} \rightleftharpoons \mathrm{H} 2 \mathrm{O} 2$

Fig. 6.1. Concentrations of selected metals in simulant solution and $\mathrm{H}_{2} \mathrm{O}_{2}$ feed over course of experiment. 


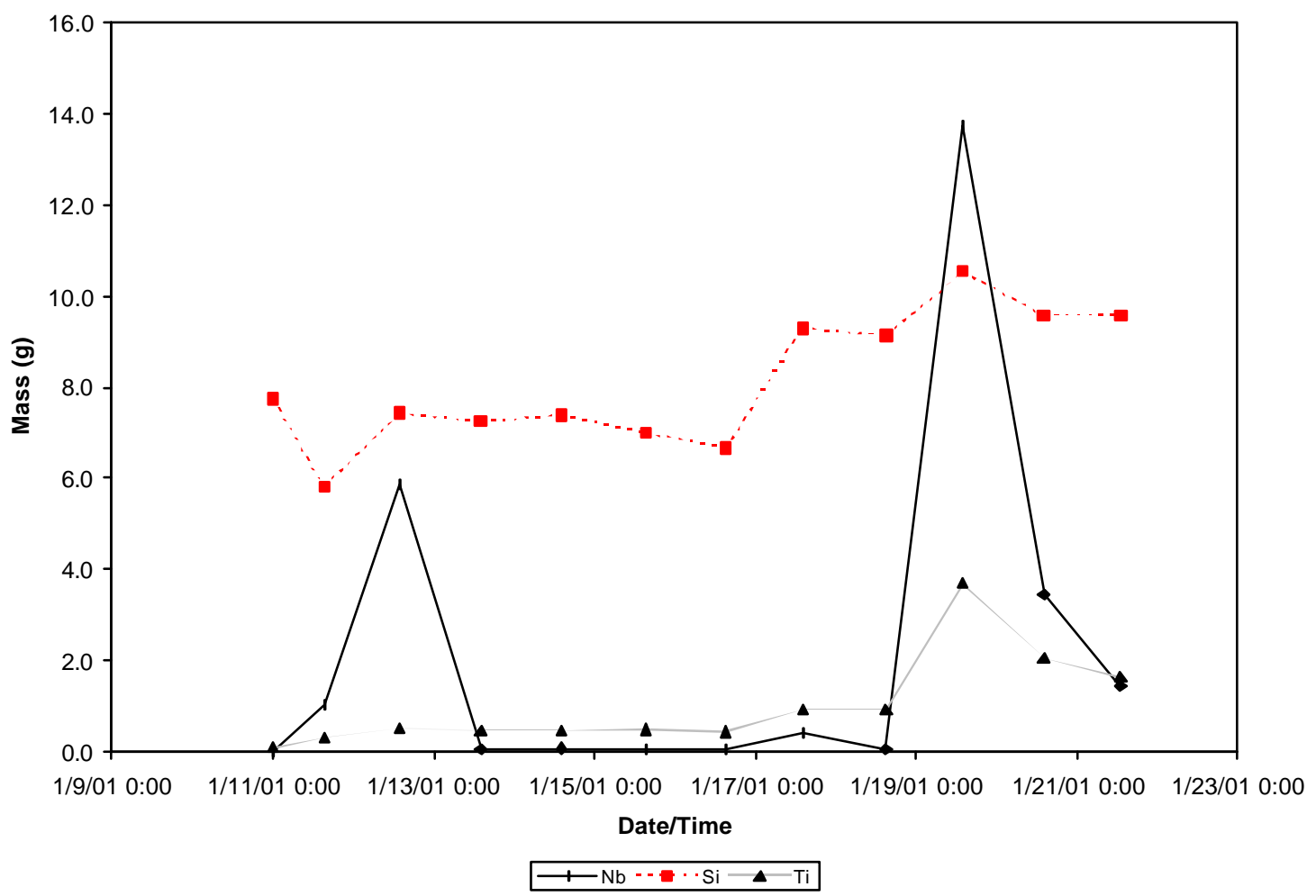

Fig. 6.2. Mass of selected metals in simulant solution as a function of time.

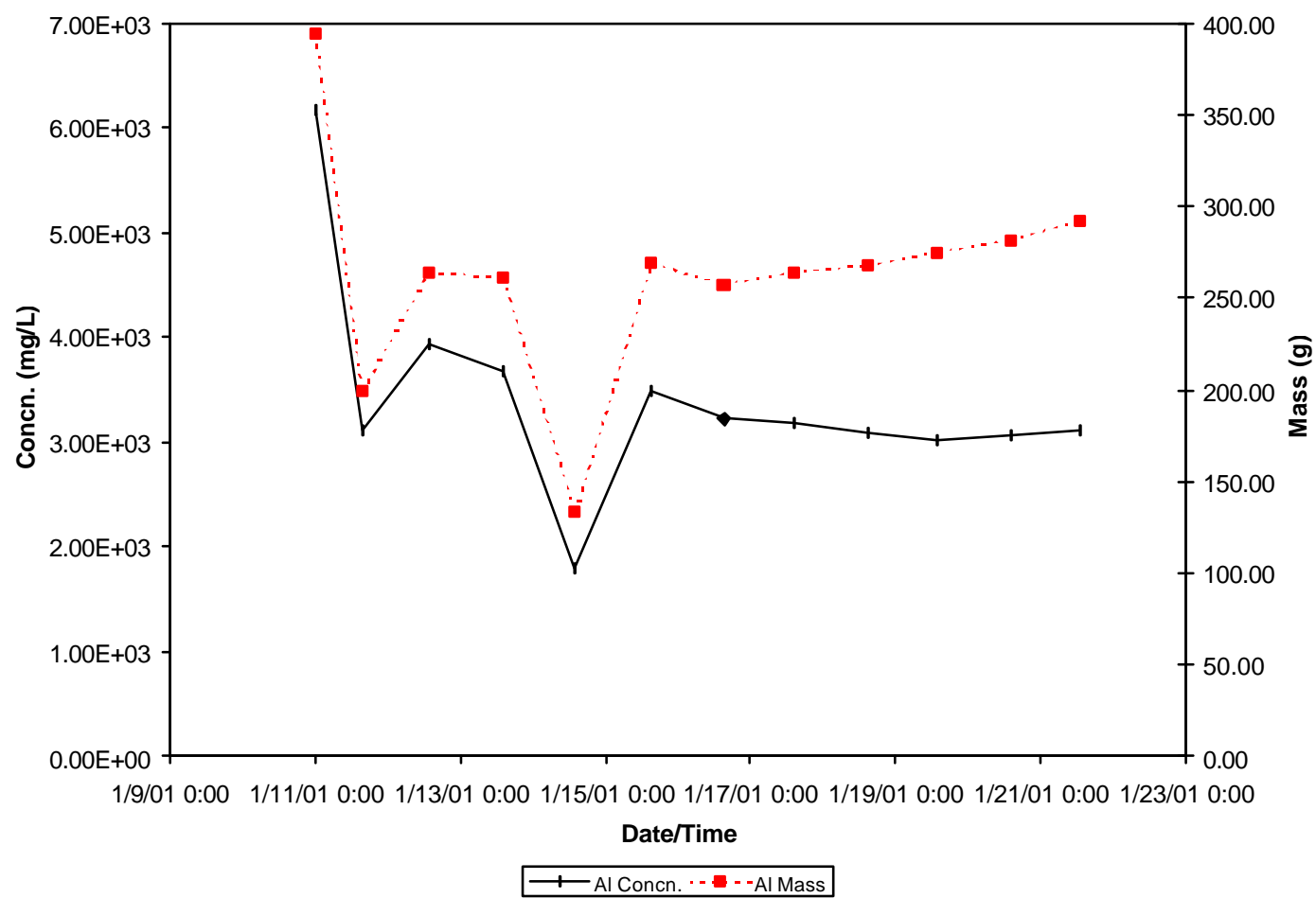

Fig. 6.3. Concentration and mass of aluminum in solution over course of experiment. 


\subsection{MICROSCOPIC ANALYSIS OF CST}

Visual observation showed that a thin layer of CST in the bed of the tall column had acquired a gray tint during the course of the experimental campaign. A photograph of this layer is provided in Fig. 6.4. Because of this discoloration and the desire to complement the data on the leaching of the CST with the simulant, samples of the CST were obtained from the tops of both columns at the end of the experimental campaign. These samples were rinsed with $1.0 \mathrm{M}$ sodium hydroxide, washed with water, and dried. They were then submitted for analysis by scanning electron microscopy (SEM) and energy-dispersive X-ray spectroscopy (EDS).

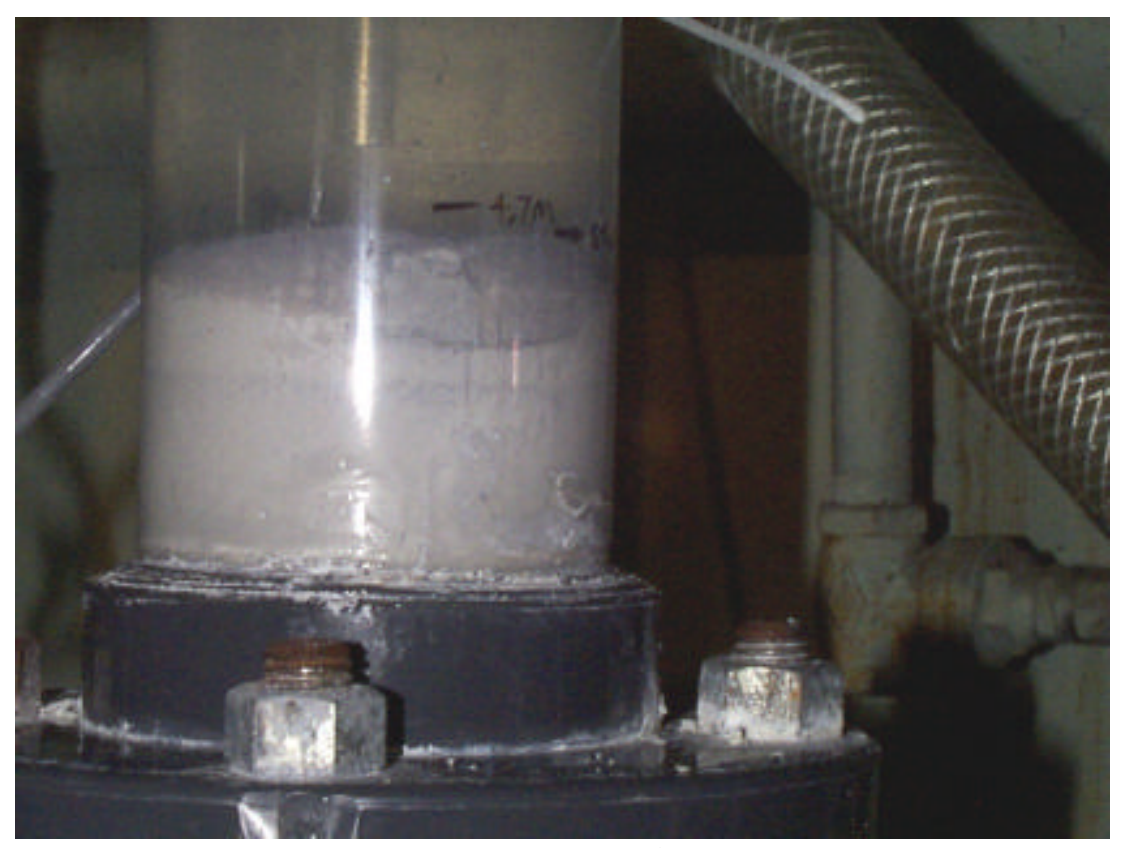

Fig. 6.4. Photograph of top of the CST bed in the tall column.

The discolored layer of CST bed at the top of the tall column was found to be crusty when an attempt was made to retrieve a sample. Therefore, a length of $1 / 4$ in. stainless steel tubing was used to break up the layer and the sample was suctioned from the column through the tube. Figures 6.5 through 6.7 show a series of photomicrographs of the CST sample, at increasing magnification. As expected, some of the granules were broken and irregular (Figs. 6.5 and 6.6). At high magnification, globular nodules were observed on the surface of a CST particle (Fig. 6.7). Additionally, small cubic crystals were also observed. The EDX spectra indicate that 


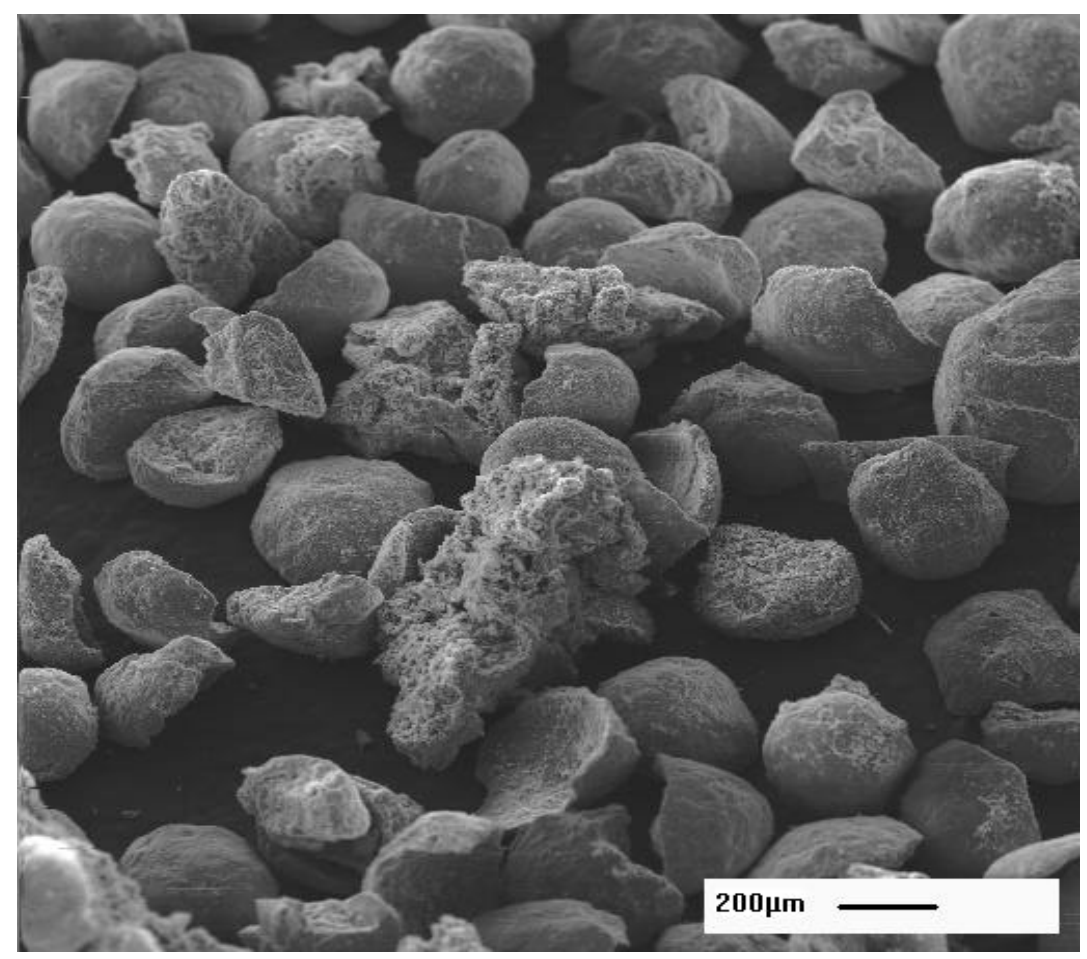

Fig. 6.5. SEM photomicrograph of CST removed from top of tall column.

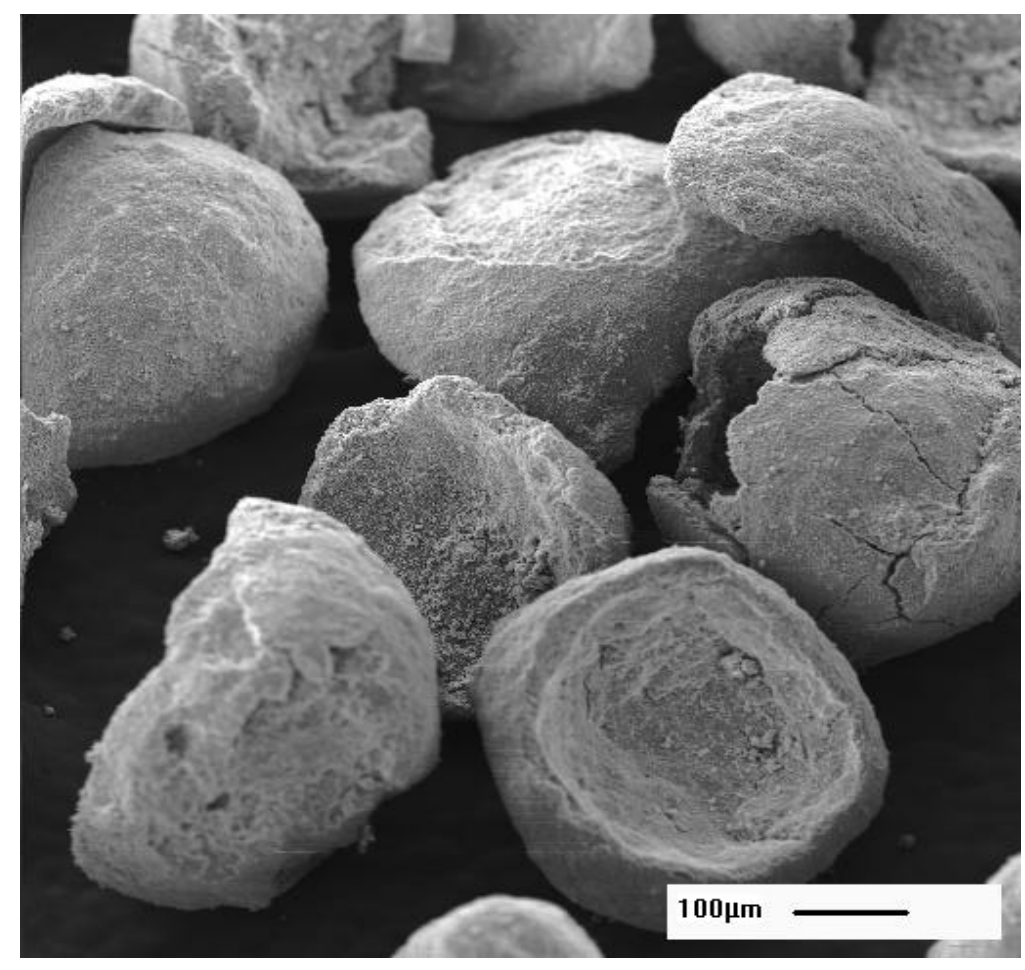

Fig. 6.6. Fractured CST granules from tall column. 
this surface was rich in sodium, aluminum, silicon, niobium, and titanium. Spectral data for the irregular particle near the center of Fig. 6.5 showed a similar composition, except that the niobium and titanium concentrations were much lower.

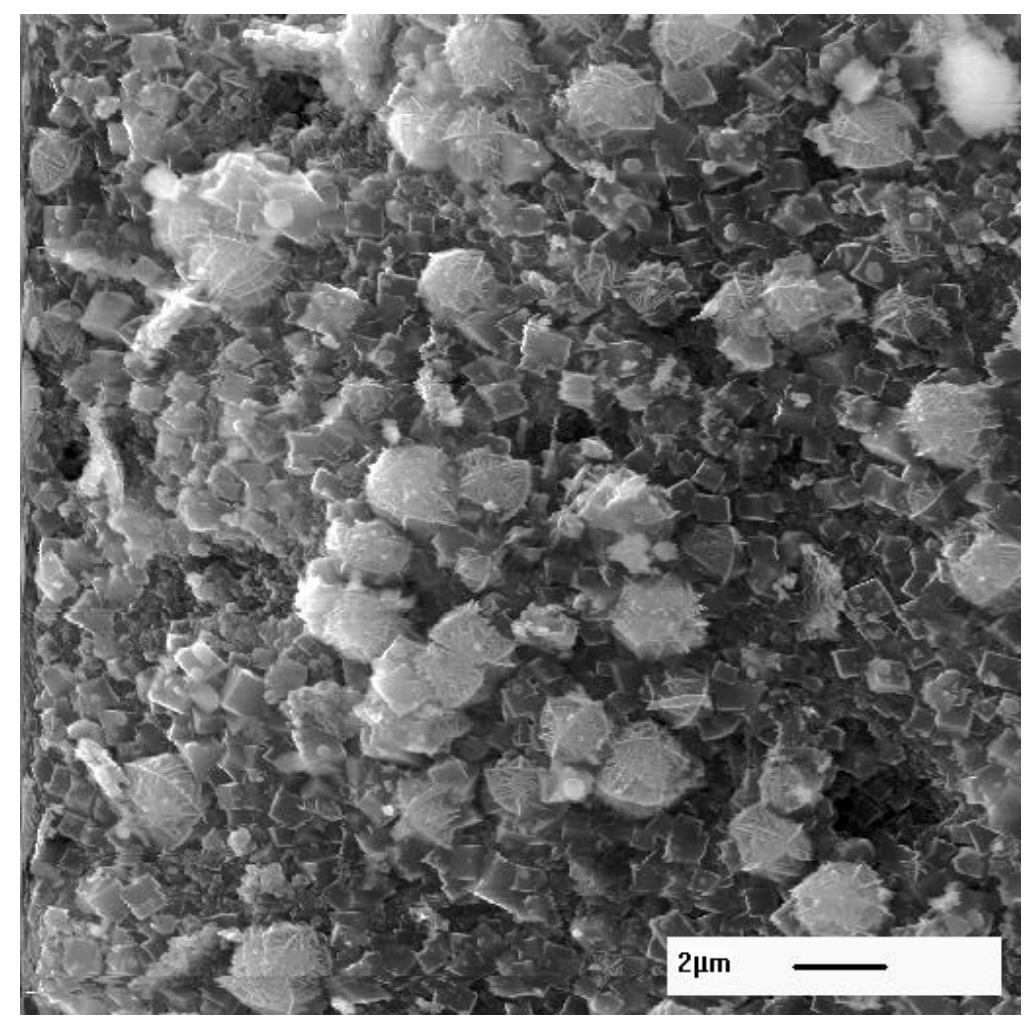

Fig. 6.7. Surface of particle from tall column, showing nodules of aluminum and silica.

A sample of CST was removed from the top of the bed in the short column by similar means. The CST was crusty, but not nearly as hard as the material in the tall column. Figures 6.8 through 6.10 show photomicrographs of the CST sample. Breakage of the CST was also less severe for the material removed from the short column (see Fig. 6.8 and compare with Fig. 6.5). The EDX spectrum of a small globular nodule (Fig. 6.10) indicated high concentrations of sodium, aluminum, silicon, niobium and titanium. The spectrum of the entire surface (Fig. 6.10) indicated a lower aluminum but a higher niobium content. The surface shows the presence of smaller cubic crystals as well as some signs of crystal joining and/or overgrowth. These data are indicative of precipitation or crystallization of niobium- and titanium-bearing materials. 


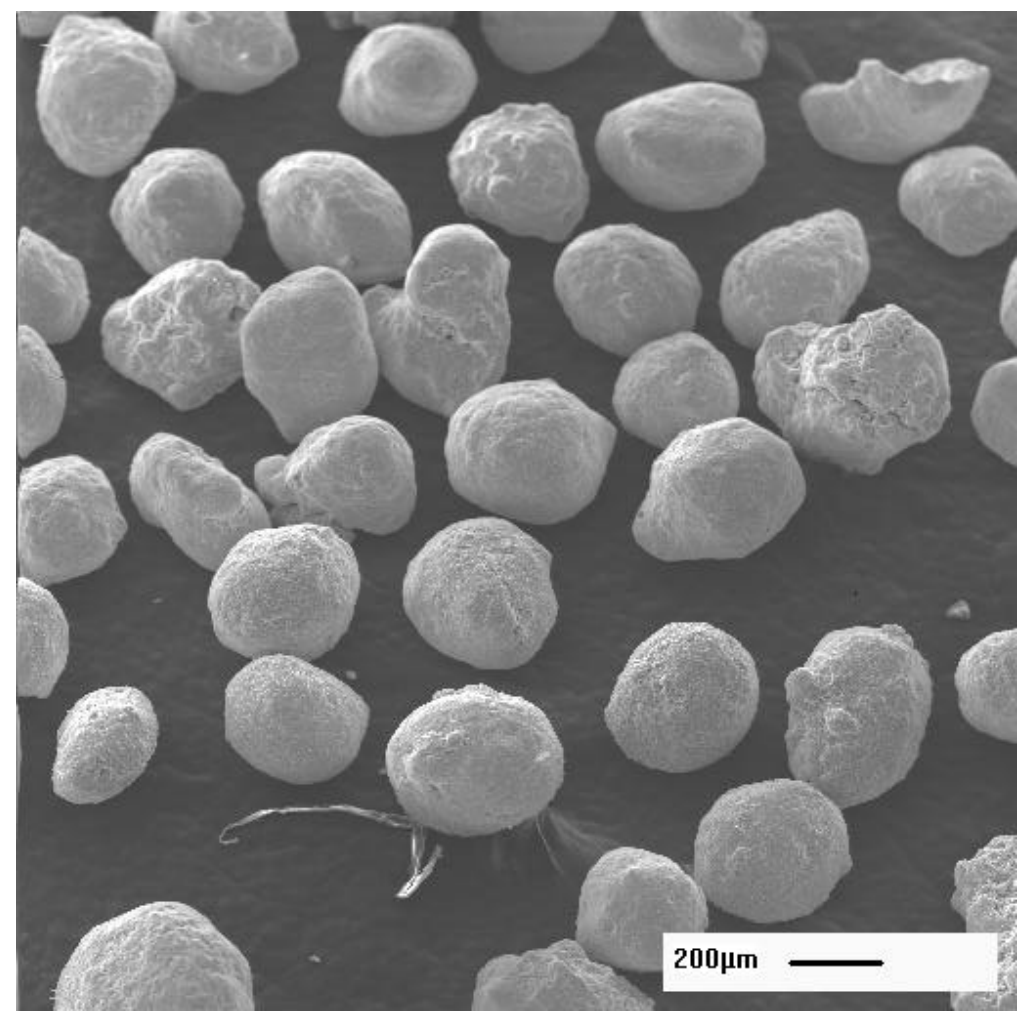

Fig. 6.8. CST removed from top of the short column.

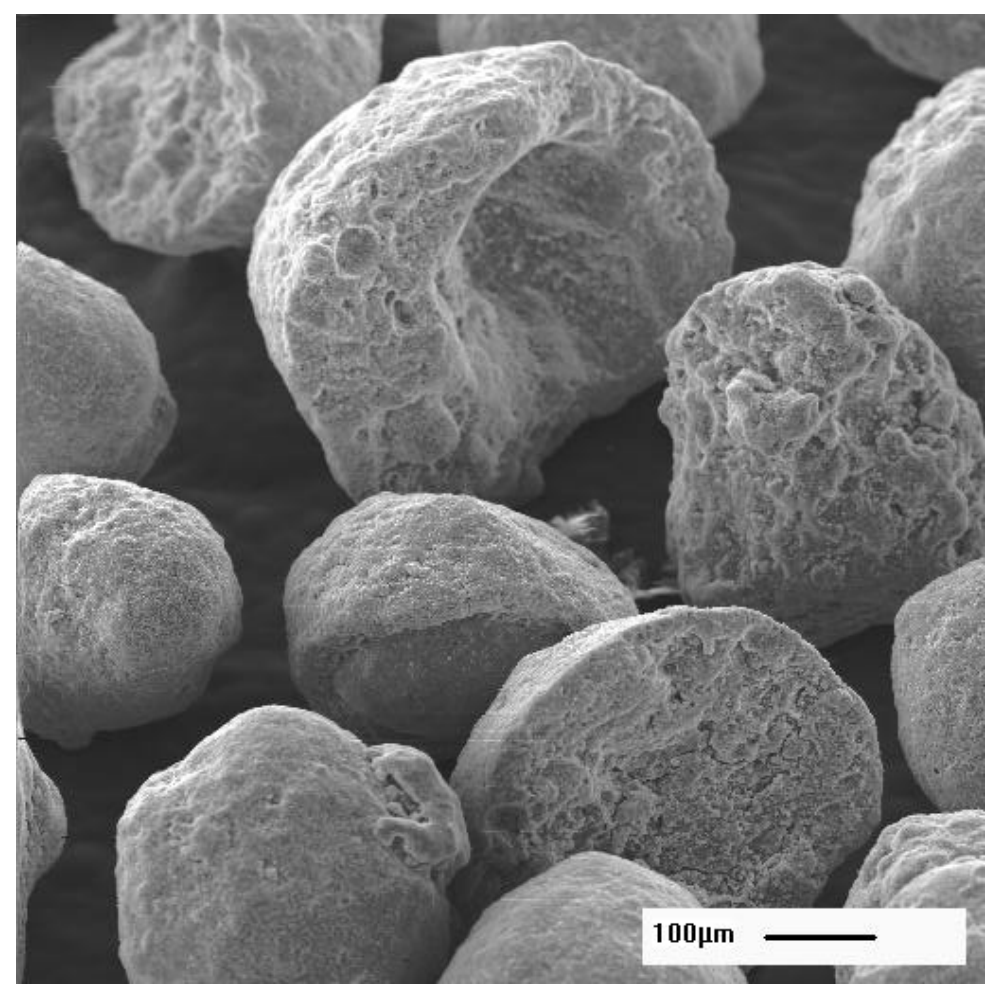

Fig. 6.9. Various-shaped CST particles removed from top of short column. 


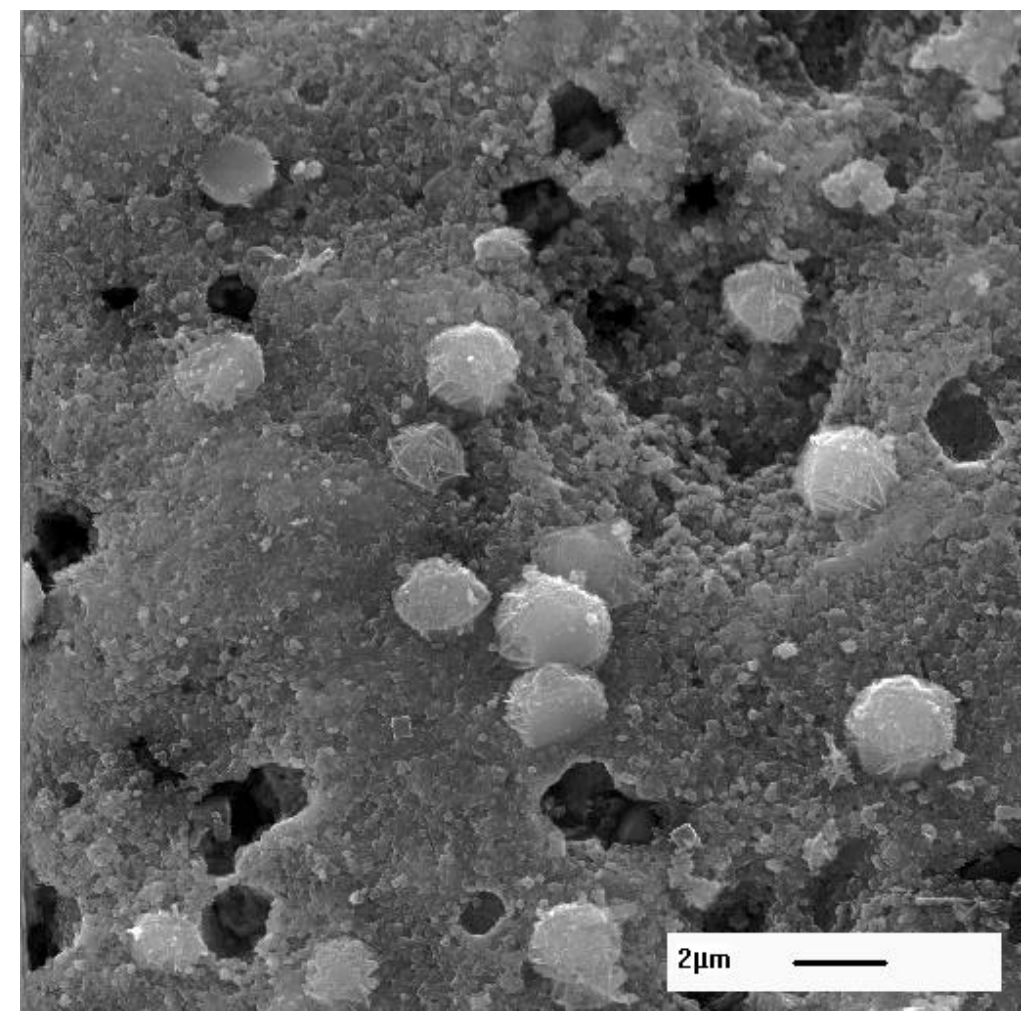

Fig. 6.10. Surface of CST particle taken from the short column.

These data are consistent with the deposition of aluminum (perhaps as aluminosilicate) and titanium on the CST. Reduction in the $\mathrm{pH}$ of the simulant could have caused precipitation of aluminosilicate. In addition, stagnant zones of low-pH solutions could have resulted from the CST loading and back-flushing operations. These zones could be expected to occur near the bottom of the column beneath, and possibly around, the Johnson screens. The flow pattern would tend to constrict as the fluid approached the Johnson screen. Fluid mixing in the corners, near the bottom of the column, was suppressed by the presence of the CST. Stagnant zones would interact with flowing simulant by diffusion, causing precipitation of salts from the simulant. Also, the addition of the small flow rate of $\mathrm{H}_{2} \mathrm{O}_{2}$ solution would have decreased the $\mathrm{pH}$ at the top of the bed in the tall column, causing precipitation there. Titanium and niobium might have been leached from the CST and migrated due to the action of the $\mathrm{H}_{2} \mathrm{O}_{2}$. It has been previously reported that $\mathrm{H}_{2} \mathrm{O}_{2}$ reacts with pertitanyl cation $\left[\mathrm{TiO}_{2}{ }^{2+}\right]$ to form the pertitanyl anion $\left[\mathrm{Ti}\left(\mathrm{O}_{2}\right)_{4}{ }^{4-}\right]$. Pertitanyl anion may have remained stable in basic solution for only a limited time; its decomposition would cause precipitation of the titanium. Similar reactions could occur with other metals such as niobium. Consequently, titanium and niobium could have dissolved and then been redeposited 
throughout the bed. Complexes with short lifetimes could also explain some of the variability in gas production rates that were experienced while using $\mathrm{H}_{2} \mathrm{O}_{2}$ decomposition to simulate production of gas (oxygen) by radiolysis. This would be particularly true in cases where the decomposition rate is pressure sensitive.

\subsection{COLUMN UNLOADING}

Following the experimental campaign, the column system was placed in the "idle" configuration for an indeterminate period. The status of the column remained as such until it was clear that no further tests would be performed ( $\sim$ weeks). The small leak that had developed in the tall column during the run, at a pressure transmitter fitting, was allowed to drip into a collection pan placed beneath the column. Prior to attempts to remove the CST from the column, it was observed that the liquid had drained to the level of the leak, about $1 \mathrm{~m}$ from the bottom of the column.

Attempts to sluice the CST from the tall column are described in Appendix B. Briefly, the column was refilled with simulant to provide a fluid to sluice the CST through the unloading line at the bottom of the colu mn. (The CST would not flow from the column by gravity.) It was thought that allowing the CST to soak in the simulant overnight would loosen the CST if it had dried due to the loss of liquid. After the soaking procedure, however, attempts to sluice small quantities of CST from the sample ports were still unsuccessful. Probing the CST through the sample ports with a capillary tube revealed that the CST was crusty, but it did not help loosen the CST for sampling. Pressurized air ( $25 \mathrm{psig}$ ) was then applied to the bottom of the column in an effort to break up the CST bed; however, this was also unsuccessful. Sampling was finally accomplished by "digging" some CST from the sampling ports with a welding rod. The column was then refilled with simulant, allowing a cushion of trapped air in the top of the column to pressurize to $25 \mathrm{psig}$. Opening the sluice line under these conditions did not result in sluicing of the CST. The bed remained stable, but it appeared that liquid and air could channel up through the bed. Finally pulsing the bed at the bottom of the column with water at a pressure of $\sim 30 \mathrm{psig}$ successfully cleared a section $\sim 18$ in. high. Above that level, the CST still remained as a slug.

The details of sluicing the CST from the short column are given in Appendix C. In summary, nitrogen and simulant were alternately admitted to the bottom of the short column. Initially, the entire bed was lifted as a slug; however, after several attempts, particles of the CST began to fall away from the lifted slug and settle at the bottom of the column. Sluicing from the bottom discharge line was impeded by a crusty layer of CST located around both the discharge line and the Johnson screen. A welding rod was used to probe and break up this crusty layer. 
The CST was then successfully sluiced from the short column. However, a small amount of CST remained as a crusty mass in the bottom of the column on the side opposite the sluice line where the CST could not be probed (because of the presence of the Johnson screen).

Difficulties in removing the CST would be a significant problem in the waste processing plant. However, the nonprototypical conditions to which the CST in this experimental program was exposed, specifically addition of concentrated $\mathrm{H}_{2} \mathrm{O}_{2}$ solution, contributed to the problem. Portions of the CST samples that were removed from the columns were sent to Sandia National Laboratory (SNL) for analysis. SNL reported ${ }^{12}$ that aluminosilicate deposition appears to be the cause of CST agglomeration; however, the root cause is believed to be dissolution of the CST (particularly the titanium component) by $\mathrm{H}_{2} \mathrm{O}_{2}$. This also brings excess silicon into solution, which can result in precipitation of aluminosilicate. The aluminosilicate deposition is heaviest at the top of the tall column, close to the injection point of the $\mathrm{H}_{2} \mathrm{O}_{2}$. Some aluminosilicate morphologies observed on the tall column samples are different than previously observed in CST samples exposed to simulant, which suggests that the chemical conditions of precipitation are different. ${ }^{12}$ Levels of $\mathrm{H}_{2} \mathrm{O}_{2}$ in the tall column test $(0.26 \mathrm{M})$ greatly exceed those anticipated from radiolysis $\left(2.5 \times 10^{-6} M\right)$, so the extent of aluminosilicate precipitation observed in this case may not be indicative of what would occur during the processing of actual wastes. 


\section{CONCLUSIONS AND RECOMMENDATIONS}

\subsection{CONCLUSIONS}

The GDE can effectively remove gas to a level that prevents bulk accumulation in the bed of downstream columns when it is operated at atmospheric (or lower) pressures. The ionexchange column system could be operated and controlled at steady state in each mode of operation. Mode B was the most sluggish with respect to system response time; however, none of the modes would be considered unworkable. Foregoing gas separation or operating the GDE at pressures higher than those in the downstream column can cause accumulation of gas in downstream columns. When the GDE was operated at a pressure lower than that of the downstream column, gas did not accumulate in the downstream column. In Mode A, the liquid in the GDE was at atmospheric, or lower, pressure. If the liquid was saturated with gas at this pressure and the pump elevated the pressure of the liquid before feeding it to the downstream column, then the liquid was below the saturation concentration of the gas. No gas evolved from the liquid because the liquid had the capacity to absorb more gas. Conversely, when the GDE was operated at a high pressure and the liquid was throttled through a control valve, a in Mode B, the liquid became supersaturated with gas. Gas evolved from the liquid and accumulated in the downstream column.

When the GDE was bypassed in Mode C, gas accumulated in the upper portion of the downstream CST bed and in the column headspace. This accumulation did not appear to disrupt the bed. However, if enough gas accumulates in the column to begin displacing liquid from the CST bed, CST performance can be expected to degrade due to short-circuiting. Interestingly, several hours after switching to Mode A operation, this accumulated gas disappeared, presumably as the result of dissolution.

Because of difficulty in saturating the CST with $\mathrm{H}_{2} \mathrm{O}_{2}$, the mass feed rate of $\mathrm{H}_{2} \mathrm{O}_{2}$ was significantly increased at times to ensure saturation. Consequently, there were periods throughout the operations in Mode A when the gas generation rate was as high as 40 times that which would be expected from radiolysis. Over the range of these gas-generation rates, measurements showed that the gas in the effluent from the GDE remained essentially unchanged. Such data indicate that the equipment is effective in separating entrained gas at atmospheric pressures.

The operational performance and results obtained were better for Mode A than for the other modes. Little gas accumulated in the downstream column during Mode A, regardless of the operational method used. In the sparging method, it was necessary to maintain a low sparge-gas flow rate $(300 \mathrm{~mL} / \mathrm{min})$ to keep entrained gas bubbles from exiting the GDE and flowing into the 
short column. Some optimization of the sparger location (submergence) might improve performance of the sparging method. In the reduced-pressure method, the system was operated similarly to that used with the passive settling method, except that the ullage space was operated at 15 in. Hg vacuum. The performance observed in this method was not significantly different from that observed for the passive settling method.

In Mode B, gas accumulated in the headspace and upper portion of the bed in the downstream column. Because gas bubbles could not be seen with the unaided eye, and only occasionally with the magnifying lens of the camera, the gas either dissolved or was present as microscopic bubbles. This indicates that dissolved gas evolving from solution is problematic.

At the end of Mode B, tests with ultrasound-enhanced gas separation were performed while sparging the GDE liquid. The approach was to "step" through the frequency range of the device and visually observe the effect, if any, on the coalescence of bubbles in the GDE. Lowpower settings were used to prevent overheating and failure of the ultrasonic actuator; however, a small effect was observed at frequencies between 18.8 and $19.1 \mathrm{kHz}$. Larger bubbles were formed in the vicinity of the ultrasonic horn when the device was engaged.

In each operating method, the liquid stream was videotaped both upstream and downstream of the GDE to measure bubble size. When bubbles were present in the tall-column effluent, they tended to range from 0.1 to $2 \mathrm{~mm}$ in diameter. Bubbles downstream of the GDE were usually few in number and very small (around $\sim 0.1 \mathrm{~mm}$ in diameter).

Samples of the simulant were obtained on a daily basis throughout the operating campaign. Analysis indicated that some niobium and titanium were leached from the CST. The concentrations of these metals in the simulant appeared to increase in response to a concentrated $\mathrm{H}_{2} \mathrm{O}_{2}$ feed. Later, the concentrations decreased, indicating that the metals had precipitated from solution. Scanning electron microscopic analysis of CST samples showed deposition of globular nodules and cubic crystals on the particle surface. Energy-dispersive X-ray spectroscopy identified these deposits as being rich in aluminum, silicon, and titanium.

Sluicing of the CST from the columns proved difficult. Probing of the beds revealed a crusty consistency, which was particularly hard at the top of the tall column where $\mathrm{H}_{2} \mathrm{O}_{2}$ had been introduced. It was concluded that the deposition of an aluminosilicate-rich precipitate had acted as a binder. The introduction of $\mathrm{H}_{2} \mathrm{O}_{2}$ may have increased the leaching of titanium and silicon from the CST which, when combined with the aluminum in the simulant, resulted in increased deposition rates. The CST in the tall column was effectively immobilized but remained porous so that liquid flow could continue. Some binding was also observed in the short column, but 
backflushing with simulant and nitrogen gas broke up the CST so that it could be removed by sluicing.

\subsection{RECOMMENDATIONS}

Based on the results obtained in this experimental program, the following recommendations are offered:

1. Column design should include gas vents at the tops of the columns to permit the release of gas that will accumulate slowly over time.

2. Gas separation between columns should be performed at a pressure lower than that expected to be encountered within the downstream column. Otherwise, gas that is dissolved in the liquid at elevated pressure will evolve from the liquid as the pressure falls and gas will accumulate in the downstream column(s).

3. Additional tests be performed in two primary areas. First, equipment that supports a falling film to permit entrained gas to separate from the liquid could be very effective and reduce the inventory of simulant in the GDE. Second, further tests of the ultrasound-enhanced separation at higher power levels seem prudent. Equipment could be operated in a pulsed mode if equipment capable of continuous operation cannot be identified. The results of these tests would help define the most effective gas-separation techniques.

4. Additional work is needed to determine conditions under which the leaching behavior can be minimized, and to determine what engineering attributes might be necessary to facilitate CST removal from columns if agglomeration cannot be avoided. The effect of temperature on leaching and precipitation may be important in systems where the first column is warmer than downstream columns. 


\section{REFERENCES}

1. S. Beck et al., Bases, Assumptions, and Results of the Flowsheet Calculations for the Short List Salt Disposition Alternatives, WSRC-RP-98-00168, Rev. 1, Westinghouse Savannah River Company, Aiken, South Carolina, October 29, 1998.

2. A. O. Delley and M. W. Geeting, Task Requirements and Criteria, Salt Waste Processing Facility, Gas Disengagement Equipment for Proof of Concept Testing, G-TC-H-00032, Rev. 0, Westinghouse Savannah River Company, Aiken, South Carolina, March 7, 2000.

3. T. D. Welch, K. K. Anderson, D. T. Bostick, T. A. Dillow, M. W. Geeting, R. D. Hunt, R. Lenarduzzi, A. J. Mattus, P. A. Taylor, and W. Wilmarth, Hydraulic Performance and Gas Behavior of a Tall, Crystalline-Silicotitinate Ion-Exchange Column, ORNL/TM-1999/103, Lockheed Martin Energy Research Corp., Oak Ridge National Laboratory, Oak Ridge, Tennessee, February 2000.

4. B. B. Spencer, Technical Task Plan for Engineering Trade Studies and Support: Alternate Column Configuration and Gas Disengagement Equipment, ORNL/CF-99/68, Rev. 0, Lockheed Martin Energy Research Corp., Oak Ridge National Laboratory, Oak Ridge, Tennessee, January 2000.

5. B. B. Spencer, Design of Modifications to Tall Column System to Support Gas Disengagement Tests, CERS/SR/IX/001, Rev. 0, UT-Battelle, Oak Ridge National Laboratory, Oak Ridge, Tennessee, October 18, 2000.

6. J. A. Pike, Pressure Profile in Non-Elutable Ion Exchange Columns, HLW-SDT-2000-00102, Westinghouse Savannah River Company, Aiken, South Carolina, March 27, 2000.

7. B. B. Spencer, Gas Measurement Devices for the Tall Column System in Support of Gas Disengagement Tests, CERS/SR/IX/002, Rev. 0, UT-Battelle, Oak Ridge National Laboratory, Oak Ridge, Tennessee, October 24, 2000.

8. L. J. Harkey, Task Technical Plan for the Ion Exchange Column Gas Disengaging Equipment Evaluation, WSRC-RP-99-01117, Rev. 1, Westinghouse Savannah River Company, Aiken, South Carolina, March 2000.

9. L. J. Harkey, Tall Column Gas Disengagement Equipment Evaluation at ORNL: Scope of Work, M-SOW-G-00013, Westinghouse Savannah River Company, Aiken, South Carolina, March 30, 2000.

10. D. D. Walker, Preparation of Simulated Waste Solutions, WSRC-TR-99-00116, Westinghouse Savannah River Company, Aiken, South Carolina, March 12, 1999.

11. D. D. Walker, Pretreatment Guidelines, SRT-LWP-2000-0028, Westinghouse Savannah River Company, Aiken, South Carolina, March 2000.

12. M. D. Nyman, Sandia National Laboratory, Albuquerque, New Mexico, personal communication to B. B. Spencer, March 20, 2001. 
APPENDIXES 


\section{Appendix A. Design of Experime ntal Scale -Johnson Screen}

Johnson screens (U.S. Filter, part No. 100N) purchased for tall-column tests in the previous fiscal year may be used as a basis of design. These are full-scale, commercially available screens with a slot width of $180 \mu \mathrm{m}$, a body length of $40 \mathrm{~mm}(1-9 / 16 \mathrm{in}$.), and a screen diameter of $50 \mathrm{~mm}(2 \mathrm{in}$.$) .$

The manufacturer recommends that the Johnson screens be spaced 8in. apart. In the ORNL tall column, one standard Johnson screen occupies a larger fraction of the column cross section than would several Johnson screens, at the recommended spacing, in the proposed fullscale column. Also, higher local fluid velocities caused by the reductions in free cross-sectional area are more pronounced in the tall column. However, the effect in each case is a local increase in velocity. The resulting difference in bubble size is expected to be insignificant.

The length of the exposed Johnson screen needs to be reduced to simulate prototypical flow conditions in the tall column. Consideration of the design data and calculations follows.

Screen Data:

Screen diameter, $50 \mathrm{~mm}(2 \mathrm{in}$.)

Screen length, $40 \mathrm{~mm}$ (19/16 in.)

Recommended maximum accumulation (flow), $15 \mathrm{~L} / \mathrm{min}$

Recommended maximum backflush flow, $44 \mathrm{~L} / \mathrm{min}$

Slots, total of 30 spiratwound slots for an average of 19.2 slots/in.

Operating Conditions and Assumptions:

Nominal feed rate to tall column, $187 \mathrm{~mL} / \mathrm{min}$

Backflush flow rate, $1.2 \mathrm{~L} / \mathrm{min}$

Normal feed and backflush flow rates are one-half the recommended maximum.

Calculation Method 1, Scaling Screen Area to Flow Rates:

In this method, the superficial velocity of the fluid through the screen is maintained; that is, surface area is scaled to the flow rate. The governing equation is

$$
\frac{Q_{1}}{A_{1}}=\frac{Q_{2}}{A_{2}},
$$

where $\quad \mathrm{Q}=$ volumetric flow rate,

$$
\mathrm{A}=\text { surface area of screen/filter. }
$$

The surface area is calculated by

$$
A=\pi d x \text {, }
$$

where $\quad \mathrm{d}=$ the diameter of the Johnson screen,

$$
\mathrm{x}=\text { the exposed length of the Johnson screen. }
$$

The length of exposed screen may be scaled by

$$
\frac{Q_{1}}{x_{1}}=\frac{Q_{2}}{x_{2}} \text {. }
$$

A similar argument can show that

where

$$
\frac{Q_{1}}{n_{1}}=\frac{Q_{2}}{n_{2}} \text {, }
$$

$$
\mathrm{n}=\text { the number of slots in the screen. }
$$


CASE A: Calculation based on normal flow.

The length of screen is calculated by

$$
\frac{15 / 2}{40}=\frac{0.187}{x_{2}}, \text { or } \mathrm{x}_{2}=0.997 \mathrm{~mm} \text { (or } 0.039 \mathrm{in} \text {.). }
$$

The number of slots is calculated by

$$
\frac{15 / 2}{30}=\frac{0.187}{n_{2}}, \text { or } \mathrm{n}_{2}=0.748 \text { slots. }
$$

CASE B: Calculation based on backflush flow.

The length of screen is calculated by

$$
\frac{44 / 2}{40}=\frac{1.2}{x_{2}}, \text { or } \mathrm{x}_{2}=2.182 \mathrm{~mm} \text { (or } 0.086 \mathrm{in} \text { ). }
$$

The number of slots is calculated by

$$
\frac{44 / 2}{30}=\frac{1.2}{n_{2}}, \text { or } \mathrm{n}_{2}=1.64 \text { slots. }
$$

Calculation Method 2, Setting Screen Area to Free Area of Packed Bed:

In this method, the exposed screen area is set equal to the free area of the packed bed, making the superficial velocity through the filter equal to the actual velocity through the packed bed. The equation that describes this is

$$
\frac{\pi}{4} D^{2} \varepsilon=\pi d x
$$

where $\quad \mathrm{D}=$ the inside diameter of the column, and

$$
\varepsilon=\text { the void fraction of the packed CST. }
$$

For the tall-column, $\mathrm{D}=2.9 \mathrm{in}$. Typically for the CST, $\varepsilon=0.35$. Thus, the exposed length of the screen is calculated by

$$
\frac{1}{4}(2.9)^{2}(0.35)=2.0 x \text {, or } x=0.37 \text { in (or } 9.3 \mathrm{~mm} \text { ). }
$$

Given that there are 19.2 slots/in., the number of slots is 7.1.

Based on the foregoing analysis, the number of exposed slots in the existing Johnson screen should range from around 2 to 7 . As a basis, custom-fabricated Johnson screens will be purchased having five slots that will filter the column effluent.

Johnson screens are normally orientated vertically. It is anticipated that effluent liquid would flow upward in a pipe built within the actual full-scale column. The vertical orientation, with the slot openings facing the wall, would then be prototypical. Vertical orientation is supported from above by $1 / 2 \mathrm{in}$. tubing. The Johnson screens shall be arranged to avoid accumulation points for gas. 


\section{Appendix B. Sampling and Sluicing of CST from the Tall Column}

\section{Column Loading and Post-Run Leak}

The CST was loaded into the ORNL tall column on October 29, 2000, using a funnel and a small sluice-water stream supplied through a 1/4-in. tube. This CST was backwashed with water on October 30. The water was then displaced with $1.2 \mathrm{M} \mathrm{NaOH}$ solution on October 31 . Simulant was first introduced on November 1. Very little pressure drop was noted at the beginning of the run. The pressure drop did increase as the run progressed, but it would be difficult to determine if this situation was caused by the buildup of some residue on the CST or by the buildup of gas in the CST bed.

During the run, a small leak developed in a fitting at a level of $1 \mathrm{~m}$ from the bottom of the column. After the run was completed on January 22, 2001, the simulant was allowed to leak from the column into a pan that was placed under the column to contain the liquid. The simulant in the column drained down to this point and the column was left in this condition until unloading operations were initiated as detailed below.

\section{Monday, February 26, 2001}

An attempt was made to remove a sample of the CST through sample ports at the 1-m and 4-m column levels. The column was filled with simulant solution to approximately 18-in. above the CST bed. We were unsuccessful at getting the CST to flow into the sample containers. We then suspected that the CST bed was bound together as the result of being without a cover of liquid solution for a prolonged period. To facilitate getting a sample of the CST, we decided to let the CST soak in simulant solution overnight, and try again to get it to flow through the sample ports.

\section{Tuesday, February 27, 2001}

Because of the leak, simulant had to be added back to the column to bring the level up over the CST bed. A second attempt was made to obtain samples of the CST through the sample ports. Again, however, the CST would not flow through the ports. Next, we attempted to pressurize the column by shutting off the vent line at the top of the column while filling the column with simulant. This permitted the trapped air to pressurize to $20-25$ psig in the column. The pressure was then released through the sample ports in an effort to obtain a CST sample. However, we still could not get a sample to flow. We then used a thin capillary tube to probe through the sample port to see if we could break any "crust" that might have formed against the wall of the column at the entrance to the sample port. Even after pushing against the CST, which felt very "crusty,"we were still not successful in obtaining a sample.

In an effort to break up the CST bed, we applied approximately 25 psig of air pressure to the bottom of the column while venting from the top. We did this with simulant covering the CST in the column. We were able to observe significant bubbling at the top of the column while applying the air pressure. This operation was continued for approximately $5 \mathrm{~min}$. There did not seem, however, to be a lot of "turnover" or "rolling" of the CST bed as one would expect. The air was vented from the top of the column through a 1/4in. line, which may have somewhat restricted flow. Once again we tried to sample the CST through the sample ports without success. The simulant was left in the column overnight. The leaking simulant was contained in the catchpan provided. 


\section{Wednesday, February 28, 2001}

In order to obtain a sample of the CST for analysis, we verified that the simulant had drained to a level below the sample ports, then removed the sample ports at the $1 \mathrm{~m}$ and $4 \mathrm{~m}$ marks. A stainless steel welding rod was used to "dig" CST from the ports. The CST had the consistency of wet sand; however, it did not seem to be packed hard enough to cause the column to plug.

After we obtained samples of the CST, the sample ports were reinstalled. Then we filled the column with simulant and attempted to sluice the CST from the column using the bottom sluice valve while venting the column at the top. This sluice valve is located on a 3/4in. PVC line at the bottom of the column beneath the Johnson screen. We were unable to get the CST to flow out of the sluice line. The simulant drained, but the CST would not sluice.

We refilled the column again with simulant until it was above the CST bed, then closed off the vent at the top of the column and allowed pressure to build in the column. When the pressure was about $25 \mathrm{psig}$, we opened the bottom sluice valve. Again, there was no movement

of the bed. Apparently, we had created a narrow channel up the bed that allowed liquid simulant and air to channel up through the bed. Because of the leak in the PVC column, we limited the pressure applied to the column.

\section{Thursday, March 1, 2001}

We removed the bottom threaded PVC plug from the column in an effort to dislodge some of the CST from around the Johnson screen, where we suspected the CST was plugged. This would also permit removal of any plugged or "crusted" CST from the point where it would exit the column through the $3 / 4$ in. PVC sluice line. We were unable to remove the solid PVC plug that was installed in the bottom of the column. This plug should freely fall from of the bottom of the column after the threaded PVC fitting is removed. However, precipitates could have caused the plug to be "frozen" within the column.

The threaded PVC fitting was replaced on the bottom of the column. We then fitted a water line (100 psig) to the bottom of the column in order to pulse water into the column. At this point, the column was empty of simulant and was not vented at the top, but the 3/4in. sluice line was left open to allow CST and water to exit the column. Water was pulsed for around $10 \mathrm{~s}$ for a total of eight repititions through a port adjacent to the Johnson screen and $180^{\circ}$ from the 3/4in. sluice port at the bottom of the column. The water was pulsed while watching the column pressure to ensure that it stayed below 30 psig during the pulses. This cleared a section about 18 in. high at the bottom of the column of CST. Above the 18-in. section, the CST is still holding together as a slug. 


\section{Appendix C. Sluicing CST from the Short Column}

We were able to sluice the CST from the short column (on March 14, 2001). Simulant and nitrogen were added alternately to the bottom of the column. Initially, the bed of CST lifted as a unit within the column, but after several attempts at adding nitrogen and simulant, the CST started to break up and fall to the bottom of the column. We tried to sluice the CST from the bottom of the column, but only simulant flowed from the column. We used a welding rod to probe through the sluice line and break up some crusty material from the junction of the line and the column. The CST still would not sluice, so we then used a small auger to work down through the CST from the top. Although the auger did not appear to reach the bottom of the column, the CST flowed easily and smoothly from the column when we tried sluicing again. A layer of CST was left around the inside wall of the column near the bottom. Rinsing this part of the column several times with simulant did not remove the CST. The Johnson screen remained partially buried in the CST. A small quantity of loose CST remained in the sluice line. 
ORNL/TM-2001/46

\section{INTERNAL DISTRIBUTION}

$\begin{aligned} \text { 1. } & \text { K. K. Anderson } & 16 . & \text { L. E. McNeese } \\ 2 . & \text { D. A. Bostick } & 17 . & \text { K. E. Plummer } \\ 3 . & \text { J. L. Collins } & 18 . & \text { S. M. Robinson } \\ 4 . & \text { M. D. Griffith } & 19 .-23 . & \text { B. B. Spencer } \\ 5 . & \text { R. D. Hunt } & 24 . & \text { P. A. Taylor } \\ 6 . & \text { H. L. Jennings } & 25 . & \text { J. F. Walker } \\ 7 . & \text { R. T. Jubin } & 26 . & \text { T. D. Welch } \\ \text { 8-12. } & \text { T. E. Kent } & 27 . & \text { ORNL Central Research Library } \\ 13 . & \text { D. D. Lee } & 28 . & \text { ORNL Laboratory Records, RC } \\ 14 . & \text { A. J. Mattus } & 29 . & \text { ORNL Laboratory Records, OSTI } \\ 15 . & \text { C. P. McGinnis } & & \end{aligned}$

\section{EXTERNAL DISTRIBUTION}

30. L. Balmer, Pacific Northwest National Laboratory, 902 Battelle Blvd., Richland, WA 99352

31. L. D. Bustard, Sandia National Laboratories, P.O. Box 5800, MS: 0728, Albuquerque, NM 87185-5800

32. J. T. Carter, Westinghouse Savannah River Company, Bldg. 704-3N, Room S151, Aiken, SC 29808

33. E. I. Cruz, U.S. Department of Energy, P.O. Box 550, MSIN: H6-60, Richland, WA 99352

34. F. Damerow, West Valley Nuclear Services, P.O. Box 191, West Valley, NY 14171

35. I. L. Drake, Jr., U.S. Department of Energy, 10282 Rock Springs Road, West Valley, NY 14171

36. Dennis Fennelly, UOP LLC, 307 Fellowship Road, Suite 207, Mt. Laurel, NJ 08054

37. S. D. Fink, Westinghouse Savannah River Company, P.O. Box 616, 773-A, Room B112, Aiken, SC 29808

39. M. W. Geeting, Westinghouse Savannah River Company, Bldg. 704-3N, Room S111, Aiken, SC 29808

40. P. W. Gibbons, Numatec Hanford Corporation, P.O. Box 999, MS: K9-91, Richland, WA 99352

41. R. L. Gilchrist, Pacific Northwest National Laboratory, P.O. Box 999, MS: K9-91, Richland, WA 99352

42. T. S. Gutmann, U.S. Department of Energy, Savannah River Operations Office, P.O. Box A, Aiken, SC 29802

43. H. D. Harmon, Tanks Focus Area at Savannah River, Bldg. 704-3N, Room N111, Aiken, SC 29808

44. R. N. Hinds, Westin ghouse Savannah River Company, Bldg. 704-3N, Room S162, Aiken, SC 29808

45. E. W. Holtzscheiter, Westinghouse Savannah River Company, Savannah River Technology Center, Building 773-A, Room A-229, MS: 28, Aiken, SC 29808

46. J. O. Honeyman, CH2M Hill (CHG), P.O. Box 1500, MS: H6-62, Richland, WA 99352

47. R. A. Jacobs, Westinghouse Savannah River Company, Bldg. 704-3N, Room S311, Aiken, SC 29808 
48. R. T. Jones, Westinghouse Savannah River Company, Bldg. 704-3N, Room S122, Aiken, SC 29808

49. J. Krumhansl, Sandia National Laboratories, P.O. Box 5800, MS: 0750, Albuquerque, NM 87185-0750

50. L. Li, Pacific Northwest National Laboratory, 902 Battelle Boulevard, Richland, WA 99352

51. K. A. Lockie, U.S. Department of Energy, Idaho Operations Office, 750 DOE Place, MS: 1145, Idaho Falls, ID 83402

52. J. W. McCullough, Jr., DOE at Savannah River, Bldg. 704-3N, Room S101, Aiken, SC 29808

53. J. P. Morin, Westinghouse Savannah River Company, Savannah River Technology Center, Bldg. 703-H, Room 119, Aiken, SC 29808

54. J. R. Noble-Dial, U.S. Department of Energy, Oak Ridge Operations Office, P.O. Box 2001, Oak Ridge, TN 37830-8620

55. Arlin Olson, Idaho National Engineering and Environmental Laboratory, Bldg. 637, MS5218, Idaho Falls, ID 83415-5218

56. L. M. Papouchado, Westinghouse Savannah River Company, P.O. Box 616, 773-A, Room A263, Aiken, SC 29808

57. S. F. Piccolo, Westinghouse Savannah River Company, Bldg. 704-3N, Room S152, Aiken, SC 29808

58. J. A. Pike, Westinghouse Savannah River Company, Bldg. 704-196N, Room N401, Aiken, SC 29808

59. J. M. Reynolds, U.S. Department of Energy, Savannah River Operations Office, Bldg. 704-196N, Room S441, Aiken, SC 29808

60. Lynne Roeder-Smith, TFA Communications, Pacific Northwest National Laboratory, P.O. Box 999, MSIN K9-69, Richland, WA 99352

61. S. N. Schlahta, TFA Salt Waste Processing Program, Westinghouse Savannah River Company, Bldg. 704-3N, Room N121, Aiken, SC 29808

62. W. W. Schultz, 12704 Sandia Ridge Place NE, Albuquerque, NM 87111

63. Y. Su, Pacific Northwest National Laboratory, 902 Battelle Boulevard, Richland, WA 99352

64. P. C. Suggs, U.S. Department of Energy, Savannah River Operations Office, Bldg. 704196N, Room S431, Aiken, SC 29808

65. W. L. Tamosaitis, Westinghouse Savannah River Company, P.O. Box 616, 773-A, Room A231, Aiken, SC 29808

66. Tanks Focus Area Headquarters Program Lead, c/o Kurt Gerdes, DOE Office of Science and Technology, 19901 Germantown Road, 1154 Cloverleaf Building, Germantown, MD 20874-1290

67. Tanks Focus Area Program Manager, c/o T. P. Pietrok, U.S. Department of Energy, Richland Operations Office, P.O. Box 550, MS: K8-50, Richland, WA 99352

68-75. Tanks Focus Area Technical Team, c/o B. J. Williams, Pacific Northwest National Laboratory, P.O. Box 999, MSIN K9-69, Richland, WA 99352

82. Larry Tavlarides, Syracuse University, Dept. of Chemical Engineering and Materials Science, 334 Hinds Hall, Syracuse, NY 13244-1190

83. M. T. Terry, Los Alamos National Laboratory, P.O. Box 999, MSIN K9-91, Richland, WA 99352

84. T. R. Thomas, Lockheed Martin Idaho Technologies Company, P.O. Box 1625, MSIN 3458, Idaho Falls, ID 83415-3423

85. T. A. Todd, Idaho National Engineering and Environmental Laboratory, Bldg. 637, MS-5218, Idaho Falls, ID 83415-5218

86. J. H. Valentine, Lockheed Martin Idaho Technologies Company, P.O. Box 1625, MS: 3204, Idaho Falls, ID 83415-3204 
87. George Vandegrift, Argonne National Laboratory, Bldg 205, 9700 South Cass Avenue, Argonne, IL 60439

88. D. D. Walker, Westinghouse Savannah River Company, P.O. Box 616, 773-A, Room B124, Aiken, SC 29808

89. D. W. Wester, TFA System Lead, Pacific Northwest National Laboratory, 902 Battelle Boulevard, P.O. Box 999, MS: P7-25, Richland, WA 99352

90. W. R. Wilmarth, Westinghouse Savannah River Company, P.O. Box 616, 773-42A, Room 153, Aiken, SC 29808 